\title{
An Analysis of Mesenchymal Stem Cell-Derived Extracellular Vesicles for Preclinical Use
}

Alvin Tieu, ${ }^{* 1,6,7}$ Manoj M Lalu, ${ }^{* 1,2,6,7}$ Mitchell Slobodian, ${ }^{6}$ Catherine Gnyra, ${ }^{6}$ Dean A Fergusson, ${ }^{3,5,6}$ Joshua Montroy, ${ }^{6}$ Dylan Burger, ${ }^{1,4,8}$ Duncan J Stewart, ${ }^{1,3,7}$ David S Allan, $, 3,6,7$

${ }^{1}$ Department of Cellular and Molecular Medicine, University of Ottawa, Ottawa, Canada, K1H 8L1 ${ }^{2}$ Departments of Anesthesiology and Pain Medicine, University of Ottawa, The Ottawa Hospital, Ottawa, Canada, K1H 8L6

${ }^{3}$ Department of Medicine, ${ }^{4}$ Department of Nephrology, and ${ }^{5}$ Department of Surgery, University of Ottawa, The Ottawa Hospital, Ottawa, Canada, K1H 8L6

${ }^{6}$ Clinical Epidemiology Program, BLUEPRINT Translational Research Group, Ottawa Hospital Research Institute, Ottawa, Canada, K1H 8L6

${ }^{7}$ Regenerative Medicine Program, and ${ }^{8}$ Kidney Research Centre, Ottawa Hospital Research Institute, Ottawa, Canada, K1H $8 \mathrm{~L} 6$

*Authors contributed equally.

Corresponding Authors:

David S. Allan, MD, MSc - Department of Medicine, University of Ottawa, and Clinical Epidemiology Program, Ottawa Hospital Research Institute, 501 Smyth Road, Ottawa, Ontario, Canada, K1H 8L6. ORCID: 0000-0003-3261-8289; Email: daallan@toh.ca

Manoj M. Lalu, MD, PhD - Department of Anesthesiology and Pain Medicine, University of Ottawa, and Clinical Epidemiology Program and Regenerative Medicine Program, Ottawa Hospital Research Institute, 501 Smyth Road, PO Box 201B, Ottawa, Ontario, Canada, K1H 8L6. ORCID: 0000-0002- 0322-382X; Email: mlalu@toh.ca; Twitter: @manojlalu

\section{ORCIDs of Co-Authors:}

Alvin Tieu, MSc - ORCID: 0000-0002-8733-6097; Email: atieu@ohri.ca; Twitter: @alvin_tieu

Dean A. Fergusson, PhD - ORCID: 0000-0002-3389-2485; Email: dafergusson@ohri.ca

Joshua Montroy, MSc - ORCID: 0000-0002-6611-0056; Email: imontroy@ohri.ca

Dylan Burger, PhD - ORCID: 0000-0003-3951-2911; Email: dburger@uottawa.ca

Duncan J. Stewart -ORCID: 0000-0002-9113-8691; Email: djstewart@ohri.ca 
Supplemental File 1 - Interventional Details

\begin{tabular}{|c|c|c|c|c|c|c|c|c|c|}
\hline$\frac{\text { Publication }}{\text { Year }}$ & $\frac{\frac{\text { First Author's }}{\text { Last Name }}}{\underline{\text { ast }}}$ & $\begin{array}{c}\text { Country of } \\
\text { Corresponding Author }\end{array}$ & Terminology Used & $\underline{\text { Size of EVs }}$ & Isolation Technique & $\frac{\text { Species Source }}{\text { of MSCs }}$ & Tissue Source of MSCs & $\stackrel{\text { EV }}{\text { Immunocompatibility }}$ & $\begin{array}{l}\text { Were EVs } \\
\text { Modified? }\end{array}$ \\
\hline 2009 & Bruno & Italy & Microvesicles & Both used Together & Ultracentrifugation & Human Source & Bone Marrow & Xenogeneic & Modified \\
\hline 2010 & Lai & Singapore & Microparticles & Small EVs (30-150nm) & Size Exclusion Chromatography & Human Source & Fetal & Xenogeneic & Unmodified \\
\hline 2011 & Chen & Singapore & Exosomes & Small EVs (30-150nm) & Size Exclusion Chromatography & Human Source & Embryonic Stem Cell-derived MSCs & Xenogeneic & Modified \\
\hline 2011 & Gatti & Italy & Microvesicles & Both used Together & Ultracentrifugation & Human Source & Bone Marrow & Xenogeneic & Modified \\
\hline 2012 & Lai & Singapore & Exosomes & Small EVs (30-150nm) & $\begin{array}{l}\text { Tangential Flow Filtration, Size Exclusion } \\
\text { Chromatography }\end{array}$ & Human Source & Embryonic Stem Cell-derived MSCs & Xenogeneic & Unmodified \\
\hline 2012 & Lee & United States & Exosomes & Small EVs (30-150nm) & $\begin{array}{l}\text { Isolation Kit, Ultracentrifugation, } \\
\text { Ultrafiltration, Size Exclusion } \\
\text { Chromatography }\end{array}$ & Mouse Source & Bone Marrow & Allogeneic & Unmodified \\
\hline 2012 & Reis & Brazil & Exosomes, Microvesicles & Not Described & Ultracentrifugation & Rat Source & Bone Marrow & Allogeneic & Modified \\
\hline 2012 & Zhang & China & Microvesicles & Small EVs (30-150nm) & Ultracentrifugation & Human Source & Umbilical Cord/Wharton's Jelly & Xenogeneic & Modified \\
\hline 2012 & van Koppen & Netherlands & Exosomes & Not Described & $\begin{array}{l}\text { Ultracentrifugation, Sucrose Gradient } \\
\text { Purification, Ultrafiltration }\end{array}$ & Human Source & Embryonic Stem Cell-derived MSCs & Xenogeneic & Unmodified \\
\hline 2012 & Bruno & Italy & Microvesicles & Both used Together & Ultracentrifugation & Human Source & Bone Marrow & Xenogeneic & Modified \\
\hline 2012 & $\mathrm{He}$ & China & Microvesicles & Small EVs (30-150nm) & Ultracentrifugation & Mouse Source & Bone Marrow & Allogeneic & Unmodified \\
\hline 2013 & Kilpinen & Finland & Extracellular Vesicles (EVs) & Both used Together & Ultracentrifugation & Human Source & Cord Blood & Xenogeneic & Modified \\
\hline 2013 & Lee & South Korea & Exosomes & Not Described & Isolation Kit & Mouse Source & Bone Marrow & Allogeneic & Unmodified \\
\hline 2013 & Xin & United States & Exosomes & Not Described & Ultracentrifugation & Rat Source & Bone Marrow & Allogeneic & Unmodified \\
\hline 2013 & Zhou & China & Exosomes & Small EVs (30-150nm) & Ultracentrifugation & Human Source & Umbilical Cord/Wharton's Jelly & Xenogeneic & Unmodified \\
\hline 2013 & Wu & China & Microvesicles & Both used Together & Ultracentrifugation & Human Source & Umbilical Cord/Wharton's Jelly & Xenogeneic & Unmodified \\
\hline 2013 & Katakowski & United States & Exosomes & Not Described & Isolation Kit & Not described & Bone Marrow & Not described & Modified \\
\hline 2013 & Arslan & Netherlands & Exosomes & Not Described & $\begin{array}{l}\text { Tangential Flow Filtration, Size Exclusion } \\
\text { Chromatography }\end{array}$ & Human Source & Embryonic Stem Cell-derived MSCs & Xenogeneic & Unmodified \\
\hline 2013 & $\mathrm{Li}$ & China & Exosomes & Small EVs (30-150nm) & Ultracentrifugation & Human Source & Umbilical Cord/Wharton's Jelly & Xenogeneic & Unmodified \\
\hline 2013 & Roccaro & United States & Exosomes & Small EVs (30-150nm) & Isolation Kit, Ultracentrifugation & Human Source & Bone Marrow & Xenogeneic & Modified \\
\hline 2013 & Bruno & Italy & Microvesicles & Small EVs (30-150nm) & Ultracentrifugation, Ultrafiltration & Human Source & Bone Marrow & Xenogeneic & Unmodified \\
\hline 2014 & Chen & United States & Microvesicles & Both used Together & Ultracentrifugation & Rat Source & Bone Marrow & Allogeneic & Unmodified \\
\hline 2014 & Feng & China & Exosomes & Small EVs (30-150nm) & Isolation Kit & Human Source & Bone Marrow & Xenogeneic & Unmodified \\
\hline & & & & & Tangential Flow Filtration, Size Exclusion & & & & \\
\hline 2014 & Tan & Singapore & Exosomes & Not Described & Chromatography & Human Source & Embryonic Stem Cell-derived MSCs & Xenogeneic & Unmodified \\
\hline 2014 & Du & China & Microvesicles & Both used Together & Ultracentrifugation & Human Source & Umbilical Cord/Wharton's Jelly & Xenogeneic & Modified \\
\hline 2014 & Raisi & Iran & Microvesicles & Not Described & Ultracentrifugation & Rat Source & Adipose & Allogeneic & Modified \\
\hline 2014 & Zou & China & Microvesicles & Both used Together & Ultracentrifugation & Human Source & Umbilical Cord/Wharton's Jelly & Xenogeneic & Unmodified \\
\hline 2014 & Zhang & China & Microvesicles & Both used Together & Ultracentrifugation & Human Source & Umbilical Cord/Wharton's Jelly & Xenogeneic & Unmodified \\
\hline 2014 & Choi & South Korea & Microvesicles & Not Described & Isolation Kit & Human Source & Bone Marrow & Xenogeneic & Unmodified \\
\hline 2014 & Feng & United States & Exosomes & Small EVs (30-150nm) & Isolation Kit, Ultracentrifugation & Mouse Source & Bone Marrow & Allogeneic & Modified \\
\hline 2014 & Choi & South Korea & Microparticles & Not Described & Ultracentrifugation & Mouse Source & Kidney & Allogeneic & Modified \\
\hline 2014 & Zhang & Singapore & Exosomes & Not Described & $\begin{array}{c}\text { Tangential Flow Filtration, Size Exclusion } \\
\text { Chromatography }\end{array}$ & Human Source & Embryonic Stem Cell-derived MSCs & Xenogeneic & Unmodified \\
\hline 2014 & Bian & China & Extracellular Vesicles (EVs) & Both used Together & Ultracentrifugation & Human Source & Bone Marrow & Xenogeneic & Modified \\
\hline 2014 & Rahman & United States & Exosomes & Small EVs $(30-150 \mathrm{~nm})$ & Ultracentrifugation & Mouse Source & pancreatic islet MSC-like cells & Allogeneic & Unmodified \\
\hline 2014 & Zhu & United States & Microvesicles & Large EVs (150-1000nm) & Ultracentrifugation & Human Source & Bone Marrow & Xenogeneic & Modified \\
\hline 2015 & Koch & Germany & Extracellular Vesicles (EVs) & Not Described & Ultracentrifugation & Rat Source & Bone Marrow & Allogeneic & Unmodified \\
\hline 2015 & Zhao & China & Exosomes & Small EVs (30-150nm) & Ultracentrifugation & Human Source & Umbilical Cord/Wharton's Jelly & Xenogeneic & Unmodified \\
\hline 2015 & Kang & United States & Exosomes & Small EVs (30-150nm) & Isolation Kit & Rat Source & Bone Marrow & Allogeneic & Modified \\
\hline 2015 & $\mathrm{Li}$ & China & Exosomes & Not Described & Isolation Kit & Human Source & Bone Marrow & Xenogeneic & Modified \\
\hline 2015 & Yang & China & Exosomes & Small EVs (30-150nm) & Isolation Kit & Rat Source & Not Described & Allogeneic & Modified \\
\hline 2015 & Teng & China & Exosomes & Small EVs $(30-150 \mathrm{~nm})$ & Isolation Kit & Rat Source & Bone Marrow & Allogeneic & Unmodified \\
\hline 2015 & Lou & China & Exosomes & Not Described & Isolation Kit & Human Source & Adipose & Xenogeneic & Modified \\
\hline 2015 & Yang & China & Extracellular Vesicles (EVs) & Both used Together & Ultracentrifugation & Rat Source & Bone Marrow & Allogeneic & Unmodified \\
\hline 2015 & Geiger & Germany & Exosomes & Small EVs $(30-150 \mathrm{~nm})$ & Ultrafiltration & Human Source & Fibrocytes & Xenogeneic & Unmodified \\
\hline 2015 & $\mathrm{Ti}$ & China & Exosomes & Small EVs (30-150nm) & Ultracentrifugation & Human Source & Umbilical Cord/Wharton's Jelly & Xenogeneic & Modified \\
\hline
\end{tabular}


Supplemental File 1 - Interventional Details

\begin{tabular}{|c|c|c|c|c|c|c|c|c|c|}
\hline 2015 & Cruz & United States & Extracellular Vesicles (EVs) & Both used Together & Ultracentrifugation & $\begin{array}{l}\text { Human Source, } \\
\text { Mouse Source }\end{array}$ & Bone Marrow & Allogeneic, Xenogeneic & Unmodified \\
\hline 2015 & Wang & United States & Exosomes & Small EVs (30-150nm) & $\begin{array}{l}\text { Ultracentrifugation, Sucrose Gradient } \\
\text { Purification }\end{array}$ & Mouse Source & Bone Marrow & Allogeneic & Modified \\
\hline 2015 & Doeppner & Germany & Extracellular Vesicles (EVs) & Not Described & Isolation Kit, Ultracentrifugation & Human Source & Bone Marrow & Xenogeneic & Unmodified \\
\hline 2015 & $\mathrm{Hu}$ & China & Exosomes & Small EVs (30-150nm) & Ultracentrifugation, Ultrafiltration & Human Source & iPSC-derived MSCs & Xenogeneic & Unmodified \\
\hline 2015 & Monsel & United States & Microvesicles & Large EVs $(150-1000 \mathrm{~nm})$ & Ultracentrifugation & Human Source & Bone Marrow & Xenogeneic & Modified \\
\hline 2015 & Wang & China & Microvesicles & Not Described & Ultracentrifugation & Mouse Source & Bone Marrow & Allogeneic & Modified \\
\hline 2015 & Choi & South Korea & Microparticles & Not Described & Ultracentrifugation & Mouse Source & Kidney & Allogeneic & Modified \\
\hline 2015 & Nakamura & Japan & Exosomes & Small EVs (30-150nm) & Ultracentrifugation, Ultrafiltration & Human Source & Bone Marrow & Xenogeneic & Unmodified \\
\hline 2015 & Zhang & China & Exosomes & Small EVs (30-150nm) & $\begin{array}{l}\text { Ultracentrifugation, Hollow Fiber } \\
\text { Membrane, Sucrose Cushion }\end{array}$ & Human Source & Umbilical Cord/Wharton's Jelly & Xenogeneic & Modified \\
\hline 2015 & $\mathrm{Ju}$ & China & Microvesicles & Both used Together & Ultracentrifugation & Human Source & Umbilical Cord/Wharton's Jelly & Xenogeneic & Modified \\
\hline 2015 & Zhang & China & Exosomes & Small EVs (30-150nm) & Ultracentrifugation & Human Source & iPSC-derived MSCs & Xenogeneic & Unmodified \\
\hline 2015 & Yu & United States & Exosomes & Small EVs (30-150nm) & Isolation Kit, Ultrafiltration & Rat Source & Bone Marrow & Allogeneic & Modified \\
\hline 2015 & Zhang & China & Exosomes & Small EVs (30-150nm) & Ultracentrifugation & Human Source & Umbilical Cord/Wharton's Jelly & Xenogeneic & Modified \\
\hline 2015 & Ko & Taiwan & Exosomes & Small EVs (30-150nm) & Ultracentrifugation & Rat Source & Adipose & Allogeneic & Unmodified \\
\hline 2015 & Zhang & United States & Exosomes & Small EVs $(30-150 \mathrm{~nm})$ & Isolation Kit & Rat Source & Bone Marrow & Allogeneic & Unmodified \\
\hline 2015 & Collino & Italy & Extracellular Vesicles (EVs) & Both used Together & Ultracentrifugation & Human Source & Bone Marrow & Xenogeneic & Modified \\
\hline 2016 & Yu & China & Exosomes & Small EVs (30-150nm) & Ultracentrifugation & $\begin{array}{l}\text { Human Source, } \\
\text { Mouse Source }\end{array}$ & $\begin{array}{l}\text { Adipose, Umbilical Cord/Wharton's } \\
\text { Jelly }\end{array}$ & Allogeneic, Xenogeneic & Modified \\
\hline 2016 & Tamura & Japan & Exosomes & Small EVs (30-150nm) & Ultracentrifugation & Mouse Source & Bone Marrow & Allogeneic & Unmodified \\
\hline 2016 & Shen & China & Exosomes & Not Described & Ultracentrifugation & Mouse Source & Bone Marrow & Allogeneic & Modified \\
\hline 2016 & Zou & China & Extracellular Vesicles (EVs) & Large EVs (150-1000nm) & Ultracentrifugation & Human Source & Umbilical Cord/Wharton's Jelly & Xenogeneic & Modified \\
\hline 2016 & Gu & China & Extracellular Vesicles (EVs) & Not Described & Ultracentrifugation & Human Source & Umbilical Cord/Wharton's Jelly & Xenogeneic & Modified \\
\hline 2016 & Nagaishi & Japan & Exosomes & Small EVs (30-150nm) & Isolation Kit & Rat Source & Bone Marrow & Allogeneic & Unmodified \\
\hline 2016 & $\mathrm{Hu}$ & China & Exosomes & Small EVs (30-150nm) & Isolation Kit & Human Source & Adipose & Xenogeneic & Unmodified \\
\hline 2016 & Lee & South Korea & Microvesicles & Not Described & $\begin{array}{l}\text { Tangential Flow Filtration, } \\
\text { Ultracentrifugation }\end{array}$ & Human Source & Adipose & Xenogeneic & Modified \\
\hline 2016 & Xie & China & Microvesicles & Both used Together & Ultracentrifugation & Rat Source & Bone Marrow & Xenogeneic & Modified \\
\hline 2016 & Zhang & Singapore & Exosomes & Small EVs (30-150nm) & Size Exclusion Chromatography & Human Source & Embryonic Stem Cell-derived MSCs & Xenogeneic & Unmodified \\
\hline 2016 & Yin & China & Microvesicles & Not Described & Ultracentrifugation & Rat Source & Bone Marrow & Allogeneic, Xenogeneic & Unmodified \\
\hline 2016 & Kalimuthu & South Korea & Extracellular Vesicles (EVs) & Small EVs (30-150nm) & Ultracentrifugation & Mouse Source & Bone Marrow & Allogeneic & Modified \\
\hline 2016 & Chen & Taiwan & Exosomes & Not Described & Ultracentrifugation & Pig Source & Adipose & Xenogeneic & Modified \\
\hline 2016 & Nakano & Japan & Exosomes & Small EVs $(30-150 \mathrm{~nm})$ & $\begin{array}{c}\text { Ultracentrifugation, Sucrose Gradient } \\
\text { Purification }\end{array}$ & Rat Source & Bone Marrow & Xenogeneic & Unmodified \\
\hline 2016 & Wen & United States & Exosomes & Not Described & Isolation Kit & Human Source & Bone Marrow & Xenogeneic & Modified \\
\hline 2016 & Liu & United States & Microvesicles & Large EVs $(150-1000 \mathrm{~nm})$ & Ultracentrifugation & Human Source & Bone Marrow & Xenogeneic & Modified \\
\hline 2016 & Zhang & China & Exosomes & Not Described & Ultracentrifugation & Human Source & Umbilical Cord/Wharton's Jelly & Xenogeneic & Modified \\
\hline 2016 & Zou & China & Extracellular Vesicles (EVs) & Large EVs (150-1000nm) & Ultracentrifugation & Human Source & Umbilical Cord/Wharton's Jelly & Xenogeneic & Unmodified \\
\hline 2016 & Wen & United States & Extracellular Vesicles (EVs) & $\begin{array}{c}\text { Large EVs (150- } \\
\text { 1000nm),Both used } \\
\text { Together }\end{array}$ & Ultracentrifugation & Mouse Source & Bone Marrow & Allogeneic & Unmodified \\
\hline 2016 & Guo & China & Exosomes & Small EVs (30-150nm) & Ultracentrifugation, Ultrafiltration & Human Source & Synovial membrane & Xenogeneic & Unmodified \\
\hline 2016 & Nong & China & Exosomes & Small EVs (30-150nm) & Ultrafiltration & Human Source & iPSC-derived MSCs & Xenogeneic & Unmodified \\
\hline 2016 & Furuta & Japan & Exosomes & Small EVs $(30-150 \mathrm{~nm})$ & Ultracentrifugation, Ultrafiltration & Human Source & Bone Marrow & Xenogeneic & Unmodified \\
\hline 2016 & $\mathrm{Hu}$ & China & Extracellular Vesicles (EVs) & Not Described & Isolation Kit & Human Source & Bone Marrow & Xenogeneic & Unmodified \\
\hline & & & & & Ultracentrifugation, Sucrose Gradient & & & & \\
\hline 2016 & Vrijsen & Netherlands & Exosomes & Small EVs (30-150nm) & Purification & Human Source & Bone Marrow & Xenogeneic & Modified \\
\hline 2016 & $\mathrm{Li}$ & China & Exosomes & Small EVs (30-150nm) & Isolation Kit & Human Source & Umbilical Cord/Wharton's Jelly & Xenogeneic & Modified \\
\hline 2016 & Fang & China & Exosomes & Small EVs (30-150nm) & Ultracentrifugation & Human Source & Umbilical Cord/Wharton's Jelly & Xenogeneic & Modified \\
\hline 2016 & Qi & China & Exosomes & Small EVs (30-150nm) & Ultracentrifugation, Ultrafiltration & Human Source & iPSC-derived MSCs & Xenogeneic & Modified \\
\hline
\end{tabular}


Supplemental File 1 - Interventional Details

\begin{tabular}{|c|c|c|c|c|c|c|c|c|c|}
\hline 2016 & Ophelders & Netherlands & Extracellular Vesicles (EVs) & Not Described & Isolation Kit & Human Source & Bone Marrow & Xenogeneic & Unmodified \\
\hline 2016 & Lin & Taiwan & Exosomes & Not Described & Ultracentrifugation & Rat Source & Adipose & Allogeneic & Unmodified \\
\hline 2016 & Rager & United States & Exosomes & Not Described & Isolation Kit & Mouse Source & Bone Marrow & Xenogeneic & Unmodified \\
\hline 2016 & Aliotta & United States & $\begin{array}{l}\text { Exosomes, Microvesicles, } \\
\text { Extracellular Vesicles (EVs) }\end{array}$ & $\begin{array}{c}\text { Small EVs (30- } \\
\text { 150nm),Both used } \\
\text { Together }\end{array}$ & Ultracentrifugation & $\begin{array}{l}\text { Human Source, } \\
\text { Mouse Source }\end{array}$ & Bone Marrow & Allogeneic, Xenogeneic & Unmodified \\
\hline 2016 & Qin & China & Extracellular Vesicles (EVs) & Not Described & Ultracentrifugation, Ultrafiltration & Human Source & Bone Marrow & Xenogeneic & Modified \\
\hline 2016 & Zhang & China & Extracellular Vesicles (EVs) & Both used Together & Ultracentrifugation & Human Source & Umbilical Cord/Wharton's Jelly & Xenogeneic & Unmodified \\
\hline 2016 & Sun & China & Exosomes & Small EVs (30-150nm) & Ultracentrifugation & Human Source & Umbilical Cord/Wharton's Jelly & Xenogeneic & Unmodified \\
\hline 2016 & Kim & United States & Extracellular Vesicles (EVs) & Both used Together & $\begin{array}{l}\text { Ultracentrifugation, Size Exclusion } \\
\text { Chromatography }\end{array}$ & Human Source & Bone Marrow & Xenogeneic & Unmodified \\
\hline 2016 & Liu & China & Extracellular Vesicles (EVs) & Small EVs (30-150nm) & Ultracentrifugation & Human Source & Adipose & Xenogeneic & Unmodified \\
\hline 2016 & Wang & China & Extracellular Vesicles (EVs) & Small EVs (30-150nm) & Ultracentrifugation & Human Source & Umbilical Cord/Wharton's Jelly & Xenogeneic & Unmodified \\
\hline 2016 & $\mathrm{Ti}$ & China & Exosomes & Small EVs $(30-150 \mathrm{~nm})$ & Ultracentrifugation & Human Source & Umbilical Cord/Wharton's Jelly & Xenogeneic & Modified \\
\hline 2016 & Shi & China & Exosomes & Small EVs (30-150nm) & Ultracentrifugation & Human Source & Bone Marrow & Xenogeneic & Unmodified \\
\hline 2016 & Lange & Germany & Microvesicles & Both used Together & Ultracentrifugation & Mouse Source & Bone Marrow & Allogeneic & Unmodified \\
\hline 2017 & Fujii & Japan & Extracellular Vesicles (EVs) & Both used Together & Isolation Kit & Human Source & Bone Marrow & Xenogeneic & Unmodified \\
\hline 2017 & Cheng & China & Exosomes & Small EVs (30-150nm) & Ultracentrifugation & Human Source & Bone Marrow & Xenogeneic & Modified \\
\hline $\begin{array}{l}2017 \\
2017\end{array}$ & $\begin{array}{l}\text { Willis } \\
\text { Zhu }\end{array}$ & $\begin{array}{l}\text { United States } \\
\text { China }\end{array}$ & $\begin{array}{l}\text { Exosomes } \\
\text { Exosomes }\end{array}$ & $\begin{array}{l}\text { Small EVs }(30-150 \mathrm{~nm}) \\
\text { Small EVs }(30-150 \mathrm{~nm})\end{array}$ & $\begin{array}{c}\text { Tangential Flow Filtration, Flotation on } \\
\text { lodixanol } \\
\text { Ultracentrifugation }\end{array}$ & $\begin{array}{l}\text { Human Source } \\
\text { Mouse Source }\end{array}$ & $\begin{array}{l}\text { Bone Marrow, Umbilical } \\
\text { Cord/Wharton's Jelly } \\
\text { Bone Marrow }\end{array}$ & $\begin{array}{l}\text { Xenogeneic } \\
\text { Allogeneic }\end{array}$ & $\begin{array}{l}\text { Unmodified } \\
\text { Modified }\end{array}$ \\
\hline 2017 & Webb & United States & Extracellular Vesicles (EVs) & Both used Together & Ultrafiltration & Human Source & Embryonic Stem Cell-derived MSCs & Xenogeneic & Unmodified \\
\hline 2017 & Wang & China & Exosomes & Not Described & Isolation Kit & Human Source & Adipose & Xenogeneic & Unmodified \\
\hline 2017 & Mead & United States & Exosomes & Not Described & Ultracentrifugation & Human Source & Bone Marrow & Xenogeneic & Modified \\
\hline 2017 & Yuan & China & Extracellular Vesicles (EVs) & Small EVs (30-150nm) & Isolation Kit & Human Source & iPSC-derived MSCs & Xenogeneic & Modified \\
\hline 2017 & Soundara Rajan & Italy & Exosomes, Microvesicles & Not Described & Isolation Kit & Human Source & Periodontal ligament & Xenogeneic & Unmodified \\
\hline 2017 & El-Tookhy & Egypt & Exosomes, Microvesicles & Not Described & Ultracentrifugation & Dog Source & Bone Marrow & Autologous & Unmodified \\
\hline 2017 & Schoefinius & Germany & Extracellular Vesicles (EVs) & Both used Together & Ultracentrifugation & Mouse Source & Bone Marrow & Allogeneic & Unmodified \\
\hline 2017 & Huang & China & Exosomes & Small EVs (30-150nm) & Ultracentrifugation & Rat Source & Bone Marrow & Allogeneic & Unmodified \\
\hline 2017 & Chen & China & Microvesicles & Not Described & Ultracentrifugation & Human Source & Umbilical Cord/Wharton's Jelly & Xenogeneic & Modified \\
\hline 2017 & Zhang & United States & Exosomes & Not Described & Isolation Kit & Human Source & Bone Marrow & Xenogeneic & Modified \\
\hline 2017 & Stone & United States & Extracellular Vesicles (EVs) & Both used Together & Ultracentrifugation & Human Source & Umbilical Cord/Wharton's Jelly & Xenogeneic & Unmodified \\
\hline 2017 & Horn & Germany & Extracellular Vesicles (EVs) & Not Described & Isolation Kit, Ultracentrifugation & Human Source & Bone Marrow & Xenogeneic & Unmodified \\
\hline 2017 & Cosenza & France & Exosomes, Microparticles & Both used Separately & Ultracentrifugation & Mouse Source & Bone Marrow & Allogeneic & Unmodified \\
\hline 2017 & Shi & China & Exosomes & Small EVs (30-150nm) & Size Exclusion Chromatography & Human Source & Gingival tissue & Xenogeneic & Modified \\
\hline 2017 & Rajendran & South Korea & Extracellular Vesicles (EVs) & Small EVs (30-150nm) & Ultracentrifugation & Mouse Source & Bone Marrow & Allogeneic & Unmodified \\
\hline 2017 & Bruno & Italy & Extracellular Vesicles (EVs) & $\begin{array}{l}\text { Both used Together,Both } \\
\text { used Separately }\end{array}$ & Ultracentrifugation, Flotation on lodixanol & Human Source & Bone Marrow & Xenogeneic & Unmodified \\
\hline 2017 & Aliotta & United States & Extracellular Vesicles (EVs) & Both used Together & Ultracentrifugation & Mouse Source & Bone Marrow & Allogeneic & Unmodified \\
\hline 2017 & Komaki & Japan & Exosomes & Small EVs (30-150nm) & Ultracentrifugation & Human Source & Placenta & Xenogeneic & Unmodified \\
\hline 2017 & $\mathrm{Li}$ & China & Exosomes & Small EVs (30-150nm) & Isolation Kit & Human Source & Exfoliated deciduous teeth & Xenogeneic & Unmodified \\
\hline 2017 & Gangadaran & South Korea & Extracellular Vesicles (EVs) & Both used Together & Ultracentrifugation, Flotation on lodixanol & Mouse Source & Bone Marrow & Allogeneic & Modified \\
\hline 2017 & Deng & China & Extracellular Vesicles (EVs) & Not Described & Isolation Kit & Mouse Source & Bone Marrow & Allogeneic & Unmodified \\
\hline 2017 & Bai & China & Exosomes & Small EVs (30-150nm) & Ultracentrifugation & Human Source & Umbilical Cord/Wharton's Jelly & Xenogeneic & Unmodified \\
\hline 2017 & Sun & Taiwan & Exosomes & Small EVs (30-150nm) & Ultracentrifugation & Pig Source & Adipose & Xenogeneic & Modified \\
\hline
\end{tabular}


Supplemental File 1 - Interventional Details

\begin{tabular}{|c|c|c|c|c|c|c|c|c|c|}
\hline 2017 & Gong & United States & Exosomes & Small EVs $(30-150 \mathrm{~nm})$ & Isolation Kit & Mouse Source & Embryonic Stem Cell-derived MSCs & Allogeneic & Modified \\
\hline 2017 & $\mathrm{Qu}$ & China & Exosomes & Not Described & Isolation Kit & Mouse Source & Adipose & Allogeneic & Modified \\
\hline 2017 & Casado & Spain & Exosomes & Both used Together & Ultrafiltration & Pig Source & Bone Marrow & Not described & Modified \\
\hline 2017 & Xie & China & Extracellular Vesicles (EVs) & Both used Together & Ultracentrifugation & Rat Source & Bone Marrow & Xenogeneic & Modified \\
\hline 2017 & Otero-Ortega & Spain & Extracellular Vesicles (EVs) & Small EVs $(30-150 \mathrm{~nm})$ & Isolation Kit & Rat Source & Adipose & Allogeneic & Unmodified \\
\hline 2017 & Wang & China & Extracellular Vesicles (EVs) & Both used Together & Ultracentrifugation & Mouse Source & Bone Marrow & Allogeneic & Modified \\
\hline 2017 & Haga & United States & Extracellular Vesicles (EVs) & Small EVs (30-150nm) & Ultracentrifugation & $\begin{array}{l}\text { Human Source, } \\
\text { Mouse Source }\end{array}$ & Bone Marrow & Allogeneic, Xenogeneic & Unmodified \\
\hline 2017 & $\mathrm{Ma}$ & China & Exosomes & Small EVs $(30-150 \mathrm{~nm})$ & Ultracentrifugation & Human Source & Umbilical Cord/Wharton's Jelly & Xenogeneic & Modified \\
\hline 2017 & Wang & China & Exosomes & Small EVs $(30-150 \mathrm{~nm})$ & Ultracentrifugation & Human Source & Embryonic Stem Cell-derived MSCs & Xenogeneic & Unmodified \\
\hline $\begin{array}{l}2017 \\
2017\end{array}$ & $\begin{array}{l}\text { Long } \\
\mathrm{Li}\end{array}$ & $\begin{array}{l}\text { United States } \\
\text { China }\end{array}$ & $\begin{array}{c}\text { Exosomes, Extracellular } \\
\text { Vesicles (EVs) } \\
\text { Exosomes }\end{array}$ & $\begin{array}{l}\text { Small EVs }(30-150 \mathrm{~nm}) \\
\text { Small EVs }(30-150 \mathrm{~nm})\end{array}$ & $\begin{array}{c}\text { Size Exclusion Chromatography } \\
\text { Isolation Kit }\end{array}$ & $\begin{array}{l}\text { Human Source } \\
\text { Rabbit Source }\end{array}$ & $\begin{array}{l}\text { Bone Marrow } \\
\text { Bone Marrow }\end{array}$ & $\begin{array}{c}\text { Xenogeneic } \\
\text { Allogeneic }\end{array}$ & $\begin{array}{l}\text { Unmodified } \\
\text { Modified }\end{array}$ \\
\hline 2017 & Eirin & United States & Extracellular Vesicles (EVs) & Both used Together & Ultracentrifugation & Pig Source & Adipose & Autologous & Modified \\
\hline 2017 & de Castro & Brazil & Extracellular Vesicles (EVs) & Both used Together & Ultracentrifugation & Human Source & Adipose & Xenogeneic & Unmodified \\
\hline 2017 & Tang & China & Microvesicles & Large EVs $(150-1000 \mathrm{~nm})$ & Ultracentrifugation & Human Source & Bone Marrow & Xenogeneic & Modified \\
\hline 2017 & Gonzalez-King & Spain & Exosomes & Small EVs (30-150nm) & Ultracentrifugation & Human Source & Dental pulp & Xenogeneic & Modified \\
\hline 2017 & Haga & United States & Extracellular Vesicles (EVs) & Small EVs $(30-150 \mathrm{~nm})$ & Ultracentrifugation & Mouse Source & Bone Marrow & Allogeneic & Unmodified \\
\hline 2017 & Mao & China & Exosomes & Small EVs $(30-150 \mathrm{~nm})$ & Ultracentrifugation & Human Source & Umbilical Cord/Wharton's Jelly & Xenogeneic & Unmodified \\
\hline 2017 & ihigemoto-Kurod & United States & Extracellular Vesicles (EVs) & Small EVs $(30-150 \mathrm{~nm})$ & Size Exclusion Chromatography & Human Source & Bone Marrow & Xenogeneic & Unmodified \\
\hline 2017 & $\mathrm{Du}$ & China & Exosomes & Small EVs $(30-150 \mathrm{~nm})$ & Ultracentrifugation & Human Source & Placenta & Xenogeneic & Modified \\
\hline 2017 & Chen & China & Exosomes & Small EVs (30-150nm) & Isolation Kit & Human Source & Menstrual blood & Xenogeneic & Unmodified \\
\hline 2017 & Song & China & Exosomes & Small EVs $(30-150 \mathrm{~nm})$ & Ultracentrifugation & Human Source & Umbilical Cord/Wharton's Jelly & Xenogeneic & Modified \\
\hline 2017 & Moisseiev & United States & Exosomes & Not Described & Tangential Flow Filtration & Human Source & Bone Marrow & Xenogeneic & Modified \\
\hline 2017 & Liu & China & Exosomes & Small EVs $(30-150 \mathrm{~nm})$ & Isolation Kit & Rat Source & Bone Marrow & Allogeneic & Modified \\
\hline 2017 & Zhu & China & Exosomes & Small EVs $(30-150 \mathrm{~nm})$ & Ultrafiltration & Human Source & $\begin{array}{l}\text { iPSC-derived MSCs, Synovial } \\
\text { membrane }\end{array}$ & Xenogeneic & Unmodified \\
\hline 2017 & Xin & United States & Exosomes & Small EVs $(30-150 \mathrm{~nm})$ & Ultracentrifugation & Rat Source & Bone Marrow & Allogeneic & Modified \\
\hline 2017 & Yan & China & Exosomes & Small EVs $(30-150 \mathrm{~nm})$ & Ultracentrifugation, Ultrafiltration & Human Source & Umbilical Cord/Wharton's Jelly & Xenogeneic & Modified \\
\hline 2017 & Tao & China & Exosomes & Small EVs $(30-150 \mathrm{~nm})$ & Ultracentrifugation, Ultrafiltration & Human Source & Synovial membrane & Xenogeneic & Modified \\
\hline 2017 & Liu & China & Exosomes & Small EVs $(30-150 \mathrm{~nm})$ & Ultracentrifugation & Human Source & iPSC-derived MSCs & Xenogeneic & Unmodified \\
\hline 2017 & Kamerkar & United States & Exosomes & Small EVs $(30-150 \mathrm{~nm})$ & Ultracentrifugation & Human Source & human foreskin fibroblast & Xenogeneic & Modified \\
\hline 2017 & Du & China & Exosomes & Small EVs $(30-150 \mathrm{~nm})$ & Isolation Kit & Human Source & iPSC-derived MSCs & Xenogeneic & Modified \\
\hline 2017 & Wang & China & Exosomes & Small EVs $(30-150 \mathrm{~nm})$ & Ultracentrifugation & Human Source & Umbilical Cord/Wharton's Jelly & Xenogeneic & Unmodified \\
\hline 2017 & Zhao & China & Exosomes & Small EVs $(30-150 \mathrm{~nm})$ & Ultracentrifugation & Human Source & Amniotic & Xenogeneic & Unmodified \\
\hline 2017 & Shao & China & Exosomes & Not Described & Isolation Kit, Ultracentrifugation & Rat Source & Bone Marrow & Allogeneic & Unmodified \\
\hline 2017 & Tao & China & Exosomes & Small EVs $(30-150 \mathrm{~nm})$ & Ultracentrifugation, Ultrafiltration & Human Source & Synovial membrane & Xenogeneic & Modified \\
\hline 2017 & Huang & China & Extracellular Vesicles (EVs) & Both used Together & Ultracentrifugation & Rat Source & Bone Marrow & Xenogeneic & Unmodified \\
\hline 2017 & Tamura & Japan & Exosomes & Small EVs $(30-150 \mathrm{~nm})$ & Ultracentrifugation & Mouse Source & Bone Marrow & Allogeneic & Modified \\
\hline 2017 & igorian-Shamagi & United States & Extracellular Vesicles (EVs) & Both used Together & Isolation Kit & Human Source & Bone Marrow & Xenogeneic & Unmodified \\
\hline 2017 & Ranghino & Italy & Extracellular Vesicles (EVs) & Both used Together & Ultracentrifugation & Human Source & Kidney & Xenogeneic & Modified \\
\hline 2017 & Cui & China & Exosomes & Small EVs $(30-150 \mathrm{~nm})$ & Ultracentrifugation, Ultrafiltration & Rat Source & Adipose & Allogeneic & Unmodified \\
\hline 2017 & Henao Agudelo & Brazil & Microvesicles & Small EVs $(30-150 \mathrm{~nm})$ & Ultracentrifugation & Mouse Source & Adipose & Allogeneic & Unmodified \\
\hline 2017 & Xin & United States & Exosomes & Not Described & Ultracentrifugation & Rat Source & Bone Marrow & Allogeneic & Modified \\
\hline 2017 & Lo Sicco & Italy & Extracellular Vesicles (EVs) & Both used Together & Ultracentrifugation & Human Source & Adipose & Xenogeneic & Modified \\
\hline 2017 & de Almeida & Brazil & Microvesicles & Small EVs $(30-150 \mathrm{~nm})$ & Ultracentrifugation & Mouse Source & Adipose & Allogeneic & Modified \\
\hline 2018 & Luther & United States & Exosomes & Not Described & Ultracentrifugation & Mouse Source & Bone Marrow & Allogeneic & Modified \\
\hline 2018 & Williams & United States & Exosomes & Not Described & Ultracentrifugation & Human Source & Bone Marrow & Xenogeneic & Unmodified \\
\hline 2018 & McCulloh & United States & Exosomes & Small EVs $(30-150 \mathrm{~nm})$ & Ultracentrifugation & Rat Source & Bone Marrow, Amniotic & Allogeneic & Unmodified \\
\hline
\end{tabular}


Supplemental File 1 - Interventional Details

\begin{tabular}{|c|c|c|c|c|c|c|c|c|c|}
\hline 2018 & Zhang & Singapore & Exosomes & Not Described & Tangential Flow Filtration & Human Source & Embryonic Stem Cell-derived MSCs & Xenogeneic & Unmodified \\
\hline 2018 & Barile & Switzerland & Exosomes & Small EVs (30-150nm) & Ultracentrifugation & Human Source & Bone Marrow & Xenogeneic & Unmodified \\
\hline 2018 & Otero-Ortega & Spain & Exosomes & Small EVs (30-150nm) & Isolation Kit & Rat Source & Adipose & Allogeneic & Unmodified \\
\hline 2018 & Ahn & South Korea & Extracellular Vesicles (EVs) & Small EVs (30-150nm) & Ultracentrifugation & Human Source & Cord Blood & Xenogeneic & Modified \\
\hline 2018 & Jiang & China & Exosomes & Small EVs (30-150nm) & Ultracentrifugation & Human Source & Umbilical Cord/Wharton's Jelly & Xenogeneic & Unmodified \\
\hline 2018 & Diomede & Italy & Extracellular Vesicles (EVs) & Both used Together & Isolation Kit & Human Source & Gingival tissue & Xenogeneic & Modified \\
\hline 2018 & $\mathrm{He}$ & China & Exosomes & Small EVs $(30-150 \mathrm{~nm})$ & Ultracentrifugation & Human Source & Cord Blood & Xenogeneic & Unmodified \\
\hline 2018 & Blazquez & Spain & Exosomes & Small EVs (30-150nm) & Ultrafiltration & Mouse Source & Bone Marrow & Allogeneic & Modified \\
\hline 2018 & Shen & China & Exosomes & Not Described & Isolation Kit & Rat Source & Bone Marrow & Allogeneic & Modified \\
\hline 2018 & Lang & United States & Exosomes & Small EVs (30-150nm) & $\begin{array}{l}\text { Ultracentrifugation, Sucrose Gradient } \\
\text { Purification }\end{array}$ & Human Source & Bone Marrow & Xenogeneic & Modified \\
\hline 2018 & Wang & China & Exosomes & Small EVs (30-150nm) & Ultracentrifugation & Human Source & Umbilical Cord/Wharton's Jelly & Xenogeneic & Unmodified \\
\hline 2018 & Cui & China & Exosomes & Not Described & Isolation Kit & Mouse Source & Bone Marrow & Allogeneic & Modified \\
\hline 2018 & Damania & India & Exosomes & Both used Together & Ultracentrifugation, Ultrafiltration & Rat Source & Bone Marrow & Allogeneic & Unmodified \\
\hline 2018 & $\mathrm{Li}$ & China & Exosomes & Small EVs $(30-150 \mathrm{~nm})$ & Ultracentrifugation & Human Source & Adipose & Xenogeneic & Modified \\
\hline 2018 & Zhu & China & Exosomes & Small EVs (30-150nm) & Isolation Kit & Rat Source & Adipose & Allogeneic & Unmodified \\
\hline 2018 & Khatri & United States & Extracellular Vesicles (EVs) & Small EVs (30-150nm) & Ultracentrifugation & Pig Source & Bone Marrow & Allogeneic & Unmodified \\
\hline 2018 & Mead & United States & Small EV & Small EVs (30-150nm) & Isolation Kit & Human Source & Bone Marrow & Xenogeneic & Modified \\
\hline 2018 & Wang & China & Extracellular Vesicles (EVs) & Not Described & Isolation Kit & Mouse Source & Bone Marrow & Allogeneic & Unmodified \\
\hline 2018 & Otsuru & United States & Extracellular Vesicles (EVs) & Both used Together & Ultracentrifugation & Mouse Source & Bone Marrow & Allogeneic & Unmodified \\
\hline 2018 & Wu & China & Microvesicles & Not Described & Ultracentrifugation & Human Source & Umbilical Cord/Wharton's Jelly & Xenogeneic & Unmodified \\
\hline 2018 & Potter & United States & Extracellular Vesicles (EVs) & Both used Together & Ultracentrifugation & Human Source & Bone Marrow & Xenogeneic & Unmodified \\
\hline 2018 & Ruppert & United States & Extracellular Vesicles (EVs) & Not Described & Tangential Flow Filtration & Human Source & Bone Marrow & Xenogeneic & Modified \\
\hline 2018 & Han & China & Exosomes & Small EVs (30-150nm) & Ultracentrifugation & Human Source & Adipose & Xenogeneic & Modified \\
\hline 2018 & Chen & China & Exosomes & Small EVs (30-150nm) & Ultracentrifugation & Mouse Source & Bone Marrow & Allogeneic & Modified \\
\hline 2018 & Mardpour & Iran & Extracellular Vesicles (EVs) & Both used Together & Ultracentrifugation & Human Source & Embryonic Stem Cell-derived MSCs & Xenogeneic & Unmodified \\
\hline & & & Exosomes, Extracellular & & & & & & \\
\hline 2018 & O'Brien & Ireland & Vesicles (EVs) & Small EVs (30-150nm) & Ultracentrifugation & Human Source & Bone Marrow & Xenogeneic & Modified \\
\hline 2018 & Chang & China & Exosomes & Not Described & Ultracentrifugation & Rat Source & Adipose & Allogeneic & Modified \\
\hline 2018 & Tian & China & Exosomes & Small EVs $(30-150 \mathrm{~nm})$ & Ultracentrifugation & Rabbit Source & Bone Marrow & Not described & Modified \\
\hline 2018 & Kou & United States & Exosomes, Small EV & Not Described & Ultracentrifugation, Sucrose Cushion & Mouse Source & Gingival tissue, Skin MSCs & Allogeneic & Modified \\
\hline 2018 & Chen & China & Exosomes & Small EVs (30-150nm) & Isolation Kit, Ultrafiltration & Human Source & Urine & Xenogeneic & Modified \\
\hline 2018 & Jia & China & Exosomes & Small EVs $(30-150 \mathrm{~nm})$ & Isolation Kit & Human Source & Umbilical Cord/Wharton's Jelly & Xenogeneic & Modified \\
\hline 2018 & Cosenza & France & $\begin{array}{l}\text { Exosomes, Extracellular } \\
\text { Vesicles (EVs), } \\
\text { Microparticles }\end{array}$ & $\begin{array}{l}\text { Both used Together,Both } \\
\text { used Separately }\end{array}$ & Ultracentrifugation & Mouse Source & Bone Marrow & Allogeneic & Unmodified \\
\hline
\end{tabular}


Supplemental File 2 - Outcomes and Animal Models

\begin{tabular}{|c|c|c|c|c|c|c|c|}
\hline Year & First Author's Last Name & Disease Domain & $\frac{\text { Species of Animal }}{\underline{\text { Model }}}$ & Treatment or Prevention Protocol & $\frac{\text { Were In Vivo Biodistribution }}{\text { Studies Performed? }}$ & $\frac{\text { Was Randomization }}{\text { Conducted? }}$ & Are Benefits Reported? \\
\hline 2009 & Bruno & Renal & Mouse & Post-injury induction (Treatment) & Yes & Not Described & Yes \\
\hline 2010 & Lai & Cardiac & Mouse & Post-injury induction (Treatment) & No & Not Described & Yes \\
\hline 2011 & Chen & Cardiac & Mouse & Post-injury induction (Treatment) & No & Not Described & Yes \\
\hline 2011 & Gatti & Renal & Rat & Post-injury induction (Treatment) & Yes & Not Described & Yes \\
\hline 2012 & Lai & Cardiac & Mouse & Post-injury induction (Treatment) & No & Not Described & Yes \\
\hline 2012 & Lee & Lung & Mouse & Both Prevention and Treatment Protocols & No & Not Described & Yes \\
\hline 2012 & Reis & Renal & Rat & Post-injury induction (Treatment) & No & Not Described & Yes \\
\hline 2012 & Zhang & $\begin{array}{l}\text { Ischemia (e.g. testing } \\
\text { angiogenesis) }\end{array}$ & Rat & Post-injury induction (Treatment) & No & Not Described & Yes \\
\hline 2012 & van Koppen & Renal & Rat & Post-injury induction (Treatment) & No & Not Described & No benefits \\
\hline 2012 & Bruno & Renal & Mouse & Post-injury induction (Treatment) & No & Not Described & Yes \\
\hline 2012 & $\mathrm{He}$ & Renal & Mouse & Post-injury induction (Treatment) & No & Yes & Mixed \\
\hline 2013 & Kilpinen & Renal & Rat & Post-injury induction (Treatment) & No & Not Described & Yes \\
\hline 2013 & Lee & Cancer & Mouse & At the same time as injury induction & No & Yes & Yes \\
\hline 2013 & Xin & Neurological & Rat & Post-injury induction (Treatment) & No & Not Described & Yes \\
\hline 2013 & Zhou & Renal & Rat & Post-injury induction (Treatment) & Yes & Not Described & Yes \\
\hline 2013 & Wu & Cancer & Mouse & At the same time as injury induction & No & Yes & Yes \\
\hline 2013 & Katakowski & Cancer & Rat & Post-injury induction (Treatment) & No & Not Described & Yes \\
\hline 2013 & Arslan & Cardiac & Mouse & Pre-injury induction (Prevention) & No & Not Described & Mixed \\
\hline 2013 & $\mathrm{Li}$ & Hepatic & Mouse & Post-injury induction (Treatment) & Yes & Not Described & Mixed \\
\hline 2013 & Roccaro & Cancer & Mouse & At the same time as injury induction & No & Not Described & Mixed \\
\hline 2013 & Bruno & Cancer & Mouse & Post-injury induction (Treatment) & No & Yes & Yes \\
\hline 2014 & Chen & Lung & Rat & Post-injury induction (Treatment) & No & Yes & Yes \\
\hline 2014 & Feng & $\begin{array}{l}\text { Angiogenesis (e.g. } \\
\text { matrigel plug) }\end{array}$ & Mouse & At the same time as injury induction & No & No & Yes \\
\hline 2014 & Tan & Hepatic & Mouse & Post-injury induction (Treatment) & No & Not Described & Yes \\
\hline 2014 & $\mathrm{Du}$ & Cancer & Mouse & At the same time as injury induction & No & Yes & Adverse effects \\
\hline 2014 & Raisi & Nerve & Rat & Post-injury induction (Treatment) & No & Yes & Yes \\
\hline 2014 & Zou & Renal & Rat & Post-injury induction (Treatment) & Yes & Not Described & Yes \\
\hline 2014 & Zhang & Renal & Rat & Post-injury induction (Treatment) & No & Not Described & Yes \\
\hline 2014 & Choi & Lung & Mouse & Post-injury induction (Treatment) & No & Yes & Mixed \\
\hline 2014 & Feng & Cardiac & Mouse & Post-injury induction (Treatment) & No & Not Described & Yes \\
\hline 2014 & Choi & Renal & Mouse & Post-injury induction (Treatment) & Yes & Not Described & Yes \\
\hline 2014 & Zhang & Transplantation & Mouse & Post-injury induction (Treatment) & No & Not Described & Yes \\
\hline 2014 & Bian & Cardiac & Rat & Post-injury induction (Treatment) & No & Not Described & Yes \\
\hline 2014 & Rahman & Autoimmune, Diabetes & Mouse & Post-injury induction (Treatment) & No & Not Described & Adverse effects \\
\hline 2014 & Zhu & Lung & Mouse & $\begin{array}{l}\text { Post-injury induction (Treatment), At the same } \\
\text { time as injury induction }\end{array}$ & No & Not Described & Yes \\
\hline 2015 & Koch & Renal, Transplantation & Rat & Post-injury induction (Treatment) & No & Not Described & Mixed \\
\hline 2015 & Zhao & Cardiac & Rat & Post-injury induction (Treatment) & No & Not Described & Mixed \\
\hline 2015 & Kang & Cardiac & Rat & Post-injury induction (Treatment) & No & Yes & Yes \\
\hline 2015 & $\mathrm{Li}$ & Lung & Mouse & Post-injury induction (Treatment) & No & Not Described & Yes \\
\hline 2015 & Yang & Neurological & Rat & Post-injury induction (Treatment) & No & Not Described & Yes \\
\hline 2015 & Teng & Cardiac & Rat & Post-injury induction (Treatment) & No & Not Described & Yes \\
\hline 2015 & Lou & Cancer & Mouse & Post-injury induction (Treatment) & No & Yes & Mixed \\
\hline 2015 & Yang & Intestinal & Rat & Post-injury induction (Treatment) & Yes & Yes & Yes \\
\hline 2015 & Geiger & Diabetes, Wound & Mouse & Post-injury induction (Treatment) & No & Yes & Yes \\
\hline 2015 & $\mathrm{Ti}$ & Diabetes, Wound & Rat & Post-injury induction (Treatment) & No & Not Described & Yes \\
\hline 2015 & Cruz & Lung & Mouse & Post-injury induction (Treatment) & No & Yes & Yes \\
\hline 2015 & Wang & Sepsis & Mouse & Post-injury induction (Treatment) & Yes & Not Described & Yes \\
\hline 2015 & Doeppner & Neurological & Mouse & Post-injury induction (Treatment) & No & Yes & Mixed \\
\hline
\end{tabular}


Supplemental File 2 - Outcomes and Animal Models

\begin{tabular}{|c|c|c|c|c|c|c|c|}
\hline 2015 & $\mathrm{Hu}$ & $\begin{array}{l}\text { Ischemia (e.g. testing } \\
\text { angiogenesis) }\end{array}$ & Mouse & Post-injury induction (Treatment) & No & Yes & Yes \\
\hline 2015 & Monsel & Lung & Mouse & Post-injury induction (Treatment) & No & Not Described & Yes \\
\hline 2015 & Wang & Renal & Mouse & Post-injury induction (Treatment) & No & Yes & Yes \\
\hline 2015 & Choi & Renal & Mouse & Post-injury induction (Treatment) & Yes & Yes & Yes \\
\hline 2015 & Nakamura & Muscle & Mouse & Post-injury induction (Treatment) & No & Not Described & Yes \\
\hline 2015 & Zhang & $\begin{array}{l}\text { Wound, Angiogenesis } \\
\text { (e.g. matrigel plug) }\end{array}$ & Rat & Post-injury induction (Treatment) & No & Not Described & Yes \\
\hline 2015 & $\mathrm{Ju}$ & Renal & Rat & Post-injury induction (Treatment) & No & Yes & Yes \\
\hline 2015 & Zhang & Wound & Rat & Post-injury induction (Treatment) & No & Yes & Yes \\
\hline 2015 & $\mathrm{Yu}$ & Cardiac & Rat & Post-injury induction (Treatment) & Yes & Not Described & Yes \\
\hline 2015 & Zhang & Wound & Rat & Post-injury induction (Treatment) & No & Not Described & Yes \\
\hline 2015 & Ko & Cancer & Rat & Post-injury induction (Treatment) & No & Not Described & Yes \\
\hline 2015 & Zhang & Neurological & Rat & Post-injury induction (Treatment) & No & Yes & Yes \\
\hline 2015 & Collino & Renal & Mouse & Post-injury induction (Treatment) & No & Not Described & Yes \\
\hline 2016 & Yu & Opthalmic & Mouse & Post-injury induction (Treatment) & Yes & Not Described & Yes \\
\hline 2016 & Tamura & Hepatic & Mouse & Post-injury induction (Treatment) & Yes & Not Described & Yes \\
\hline 2016 & Shen & Renal & Mouse & Post-injury induction (Treatment) & No & Not Described & Yes \\
\hline 2016 & Zou & Renal & Rat & Post-injury induction (Treatment) & Yes & Not Described & Yes \\
\hline 2016 & Gu & Renal & Rat & Post-injury induction (Treatment) & Yes & Not Described & Yes \\
\hline 2016 & Nagaishi & Renal, Diabetes & Rat & Post-injury induction (Treatment) & Yes & Not Described & Yes \\
\hline 2016 & $\mathrm{Hu}$ & Wound & Mouse & Post-injury induction (Treatment) & Yes & Yes & Yes \\
\hline 2016 & Lee & Neurological & Rat & Post-injury induction (Treatment) & No & Yes & Yes \\
\hline 2016 & Xie & Bone/Joint & Mouse & Post-injury induction (Treatment) & No & Not Described & Yes \\
\hline 2016 & Zhang & Bone/Joint & Rat & Post-injury induction (Treatment) & No & Yes & Mixed \\
\hline 2016 & Yin & Pancreas & Mouse, Rat & Post-injury induction (Treatment) & Yes & Yes & Yes \\
\hline 2016 & Kalimuthu & Cancer & Mouse & Post-injury induction (Treatment) & Yes & Yes & Yes \\
\hline 2016 & Chen & Neurological & Rat & Post-injury induction (Treatment) & Yes & Not Described & Yes \\
\hline 2016 & Nakano & Neurological, Diabetes & Mouse & Post-injury induction (Treatment) & Yes & Not Described & Yes \\
\hline 2016 & Wen & Transplantation, Diabetes & Mouse & Post-injury induction (Treatment) & Yes & Yes & Yes \\
\hline 2016 & Liu & Neurological & Mouse & Post-injury induction (Treatment) & Yes & Not Described & Yes \\
\hline 2016 & Zhang & Wound & Rat & Post-injury induction (Treatment) & No & Not Described & Mixed \\
\hline 2016 & Zou & Renal & Rat & Post-injury induction (Treatment) & Yes & Not Described & Yes \\
\hline 2016 & Wen & Irradiation & Mouse & Post-injury induction (Treatment) & Yes & Not Described & Yes \\
\hline 2016 & Guo & Bone/Joint & Rat & Post-injury induction (Treatment) & No & Yes & Yes \\
\hline 2016 & Nong & Hepatic & Rat & Post-injury induction (Treatment) & No & Not Described & Yes \\
\hline 2016 & Furuta & Bone/Joint & Mouse & Post-injury induction (Treatment) & No & Not Described & Yes \\
\hline 2016 & $\mathrm{Hu}$ & Neurological & Rat & Post-injury induction (Treatment) & No & Yes & Mixed \\
\hline 2016 & Vrijsen & $\begin{array}{l}\text { Angiogenesis (e.g. } \\
\text { matrigel plug) }\end{array}$ & Mouse & Post-injury induction (Treatment) & No & Not Described & Yes \\
\hline 2016 & $\mathrm{Li}$ & Wound & Rat & Post-injury induction (Treatment) & No & Yes & Yes \\
\hline 2016 & Fang & Wound & Mouse & Post-injury induction (Treatment) & No & Not Described & Yes \\
\hline 2016 & Qi & Bone/Joint & Rat & Post-injury induction (Treatment) & No & Yes & Yes \\
\hline 2016 & Ophelders & Neurological & Sheep & Post-injury induction (Treatment) & No & Yes & Mixed \\
\hline 2016 & Lin & Renal & Rat & Post-injury induction (Treatment) & No & Not Described & Yes \\
\hline 2016 & Rager & $\begin{array}{l}\text { Intestinal, Infection (non } \\
\text { sepsis) }\end{array}$ & Rat & Post-injury induction (Treatment) & No & Yes & Yes \\
\hline 2016 & Aliotta & Lung & Mouse & Post-injury induction (Treatment) & No & Not Described & Yes \\
\hline 2016 & Qin & Bone/Joint & Rat & Post-injury induction (Treatment) & No & Not Described & Yes \\
\hline 2016 & Zhang & Renal & Rat & Post-injury induction (Treatment) & No & Not Described & Yes \\
\hline 2016 & Sun & Cardiac & Rat & Post-injury induction (Treatment) & No & Not Described & No benefits \\
\hline 2016 & Kim & Neurological & Mouse & Post-injury induction (Treatment) & No & Not Described & Mixed \\
\hline 2016 & Liu & & Mouse & Post-injury induction (Treatment) & Yes & Not Described & Yes \\
\hline
\end{tabular}


Supplemental File 2 - Outcomes and Animal Models

\begin{tabular}{|c|c|c|c|c|c|c|c|}
\hline 2016 & Wang & Graft versus host disease & Mouse & Pre-injury induction (Prevention) & No & Not Described & Yes \\
\hline 2016 & $\mathrm{Ti}$ & Diabetes, Wound & Rat & Post-injury induction (Treatment) & No & Not Described & Yes \\
\hline 2016 & Shi & Cancer & Mouse & Post-injury induction (Treatment) & No & Yes & Adverse effects \\
\hline 2016 & Lange & Irradiation & Mouse & Post-injury induction (Treatment) & No & Not Described & Yes \\
\hline 2017 & Fujii & Graft versus host disease & Mouse & Post-injury induction (Treatment) & No & Yes & Yes \\
\hline 2017 & Cheng & $\begin{array}{l}\text { Intervertebral disc } \\
\text { degeneration }\end{array}$ & Rat & Post-injury induction (Treatment) & No & Yes & Mixed \\
\hline 2017 & Willis & Lung & Mouse & Post-injury induction (Treatment) & No & Not Described & Yes \\
\hline 2017 & Zhu & Cardiac & Mouse & Post-injury induction (Treatment) & No & Yes & Yes \\
\hline 2017 & Webb & Neurological & Mouse & Post-injury induction (Treatment) & Yes & Yes & No benefits \\
\hline 2017 & Wang & Wound & Mouse & Post-injury induction (Treatment) & Yes & Yes & Yes \\
\hline 2017 & Mead & Opthalmic & Rat & Post-injury induction (Treatment) & Yes & Not Described & Yes \\
\hline 2017 & Yuan & Renal & Rat & Pre-injury induction (Prevention) & No & Not Described & Yes \\
\hline 2017 & Soundara Rajan & Autoimmune & Mouse & Post-injury induction (Treatment) & No & Yes & Yes \\
\hline 2017 & El-Tookhy & Wound & Dog & Post-injury induction (Treatment) & No & Yes & Yes \\
\hline 2017 & Schoefinius & Total Body Irradiation & Mouse & Post-injury induction (Treatment) & Yes & Not Described & Mixed \\
\hline 2017 & Huang & Spinal cord injury & Rat & Post-injury induction (Treatment) & No & Yes & Yes \\
\hline 2017 & Chen & Renal & Rat & Post-injury induction (Treatment) & No & Not Described & Yes \\
\hline 2017 & Zhang & Neurological & Rat & Post-injury induction (Treatment) & No & Yes & Mixed \\
\hline 2017 & Stone & Lung & Mouse & Pre-injury induction (Prevention) & No & Yes & Yes \\
\hline 2017 & Horn & Neurological & Rat & Both Prevention and Treatment Protocols & No & Yes & Mixed \\
\hline 2017 & Cosenza & Bone/Joint & Mouse & Post-injury induction (Treatment) & No & Not Described & Mixed \\
\hline 2017 & Shi & Diabetes, Wound & Rat & Post-injury induction (Treatment) & No & Yes & Yes \\
\hline 2017 & Rajendran & Hair growth & Mouse & Post-injury induction (Treatment) & Yes & Not Described & Yes \\
\hline 2017 & Bruno & Renal & Mouse & Post-injury induction (Treatment) & No & Not Described & Mixed \\
\hline 2017 & Aliotta & Lung & Mouse & Post-injury induction (Treatment) & No & Not Described & Yes \\
\hline 2017 & Komaki & $\begin{array}{l}\text { Ischemia (e.g. testing } \\
\text { angiogenesis) }\end{array}$ & Mouse & Post-injury induction (Treatment) & No & Not Described & Yes \\
\hline 2017 & $\mathrm{Li}$ & Neurological & Rat & Post-injury induction (Treatment) & No & Not Described & Yes \\
\hline 2017 & Gangadaran & $\begin{array}{l}\text { Ischemia (e.g. testing } \\
\text { angiogenesis) }\end{array}$ & Mouse & Post-injury induction (Treatment) & Yes & Yes & Yes \\
\hline 2017 & Deng & Neurological & Mouse & Pre-injury induction (Prevention) & No & Yes & Mixed \\
\hline 2017 & Bai & Autoimmune, Opthalmic & Rat & Post-injury induction (Treatment) & No & Not Described & Yes \\
\hline 2017 & Sun & Hepatic & Rat & Post-injury induction (Treatment) & No & Yes & Yes \\
\hline 2017 & Gong & $\begin{array}{l}\text { Angiogenesis (e.g. } \\
\text { matrigel plug) }\end{array}$ & Mouse & Post-injury induction (Treatment) & No & Not Described & Yes \\
\hline 2017 & $\mathrm{Qu}$ & Hepatic & Mouse & Post-injury induction (Treatment) & No & Yes & Yes \\
\hline 2017 & Casado & Bone/Joint & Pig & Post-injury induction (Treatment) & No & Not Described & Mixed \\
\hline 2017 & Xie & Bone/Joint & Mouse & Post-injury induction (Treatment) & No & Not Described & Yes \\
\hline 2017 & Otero-Ortega & Neurological & Rat & Post-injury induction (Treatment) & Yes & Yes & Mixed \\
\hline 2017 & Wang & Cardiac & Mouse & Post-injury induction (Treatment) & No & Not Described & Mixed \\
\hline 2017 & Haga & Hepatic & Mouse & Post-injury induction (Treatment) & Yes & Not Described & Yes \\
\hline 2017 & $\mathrm{Ma}$ & Cardiac & Rat & Post-injury induction (Treatment) & No & Yes & Yes \\
\hline 2017 & Wang & Bone/Joint & Mouse & Post-injury induction (Treatment) & No & Yes & Mixed \\
\hline 2017 & Long & Neurological & Mouse & Post-injury induction (Treatment) & Yes & Yes & Yes \\
\hline 2017 & $\mathrm{Li}$ & Bone/Joint & Rabbit & Post-injury induction (Treatment) & No & Yes & Yes \\
\hline 2017 & Eirin & Renal & Pig & Post-injury induction (Treatment) & Yes & Yes & Yes \\
\hline 2017 & de Castro & Lung & Mouse & Post-injury induction (Treatment) & No & Yes & Mixed \\
\hline 2017 & Tang & Lung & Mouse & At the same time as injury induction & No & Not Described & Yes \\
\hline 2017 & Gonzalez-King & $\begin{array}{c}\text { Angiogenesis (e.g. } \\
\text { matrigel plug) }\end{array}$ & Mouse & Post-injury induction (Treatment) & No & Not Described & Yes \\
\hline 2017 & Haga & Hepatic & Mouse & Pre-injury induction (Prevention) & Yes & Not Described & Yes \\
\hline
\end{tabular}


Supplemental File 2 - Outcomes and Animal Models

\begin{tabular}{|c|c|c|c|c|c|c|c|}
\hline 2017 & Mao & Intestinal & Mouse & Post-injury induction (Treatment) & Yes & Yes & Yes \\
\hline 2017 & Shigemoto-Kuroda & $\begin{array}{l}\text { Autoimmune, Opthalmic, } \\
\text { Diabetes }\end{array}$ & Mouse & Post-injury induction (Treatment) & No & Not Described & Yes \\
\hline 2017 & 5 & $\begin{array}{l}\text { Ischemia (e.g. testing } \\
\text { angiogenesis) }\end{array}$ & Mouse & Post-injury induction (Treatment) & No & Yes & Yes \\
\hline 2017 & Chen & Hepatic & Mouse & Pre-injury induction (Prevention) & Yes & Not Described & Yes \\
\hline 2017 & Song & Sepsis & Mouse & Post-injury induction (Treatment) & Yes & Yes & Yes \\
\hline 2017 & Moisseiev & Opthalmic & Mouse & Post-injury induction (Treatment) & No & Not Described & Yes \\
\hline 2017 & Liu & Cardiac & Rat & Post-injury induction (Treatment) & No & Yes & Yes \\
\hline 2017 & Zhu & Bone/Joint & Mouse & Post-injury induction (Treatment) & No & Yes & Yes \\
\hline 2017 & Xin & Neurological & Rat & Post-injury induction (Treatment) & No & Yes & Yes \\
\hline 2017 & Yan & Hepatic & Mouse & Post-injury induction (Treatment) & Yes & Yes & Yes \\
\hline 2017 & Tao & Bone/Joint & Rat & Post-injury induction (Treatment) & No & Yes & Yes \\
\hline 2017 & Liu & Bone/Joint & Rat & Pre-injury induction (Prevention) & No & Yes & Yes \\
\hline 2017 & Kamerkar & Cancer & Mouse & Post-injury induction (Treatment) & Yes & Yes & Mixed \\
\hline 2017 & $\mathrm{Du}$ & Hepatic & Mouse & Post-injury induction (Treatment) & No & Not Described & Yes \\
\hline 2017 & Wang & Renal & Rat & Pre-injury induction (Prevention) & No & Not Described & Yes \\
\hline 2017 & Zhao & Wound & Rat & Post-injury induction (Treatment) & No & Not Described & Yes \\
\hline 2017 & Shao & Cardiac & Rat & Post-injury induction (Treatment) & No & Not Described & Yes \\
\hline 2017 & Tao & Diabetes, Wound & Rat & Post-injury induction (Treatment) & No & Not Described & Yes \\
\hline 2017 & Huang & Transplantation & Mouse & At the same time as injury induction & No & Yes & Yes \\
\hline 2017 & Tamura & Hepatic & Mouse & Post-injury induction (Treatment) & Yes & Not Described & Yes \\
\hline 2017 & Grigorian-Shamagian & Cancer & Mouse & Post-injury induction (Treatment) & No & Yes & No benefits \\
\hline 2017 & Ranghino & Renal & Mouse & Post-injury induction (Treatment) & Yes & Not Described & Yes \\
\hline 2017 & Cui & Cardiac & Rat & Post-injury induction (Treatment) & No & Yes & Yes \\
\hline 2017 & Henao Agudelo & $\begin{array}{l}\text { Intestinal, Infection (non } \\
\text { sepsis) }\end{array}$ & Mouse & Post-injury induction (Treatment) & No & Not Described & Mixed \\
\hline 2017 & Xin & Neurological & Rat & Post-injury induction (Treatment) & No & Not Described & Yes \\
\hline 2017 & Lo Sicco & $\begin{array}{l}\text { Muscle, Angiogenesis } \\
\text { (e.g. matrigel plug) }\end{array}$ & Mouse & Post-injury induction (Treatment) & No & Not Described & Yes \\
\hline 2017 & de Almeida & Renal & Mouse & Post-injury induction (Treatment) & No & Not Described & Yes \\
\hline 2018 & Luther & Cardiac & Mouse & Pre-injury induction (Prevention) & No & Not Described & Yes \\
\hline 2018 & Williams & Neurological, Shock & Pig & Post-injury induction (Treatment) & No & Yes & Yes \\
\hline 2018 & McCulloh & $\begin{array}{l}\text { Intestinal, Infection (non } \\
\text { sepsis) }\end{array}$ & Rat & Pre-injury induction (Prevention) & No & Yes & Yes \\
\hline 2018 & Zhang & Graft versus host disease & Mouse & Post-injury induction (Treatment) & No & Not Described & Yes \\
\hline 2018 & Barile & Cardiac & Rat & Post-injury induction (Treatment) & No & Not Described & Mixed \\
\hline 2018 & Otero-Ortega & Neurological & Rat & Post-injury induction (Treatment) & Yes & Yes & Mixed \\
\hline 2018 & Ahn & Lung & Rat & Post-injury induction (Treatment) & Yes & Yes & Yes \\
\hline 2018 & Jiang & Hepatic & Mouse & Post-injury induction (Treatment) & Yes & Yes & Mixed \\
\hline 2018 & Diomede & Bone/Joint & Rat & Post-injury induction (Treatment) & Yes & Yes & Yes \\
\hline 2018 & $\mathrm{He}$ & Opthalmic & Rat & Post-injury induction (Treatment) & No & Yes & Yes \\
\hline 2018 & Blazquez & Incisional hernia & Mouse & Post-injury induction (Treatment) & No & Not Described & Mixed \\
\hline 2018 & Shen & Neurological & Rat & Post-injury induction (Treatment) & No & Yes & Yes \\
\hline 2018 & Lang & Cancer & Mouse & Post-injury induction (Treatment) & No & Not Described & Yes \\
\hline 2018 & Wang & Cardiac & Rat & Post-injury induction (Treatment) & No & Yes & Yes \\
\hline 2018 & Cui & Neurological & Mouse & Post-injury induction (Treatment) & Yes & Not Described & Yes \\
\hline 2018 & Damania & Hepatic & Rat & Post-injury induction (Treatment) & No & Not Described & Yes \\
\hline 2018 & $\mathrm{Li}$ & Bone/Joint & Mouse & Post-injury induction (Treatment) & Yes & Yes & Yes \\
\hline 2018 & Zhu & $\begin{array}{l}\text { Diabetes, Erectile } \\
\text { dysfunction }\end{array}$ & Rat & Post-injury induction (Treatment) & No & Yes & Yes \\
\hline 2018 & Khatri & Lung & Pig & Post-injury induction (Treatment) & No & Not Described & Yes \\
\hline 2018 & Mead & Opthalmic & Rat & Post-injury induction (Treatment) & No & Not Described & Mixed \\
\hline
\end{tabular}




\section{Supplemental File 2 - Outcomes and Animal Models}

\begin{tabular}{|c|c|c|c|c|c|c|c|}
\hline 2018 & Wang & Neurological & Mouse & Post-injury induction (Treatment) & No & Yes & Yes \\
\hline 2018 & Otsuru & Bone/Joint & Mouse & Post-injury induction (Treatment) & No & Not Described & Yes \\
\hline 2018 & Wu & Renal & Rat & Post-injury induction (Treatment) & No & Not Described & Yes \\
\hline 2018 & Potter & Lung, Shock & Mouse & Post-injury induction (Treatment) & No & Not Described & Yes \\
\hline 2018 & Ruppert & Spinal cord injury & Rat & Post-injury induction (Treatment) & No & Yes & Yes \\
\hline 2018 & Han & Transplantation & Mouse & Post-injury induction (Treatment) & No & Not Described & Yes \\
\hline 2018 & Chen & Hepatic & Mouse & Post-injury induction (Treatment) & No & Yes & Yes \\
\hline 2018 & Mardpour & Hepatic & Rat & Post-injury induction (Treatment) & Yes & Not Described & Yes \\
\hline 2018 & O'Brien & Cancer & Mouse & Post-injury induction (Treatment) & No & Not Described & Yes \\
\hline 2018 & Chang & Sepsis & Rat & Post-injury induction (Treatment) & No & Not Described & Yes \\
\hline 2018 & Tian & Bone/Joint & Rabbit & Post-injury induction (Treatment) & No & Yes & Yes \\
\hline 2018 & Kou & Diabetes, Wound & Mouse & Post-injury induction (Treatment) & No & Yes & Yes \\
\hline 2018 & Chen & Diabetes, Wound & Mouse & Post-injury induction (Treatment) & No & Yes & Yes \\
\hline 2018 & Jia & Renal & Rat & Pre-injury induction (Prevention) & No & Yes & Yes \\
\hline 2018 & Cosenza & Bone/Joint & Mouse & Post-injury induction (Treatment) & No & Not Described & Yes \\
\hline
\end{tabular}


Supplemental File 3 - Dosage Data

\begin{tabular}{|c|c|c|c|c|c|c|c|c|c|c|}
\hline$\frac{\text { Publication }}{\text { Year }}$ & $\frac{\text { First Author's }}{\text { Last Name }}$ & $\frac{\text { Single or Multiple Dose }}{\underline{\text { Study }}}$ & Dose Administered & Dosage Units & Route of Administration & $\frac{\text { No. of }}{\underline{\text { Doses }}}$ & $\begin{array}{l}\frac{\text { If multi-dose study, }}{\text { how often were }} \\
\text { treatments given? }\end{array}$ & $\frac{\text { Was a dose- }}{\text { response study }}$ & $\begin{array}{l}\text { If a dose-response study was } \\
\frac{\text { conducted, how many }}{\text { different doses were }} \\
\text { administered? }\end{array}$ & $\begin{array}{l}\frac{\text { If a dose-response }}{\text { study was }} \\
\text { conducted, what was } \\
\text { the dose range? }\end{array}$ \\
\hline$\overline{2009}$ & Bruno & Single Dose of EVs & $15 u g$ & EV protein concentration (e.g. ug) & IV - tail vein & 1 & & No & & \\
\hline 2010 & Lai & Single Dose of EVs & 10ug & EV protein concentration (e.g. ug) & IV - tail vein & 1 & & No & & \\
\hline 2011 & Chen & Single Dose of EVs & $0.3 \mathrm{ug}$ & EV protein concentration (e.g. ug) & IV - Other (e.g. peripheral sites) & 1 & & No & & \\
\hline 2011 & Gatti & Single Dose of EVs & $30 u g$ & EV protein concentration (e.g. ug) & IV - Other (e.g. peripheral sites) & 1 & & No & & \\
\hline 2012 & Lai & Single Dose of EVs & $0.4 \mathrm{ug}$ & EV protein concentration (e.g. ug) & IV - tail vein & 1 & & No & & \\
\hline 2012 & Lee & $\begin{array}{l}\text { Single Dose of EVs, Both } \\
\text { (Same experiment) }\end{array}$ & $0.1 \mathrm{ug}$ & EV protein concentration (e.g. ug) & IV - jugular vein, IV - tail vein & 2 & Day 0 and 4 & Yes & 2 & 0.1 and $10 \mathrm{ug}$ \\
\hline 2012 & Reis & Single Dose of EVs & $100 \mathrm{ug} / \mathrm{mL}$ & EV protein concentration (e.g. ug) & IV - tail vein & 1 & & No & & 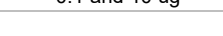 \\
\hline 2012 & Zhang & Multiple Doses of EV & 10,50 and $100 \mathrm{ug}$ & EV protein concentration (e.g. ug) & Intramuscular (IM) & 1 & & Yes & 3 & 10,50 and $100 \mathrm{ug}$ \\
\hline 2012 & van Koppen & Multiple Doses of EV & 7 ug & EV protein concentration (e.g. ug) & IV - tail vein & 8 & Twice daily for 4 days & No & & \\
\hline 2012 & Bruno & Both (Same experiment) & $\begin{array}{l}\text { 100ug (+50ug for } \\
\text { subsequent doses) }\end{array}$ & EV protein concentration (e.g. ug) & IV - tail vein & 6 & $\begin{array}{c}8 \mathrm{~h} \text { and days } 2,6,10 \text {, } \\
14, \text { and } 18\end{array}$ & No & & \\
\hline 2012 & $\mathrm{He}$ & Multiple Doses of EV & 30ug & EV protein concentration (e.g. ug) & IV - tail vein & 3 & Days $2,3,5$ & No & & \\
\hline 2013 & Kilpinen & Single Dose of EVs & Not Described & Not Described & Intra-arterial & 1 & & No & & \\
\hline 2013 & Lee & Single Dose of EVs & 100 ug or $200 u g$ & EV protein concentration (e.g. ug) & Subcutaneous & 1 & & Yes & 2 & 100 or 200 ug \\
\hline 2013 & Xin & Single Dose of EVs & 100ug & EV protein concentration (e.g. ug) & IV - tail vein & 1 & & No & & \\
\hline 2013 & Zhou & Single Dose of EVs & 200ug & EV protein concentration (e.g. ug) & Direct tissue injection & 1 & & No & & \\
\hline 2013 & Wu & Single Dose of EVs & $200 u g$ & EV protein concentration (e.g. ug) & Subcutaneous & 1 & & No & & \\
\hline 2013 & Katakowski & Single Dose of EVs & 50ug & EV protein concentration (e.g. ug) & Direct tissue injection & 1 & & No & & \\
\hline 2013 & Arslan & Single Dose of EVs & 1,4 or $16 u g / k g$ & EV protein / weight of animal (e.g. ug $/ \mathrm{kg})$ & IV - tail vein & 1 & & Yes & 3 & 1,4 or $16 \mathrm{ug} / \mathrm{kg}$ \\
\hline 2013 & $\mathrm{Li}$ & Single Dose of EVs & 250ug & EV protein concentration (e.g. ug) & Direct tissue injection & 1 & & No & & \\
\hline 2013 & Roccaro & Multiple Doses of EV & 1ug & EV protein concentration (e.g. ug) & Implanted (e.g. with scaffolds) & $2,3,4$ & $\begin{array}{l}\text { Ever } 4 \text { days for } 7,10 \text { or } \\
14 \text { days }\end{array}$ & No & & \\
\hline 2013 & Bruno & Multiple Doses of EV & $\begin{array}{l}\text { 100ug (first dose), } \\
50 \text { ug (subsequent) }\end{array}$ & EV protein concentration (e.g. ug) & Direct tissue injection & 3,4 & Weekly for 3 or 4 weeks & No & & \\
\hline 2014 & Chen & Multiple Doses of EV & 30ug & EV protein concentration (e.g. ug) & IV - tail vein & 14 & $\begin{array}{l}\text { Once every } 2 \text { days for } 2 \\
\text { weeks }\end{array}$ & No & & \\
\hline 2014 & Feng & Single Dose of EVs & $100 \mathrm{ug}$ & EV protein concentration (e.g. ug) & Subcutaneous & 1 & & No & & \\
\hline 2014 & Tan & Single Dose of EVs & $0.4 \mathrm{ug}$ & EV protein concentration (e.g. ug) & Intrasplenic & 1 & & No & & \\
\hline 2014 & $\mathrm{Du}$ & Single Dose of EVs & $200 \mathrm{ug} / \mathrm{mL}$ & EV protein concentration (e.g. ug) & Subcutaneous & 1 & & No & & \\
\hline 2014 & Raisi & Single Dose of EVs & $45 \mathrm{ug}$ & EV protein concentration (e.g. ug) & Implanted (e.g. with scaffolds) & 1 & & No & & \\
\hline 2014 & Zou & Single Dose of EVs & 100ug & EV protein concentration (e.g. ug) & IV - tail vein & 1 & & No & & \\
\hline 2014 & Zhang & Single Dose of EVs & 100ug & EV protein concentration (e.g. ug) & IV - tail vein & 1 & & No & & \\
\hline 2014 & Choi & Multiple Doses of EV & 10ug & EV protein concentration (e.g. ug) & IV - tail vein & 2 & 12 and 14 weeks & No & & \\
\hline 2014 & Feng & Single Dose of EVs & 1ug & EV protein concentration (e.g. ug) & Direct tissue injection & 1 & & No & & \\
\hline 2014 & Choi & Single Dose of EVs & 2e7 particles & $\begin{array}{c}\text { EV particle concentration (e.g. exo's } / \mathrm{mL} \\
\text { PBS) }\end{array}$ & IV - tail vein & 1 & & No & & \\
\hline 2014 & Zhang & Both (Separate experiments) & $0.3 \mathrm{ug}$ & EV protein concentration (e.g. ug) & Subcutaneous, Intrasplenic & 11 & $\begin{array}{l}\text { Daily for } 4 \text { days, then } \\
\text { every other day for } 15 \\
\text { days }\end{array}$ & No & & \\
\hline 2014 & Bian & Single Dose of EVs & $80 u g$ & EV protein concentration (e.g. ug) & Direct tissue injection & 1 & & No & & \\
\hline 2014 & Rahman & Multiple Doses of EV & $\begin{array}{l}2.5 u g \text { (first dose) and } \\
\text { 5ug ( } 2 \text { doses) }\end{array}$ & EV protein concentration (e.g. ug) & Intraperitoneal & 3 & Once per week & No & & \\
\hline 2014 & Zhu & Single Dose of EVs & 3e6 MSC Equivalent & $\begin{array}{l}\text { \# of EVs made over time by cell culture } \\
\text { (MSCs) }\end{array}$ & IV - jugular vein, Intratracheal & 1 & 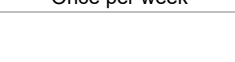 & Yes & 2 & $\begin{array}{l}3 \mathrm{e} 6 \text { or } 6 \mathrm{e} 6 \mathrm{MSC} \\
\text { Equivalent }\end{array}$ \\
\hline 2015 & Koch & Single Dose of EVs & Not Described & Not Described & Not described & 1 & & No & & \\
\hline 2015 & Zhao & Single Dose of EVs & $400 u g$ & EV protein concentration (e.g. ug) & IV - tail vein & 1 & & No & & \\
\hline 2015 & Kang & Single Dose of EVs & Not Described & Not Described & Implanted (e.g. with scaffolds) & 1 & & No & & \\
\hline 2015 & $\mathrm{Li}$ & Single Dose of EVs & $1.5 \mathrm{ug} / \mathrm{g}$ & EV protein / weight of animal (e.g. ug $/ \mathrm{kg})$ & IV - tail vein & 1 & & Yes & 2 & 1.5 or $3 u g / g$ \\
\hline 2015 & Yang & Single Dose of EVs & $400 \mathrm{ug} / \mathrm{kg}$ & EV protein / weight of animal (e.g. ug $/ \mathrm{kg}$ ) & Not described & 1 & & No & & \\
\hline 2015 & Teng & Single Dose of EVs & 80ug & EV protein concentration (e.g. ug) & Direct tissue injection & 1 & & No & & \\
\hline 2015 & Lou & Single Dose of EVs & 50ug & EV protein concentration (e.g. ug) & Direct tissue injection & 1 & & No & & \\
\hline 2015 & Yang & Single Dose of EVs & 50,100 or 200 ug & EV protein concentration (e.g. ug) & IV - tail vein & 1 & & Yes & 3 & 50,100 and $200 \mathrm{ug}$ \\
\hline 2015 & Geiger & Single Dose of EVs & 5 or 50 ug & EV protein concentration (e.g. ug) & $\begin{array}{l}\text { Direct tissue injection, } \\
\text { Subcutaneous }\end{array}$ & 1 & & Yes & 2 & 5 or 50 ug \\
\hline 2015 & $\mathrm{Ti}$ & Single Dose of EVs & $60 u g$ & EV protein concentration (e.g. ug) & Subcutaneous & 1 & & No & & \\
\hline 2015 & Cruz & Single Dose of EVs & 3e6 MSC Equivalent & $\begin{array}{l}\text { EV dose based on cell count (e.g. per weight } \\
\text { of animal) }\end{array}$ & IV - tail vein & 1 & & No & & \\
\hline 2015 & Wang & Single Dose of EVs & $2 u g / g$ & EV protein / weight of animal (e.g. ug/kg) & IV - tail vein & 1 & & No & & \\
\hline 2015 & Doeppner & Both (Separate experiments) & 2e6 MSC Equivalent & $\begin{array}{c}\text { EV dose based on cell count (e.g. per weight } \\
\text { of animal) }\end{array}$ & IV - Other (e.g. peripheral sites) & 3 & Day 1,3 and 5 & No & & \\
\hline
\end{tabular}




\section{Supplemental File 3 - Dosage Data}

\begin{tabular}{|c|c|c|c|c|c|c|c|c|c|c|}
\hline 2015 & $\mathrm{Hu}$ & Multiple Doses of EV & 200ug & EV protein concentration (e.g. ug) & Intramuscular (IM) & 4 & Day 0 & No & & \\
\hline 2015 & Monsel & Single Dose of EVs & $\begin{array}{c}\text { 3e6, 6e6 or 9e6 MSC } \\
\text { Equivalent }\end{array}$ & $\begin{array}{l}\text { \# of EVs made over time by cell culture } \\
\text { (MSCs) }\end{array}$ & $\begin{array}{l}\text { IV - Other (e.g. peripheral sites), } \\
\text { Intratracheal }\end{array}$ & 1 & & Yes & 3 & $\begin{array}{c}\text { 3e6, 6e6 or } 9 \mathrm{e} 6 \mathrm{MSC} \\
\text { Equivalent }\end{array}$ \\
\hline 2015 & Wang & Single Dose of EVs & 30ug & EV protein concentration (e.g. ug) & IV - tail vein & 1 & & No & & \\
\hline 2015 & Choi & Single Dose of EVs & 2e7 particles & $\begin{array}{l}\text { EV particle concentration (e.g. exo's } / \mathrm{mL} \\
\text { PBS) }\end{array}$ & IV - tail vein & 1 & & No & & \\
\hline 2015 & Nakamura & Multiple Doses of EV & Not Described & Not Described & Intramuscular (IM) & 3 & Day 1,3 and 5 & No & & \\
\hline 2015 & Zhang & Single Dose of EVs & $200 u g$ & EV protein concentration (e.g. ug) & Subcutaneous & 1 & & No & & \\
\hline 2015 & $\mathrm{Ju}$ & Single Dose of EVs & 30ug & EV protein concentration (e.g. ug) & IV - tail vein & 1 & & No & & \\
\hline 2015 & Zhang & Single Dose of EVs & $160 u g$ & EV protein concentration (e.g. ug) & Subcutaneous & 1 & & No & & \\
\hline 2015 & Yu & Single Dose of EVs & 4e6 MSC Equivalent & $\begin{array}{l}\text { EV dose based on cell count (e.g. per weight } \\
\text { of animal) }\end{array}$ & Direct tissue injection & 1 & & No & & \\
\hline 2015 & Zhang & Single Dose of EVs & $200 u g$ & EV protein concentration (e.g. ug) & Subcutaneous & 1 & & No & & \\
\hline 2015 & Ko & Multiple Doses of EV & 2000ug & EV protein concentration (e.g. ug) & IV - Other (e.g. peripheral sites) & 2 & Day 10 and 20 & Yes & 3 & $\begin{array}{l}1000,2000 \text { and } 4000 \\
\text { ug }\end{array}$ \\
\hline 2015 & Zhang & Single Dose of EVs & 100ug & EV protein concentration (e.g. ug) & IV - tail vein & 1 & & No & & \\
\hline 2015 & Collino & Single Dose of EVs & $2.2 \mathrm{e} 8$ & $\begin{array}{c}\text { EV particle concentration (e.g. exo's/mL } \\
\text { PBS) }\end{array}$ & IV - tail vein & 1 & & No & & \\
\hline 2016 & Yu & Single Dose of EVs & $2.5 \mathrm{ug}$ & EV protein concentration (e.g. ug) & Direct tissue injection & 1 & & Yes & 6 & $0.05-10 \mathrm{ug}$ \\
\hline 2016 & Tamura & Both (Same experiment) & 10ug & EV protein concentration (e.g. ug) & IV - Other (e.g. peripheral sites) & 3 & 0,8 or $16 \mathrm{~h}$ & No & & \\
\hline 2016 & Shen & Single Dose of EVs & $200 u g$ & EV protein concentration (e.g. ug) & Direct tissue injection & 1 & & No & & \\
\hline 2016 & Zou & Single Dose of EVs & 100ug & EV protein concentration (e.g. ug) & IV - tail vein & 1 & & No & & \\
\hline 2016 & Gu & Single Dose of EVs & 100ug & EV protein concentration (e.g. ug) & IV - tail vein & 1 & & No & & \\
\hline 2016 & Nagaishi & Single Dose of EVs & $5.3 e 7$ & $\begin{array}{l}\text { EV particle concentration (e.g. exo's/mL } \\
\text { PBS) }\end{array}$ & Direct tissue injection & 1 & & No & & \\
\hline 2016 & $\mathrm{Hu}$ & Single Dose of EVs & 200 ug & EV protein concentration (e.g. ug) & IV - tail vein, Subcutaneous & 1 & & No & & \\
\hline 2016 & Lee & Single Dose of EVs & $0.2 \mathrm{mg} / \mathrm{kg}$ & EV protein / weight of animal (e.g. ug $/ \mathrm{kg})$ & Intra-arterial & 1 & & No & & \\
\hline 2016 & Xie & Single Dose of EVs & $20 u g$ & EV protein concentration (e.g. ug) & Subcutaneous & 1 & & No & & \\
\hline 2016 & Zhang & Multiple Doses of EV & 100ug & EV protein concentration (e.g. ug) & Direct tissue injection & 6,12 & $\begin{array}{l}\text { Weekly for } 6 \text { or } 12 \\
\text { weeks }\end{array}$ & No & & \\
\hline 2016 & Yin & Single Dose of EVs & 100 or 1000 ug & EV protein concentration (e.g. ug) & IV - tail vein & 1 & & No & & \\
\hline 2016 & Kalimuthu & Multiple Doses of EV & $50 u g$ & EV protein concentration (e.g. ug) & Direct tissue injection & 2 & Day 21 and 26 & No & & \\
\hline 2016 & Chen & Single Dose of EVs & 100ug & EV protein concentration (e.g. ug) & IV - Other (e.g. peripheral sites) & 1 & & No & & \\
\hline 2016 & Nakano & Multiple Doses of EV & $0.5 \mathrm{ug}$ & EV protein concentration (e.g. ug) & Intracerebroventricle & 5 & Daily for 5 days & No & & \\
\hline 2016 & Wen & Multiple Doses of EV & $10 \mathrm{mg} / \mathrm{kg}$ & EV protein / weight of animal (e.g. ug/kg) & IV - Other (e.g. peripheral sites) & 4 & $\begin{array}{l}\text { Every } 2 \text { days for } 4 \\
\text { doses }\end{array}$ & No & & \\
\hline 2016 & Liu & Multiple Doses of EV & 27 ug & EV protein concentration (e.g. ug) & IV - jugular vein & 2 & Day 6 and 9 & No & & \\
\hline 2016 & Zhang & Single Dose of EVs & $200 u g$ & EV protein concentration (e.g. ug) & Subcutaneous & 1 & & No & & \\
\hline 2016 & Zou & Single Dose of EVs & 100ug & EV protein concentration (e.g. ug) & IV - tail vein & 1 & & No & & \\
\hline 2016 & Wen & Multiple Doses of EV & $4 \mathrm{e} 9$ particles & $\begin{array}{c}\text { EV particle concentration (e.g. exo's/mL } \\
\text { PBS) }\end{array}$ & IV - tail vein & 3 & $6,24,72 \mathrm{~h}$ & No & & \\
\hline 2016 & Guo & Multiple Doses of EV & 1e11 particles & $\begin{array}{c}\text { EV particle concentration (e.g. exo's/mL } \\
\text { PBS) }\end{array}$ & IV - tail vein & 9 & $\begin{array}{l}\text { First } 3 \text { days for } 1 \text { or } 3 \\
\text { weeks }\end{array}$ & No & & \\
\hline 2016 & Nong & Single Dose of EVs & 600 ug & EV protein concentration (e.g. ug) & IV - Other (e.g. peripheral sites) & 1 & & No & & \\
\hline 2016 & Furuta & Multiple Doses of EV & 1e6 MSC Equivalent & $\begin{array}{c}\text { EV dose based on cell count (e.g. per weight } \\
\text { of animal) }\end{array}$ & Direct tissue injection & 2 & Days 1 and 8 & No & & \\
\hline 2016 & $\mathrm{Hu}$ & Multiple Doses of EV & 264e4 particles & $\begin{array}{c}\text { EV particle concentration (e.g. exo's/mL } \\
\text { PBS) }\end{array}$ & IV - Other (e.g. peripheral sites) & 3 & Day 1,3 and 5 & No & & \\
\hline 2016 & Vrijsen & Single Dose of EVs & $20 \mathrm{ug}$ & EV protein concentration (e.g. ug) & Subcutaneous & 1 & & Yes & 2 & 1,2 or 4 ug \\
\hline 2016 & $\mathrm{Li}$ & Single Dose of EVs & $800 u g$ & EV protein concentration (e.g. ug) & IV - tail vein & 1 & & No & & \\
\hline 2016 & Fang & Single Dose of EVs & Not Described & EV protein concentration (e.g. ug) & Subcutaneous & 1 & & No & & \\
\hline 2016 & Qi & Single Dose of EVs & 100 or 200 ug & EV protein concentration (e.g. ug) & Implanted (e.g. with scaffolds) & 1 & & Yes & 2 & 100 or 200 ug \\
\hline 2016 & Ophelders & Multiple Doses of EV & 2e7 MSC Equivalent & $\begin{array}{c}\text { EV dose based on cell count (e.g. per weight } \\
\text { of animal) }\end{array}$ & Intra-arterial & 2 & $1 \mathrm{~h}$ and 4 days & No & & \\
\hline 2016 & Lin & Single Dose of EVs & 100ug & EV protein concentration (e.g. ug) & IV - Other (e.g. peripheral sites) & 1 & & No & & \\
\hline 2016 & Rager & Single Dose of EVs & 2.5e9 particles & $\begin{array}{c}\begin{array}{l}\text { EV particle concentration (e.g. exo's } / \mathrm{mL} \\
\text { PBS) }\end{array} \\
\text { (a) }\end{array}$ & Intraperitoneal & 1 & & No & & \\
\hline 2016 & Aliotta & Multiple Doses of EV & 25ug & EV protein concentration (e.g. ug) & IV - tail vein & 3,4 & $\begin{array}{l}3 \text { doses (daily), or } 4 \\
\text { doses (1/week) }\end{array}$ & No & & \\
\hline 2016 & Qin & Single Dose of EVs & 100 ug & EV protein concentration (e.g. ug) & Implanted (e.g. with scaffolds) & 1 & & No & & \\
\hline 2016 & Zhang & Single Dose of EVs & 100ug & EV protein concentration (e.g. ug) & IV - tail vein & 1 & & No & & \\
\hline 2016 & Sun & Multiple Doses of EV & $400 u g$ or $800 u g$ & EV protein concentration (e.g. ug) & IV - tail vein & 7 & Daily for 7 days & Yes & 2 & 400 and 800 ug \\
\hline 2016 & Kim & Single Dose of EVs & $3.8-30$ ug & EV protein concentration (e.g. ug) & IV - tail vein & 1 & & Yes & 4 & $3.8-30 \mathrm{ug}$ \\
\hline 2016 & Liu & Multiple Doses of EV & 20ug & EV protein concentration (e.g. ug) & Intraperitoneal & 11 & $\begin{array}{l}\text { Every other day for } 20 \\
\text { days }\end{array}$ & No & & \\
\hline
\end{tabular}




\section{Supplemental File 3 - Dosage Data}

\begin{tabular}{|c|c|c|c|c|c|c|c|c|c|c|}
\hline 2016 & Wang & Multiple Doses of EV & 200ug & EV protein concentration (e.g. ug) & IV - tail vein & 2 & Day 0 and 7 & No & & \\
\hline 2016 & $\mathrm{Ti}$ & Multiple Doses of EV & $60 u g$ & EV protein concentration (e.g. ug) & Subcutaneous & 10 & Daily for 10 days & No & & \\
\hline 2016 & Shi & Multiple Doses of EV & Not Described & Not Described & Direct tissue injection & 7 & $\begin{array}{l}\text { Every } 3 \text { days until day } \\
20\end{array}$ & No & & \\
\hline 2016 & Lange & Not Described & Not Described & Not Described & Not described & 1 & & No & & \\
\hline 2017 & Fujii & Single Dose of EVs & $\begin{array}{l}\text { 2e6 MSC equivalent } \\
\text { per kg }\end{array}$ & $\begin{array}{c}\text { EV dose based on cell count (e.g. per weight } \\
\text { of animal) }\end{array}$ & IV - tail vein & 1 & & No & & \\
\hline 2017 & Cheng & Multiple Doses of EV & $1.5 \mathrm{e} 6$ & $\begin{array}{c}\text { EV particle concentration (e.g. exo's/mL } \\
\text { PBS) }\end{array}$ & Direct tissue injection & 2 & $\begin{array}{l}\text { At } 1 \text { week and } 5 \text { weeks } \\
\text { after puncture }\end{array}$ & No & & \\
\hline 2017 & Willis & Single Dose of EVs & $\begin{array}{l}0.5 \mathrm{e} 6 \mathrm{MSC} \text { over } 36 \mathrm{~h} \\
\text { equivalent }\end{array}$ & $\begin{array}{l}\text { \# of EVs made over time by cell culture } \\
\text { (MSCs) }\end{array}$ & IV - Other (e.g. peripheral sites) & 1 & & No & & \\
\hline 2017 & Zhu & Single Dose of EVs & 2e7 MSC Equivalent & $\begin{array}{l}\text { \# of EVs made over time by cell culture } \\
\text { (MSCs) }\end{array}$ & Direct tissue injection & 1 & & No & & \\
\hline 2017 & Webb & Multiple Doses of EV & $2.7 \mathrm{e} 11$ particles/kg & EV particles / weight of animal (e.g. exo's $/ \mathrm{kg}$ ) & IV - tail vein & 3 & $\begin{array}{l}\text { At } 2,14, \text { and } 38 \mathrm{~h} \text { post } \\
\text { injury }\end{array}$ & No & & \\
\hline 2017 & Wang & Single Dose of EVs & 200 ug & EV protein concentration (e.g. ug) & IV - Other (e.g. peripheral sites) & 1 & & No & & \\
\hline 2017 & Mead & Multiple Doses of EV & 3e9 particles & $\begin{array}{c}\text { EV particle concentration (e.g. exo's/mL } \\
\text { PBS) }\end{array}$ & Direct tissue injection & 3 & Day 0,7 and 14 & No & & \\
\hline 2017 & Yuan & Single Dose of EVs & 1e12 particles & $\begin{array}{l}\text { EV particle concentration (e.g. exo's/mL } \\
\text { PBS) }\end{array}$ & IV - Other (e.g. peripheral sites) & 1 & & No & & \\
\hline 2017 & Soundara Rajan & Single Dose of EVs & $24 u g$ & EV protein concentration (e.g. ug) & IV - tail vein & 1 & & No & & \\
\hline 2017 & El-Tookhy & Single Dose of EVs & 2e6 MSC equivalent & $\begin{array}{l}\text { EV dose based on cell count (e.g. per weight } \\
\text { of animal) }\end{array}$ & Subcutaneous & 1 & & No & & \\
\hline 2017 & Schoefinius & Single Dose of EVs & 1e6 MSC Equivalent & $\begin{array}{l}\text { EV dose based on cell count (e.g. per weight } \\
\text { of animal) }\end{array}$ & IV - tail vein & 1 & & No & & \\
\hline 2017 & Huang & Single Dose of EVs & 100ug & EV protein concentration (e.g. ug) & IV - tail vein & 1 & & No & & \\
\hline 2017 & Chen & Single Dose of EVs & 100 ug & EV protein concentration (e.g. ug) & IV - tail vein & 1 & & No & & \\
\hline 2017 & Zhang & Single Dose of EVs & 100ug & EV protein concentration (e.g. ug) & IV - tail vein & 1 & & No & & \\
\hline 2017 & Stone & Single Dose of EVs & $1 \mathrm{e} 6$ & $\begin{array}{c}\text { EV particle concentration (e.g. exo's } / \mathrm{mL} \\
\text { PBS) }\end{array}$ & Intratracheal & 1 & & No & & \\
\hline 2017 & Horn & Multiple Doses of EV & $\begin{array}{l}\text { 1e8 MSC Equivalent } \\
\text { per kg }\end{array}$ & $\begin{array}{l}\text { EV dose based on cell count (e.g. per weight } \\
\text { of animal) }\end{array}$ & Intraperitoneal & 2 & $\begin{array}{l}3 \mathrm{~h} \text { before and } 24 \mathrm{~h} \text { after } \\
\text { injury }\end{array}$ & No & & \\
\hline 2017 & Cosenza & Single Dose of EVs & $\begin{array}{l}0.5 \text { ug MVs or } 0.25 u g \\
\text { Exos }\end{array}$ & EV protein concentration (e.g. ug) & Direct tissue injection & 1 & & No & & \\
\hline 2017 & Shi & Multiple Doses of EV & 150ug & EV protein concentration (e.g. ug) & Implanted (e.g. with scaffolds) & 3,6 & $\begin{array}{l}\text { Every } 3 \text { days for } 1 \text { week } \\
\text { or } 2 \text { weeks }\end{array}$ & No & & \\
\hline 2017 & Rajendran & Multiple Doses of EV & 200ug & EV protein concentration (e.g. ug) & Subcutaneous & 15 & Every 2 days for 28 days & No & & \\
\hline 2017 & Bruno & Single Dose of EVs & $1.65 \mathrm{e} 8$ & $\begin{array}{c}\text { EV particle concentration (e.g. exo's/mL } \\
\text { PBS) }\end{array}$ & IV - Other (e.g. peripheral sites) & 1 & & No & & \\
\hline 2017 & Aliotta & Multiple Doses of EV & $25 u g$ & EV protein concentration (e.g. ug) & IV - tail vein & 3 & Daily for 3 days & No & & \\
\hline 2017 & Komaki & Multiple Doses of EV & $2.2 \mathrm{ug} / \mathrm{dose}$ & EV protein concentration (e.g. ug) & Subcutaneous & 2 & Daily for 2 days & No & & \\
\hline 2017 & Li & Not Described & $1000 \mathrm{ug} / \mathrm{mL}$ & EV protein concentration (e.g. ug) & Intracerebral & 1 & & Yes & 4 & 100 to $1000 \mathrm{ug} / \mathrm{mL}$ \\
\hline 2017 & Gangadaran & Multiple Doses of EV & 100ug & EV protein concentration (e.g. ug) & Intramuscular (IM) & 6 & $\begin{array}{l}\text { twice a week for } 3 \\
\text { weeks }\end{array}$ & No & & \\
\hline 2017 & Deng & Single Dose of EVs & 200 ug & EV protein concentration (e.g. ug) & Intracerebroventricle & 1 & & No & & \\
\hline 2017 & Bai & Multiple Doses of EV & $50 u g$ & EV protein concentration (e.g. ug) & Direct tissue injection & 7 & Daily for 7 days & Yes & 4 & $10-100$ ug \\
\hline 2017 & Sun & Single Dose of EVs & $100 u g$ & EV protein concentration (e.g. ug) & IV - Other (e.g. peripheral sites) & 1 & & No & & \\
\hline 2017 & Gong & Single Dose of EVs & 100ug & EV protein concentration (e.g. ug) & Subcutaneous & 1 & & No & & \\
\hline 2017 & Qu & Multiple Doses of EV & 40ug & EV protein concentration (e.g. ug) & Intrasplenic & 16 & $\begin{array}{l}\text { Twice per week for } 8 \\
\text { weeks }\end{array}$ & No & & \\
\hline 2017 & Casado & Single Dose of EVs & $500 u g$ & EV protein concentration (e.g. ug) & Direct tissue injection & 1 & & No & & \\
\hline 2017 & Xie & Single Dose of EVs & 20 ug & EV protein concentration (e.g. ug) & Implanted (e.g. with scaffolds) & 1 & & No & & \\
\hline 2017 & Otero-Ortega & Single Dose of EVs & 100ug & EV protein concentration (e.g. ug) & IV - tail vein & 1 & & No & & \\
\hline 2017 & Wang & Single Dose of EVs & Not Described & Not Described & IV - tail vein & 1 & & No & & \\
\hline 2017 & Haga & Single Dose of EVs & $2 \mathrm{e} 8$ to $2 \mathrm{e} 10$ & $\begin{array}{l}\text { EV particle concentration (e.g. exo's/mL } \\
\text { PBS) }\end{array}$ & $\begin{array}{c}\text { IV - Other (e.g. peripheral sites), } \\
\text { Intraperitoneal }\end{array}$ & 1 & & Yes & 2 & $\begin{array}{l}\text { 2e9 or } 2 \mathrm{e} 10 \text { particles, } \\
\text { IP (Fig 3D) }\end{array}$ \\
\hline 2017 & $\mathrm{Ma}$ & Single Dose of EVs & 400ug & EV protein concentration (e.g. ug) & IV - tail vein & 1 & & No & & \\
\hline 2017 & Wang & Multiple Doses of EV & Not Described & EV protein concentration (e.g. ug) & Direct tissue injection & 10 & $\begin{array}{l}\text { Every } 3 \text { days for } 4 \\
\text { weeks }\end{array}$ & No & & \\
\hline 2017 & Long & Multiple Doses of EV & 15ug per dose & EV protein concentration (e.g. ug) & IV - tail vein, Intranasal & 2 & 2 doses in $18 \mathrm{~h}$ & No & & \\
\hline 2017 & $\mathrm{Li}$ & Single Dose of EVs & $40 u g$ & EV protein concentration (e.g. ug) & Direct tissue injection & 1 & & No & & \\
\hline 2017 & Eirin & Single Dose of EVs & Not Described & 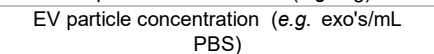 & Direct tissue injection & 1 & & No & & \\
\hline 2017 & de Castro & Single Dose of EVs & 1e5 MSC Equivalent & EV protein concentration (e.g. ug) & IV - jugular vein & 1 & & No & & \\
\hline
\end{tabular}




\section{Supplemental File 3 - Dosage Data}

\begin{tabular}{|c|c|c|c|c|c|c|c|c|c|c|}
\hline 2017 & Tang & Single Dose of EVs & Not Described & $\begin{array}{l}\text { \# of EVs made over time by cell culture } \\
\text { (MSCs) }\end{array}$ & Intratracheal & 1 & & No & & \\
\hline 2017 & Gonzalez-King & Single Dose of EVs & $1.5 \mathrm{ug}$ & EV protein concentration (e.g. ug) & Subcutaneous & 1 & & No & & \\
\hline & & & & EV particle concentration (e.g. exo's/mL & & & & & & \\
\hline 2017 & Haga & Single Dose of EVs & $2 \mathrm{e} 10$ & PBS) & IV - tail vein & 1 & & No & & \\
\hline 2017 & Mao & Multiple Doses of EV & 400ug & EV protein concentration (e.g. ug) & IV - tail vein & 3 & Days 3,6 and 9 & No & & \\
\hline 2017 & $\begin{array}{l}\text { Shigemoto- } \\
\text { Kuroda }\end{array}$ & Both (Separate experiments) & 3ug or 30ug & EV protein concentration (e.q. uq) & IV - tail vein & 2 & Day 0 and 4 & Yes & 2 & 3 or 30 ug (Fig 1 ) \\
\hline 2017 & Du & Single Dose of EVs & $100 \mathrm{ug}$ & EV protein concentration (e.g. ug) & Intramuscular (IM) & 1 & Say dirut 7 & No & 2 & 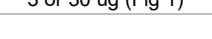 \\
\hline 2017 & Chen & Single Dose of EVs & Not Described & EV protein concentration (e.g. ug) & IV - tail vein & 1 & & No & & \\
\hline 2017 & Song & Single Dose of EVs & $30 u g$ & EV protein concentration (e.g. ug) & IV - tail vein & 1 & & No & & \\
\hline 2017 & Moisseiev & Single Dose of EVs & $20 u g$ & EV protein concentration (e.g. ug) & Direct tissue injection & 1 & & No & & \\
\hline 2017 & Liu & Single Dose of EVs & 5 ug & EV protein concentration (e.g. ug) & Direct tissue injection & 1 & & No & & \\
\hline 2017 & Zhu & Multiple Doses of EV & $8 \mathrm{e} 7$ particles & $\begin{array}{c}\text { EV particle concentration (e.g. exo's/mL } \\
\text { PBS) }\end{array}$ & Direct tissue injection & 3 & Days $7,14,21$ & No & & \\
\hline 2017 & Xin & Single Dose of EVs & 3e11 particles & $\begin{array}{l}\text { EV particle concentration (e.g. exo's/mL } \\
\text { PBS) }\end{array}$ & Intra-arterial & 1 & & No & & \\
\hline 2017 & Yan & Single Dose of EVs & $32 \mathrm{mg} / \mathrm{kg}$ & EV protein / weight of animal (e.g. ug/kg) & IV - tail vein, Oral Gavage & 1 & & Yes & 3 & 8,16 or $32 \mathrm{mg} / \mathrm{kg}$ \\
\hline 2017 & Tao & Multiple Doses of EV & 1e10 & $\begin{array}{l}\text { EV particle concentration (e.g. exo's/mL } \\
\text { PBS) }\end{array}$ & Direct tissue injection & 4 & $\begin{array}{l}\text { Once a week for } 4 \\
\text { weeks }\end{array}$ & No & & \\
\hline 2017 & Liu & Multiple Doses of EV & $1 \mathrm{e} 9$ or $1 \mathrm{e} 10$ particles & $\begin{array}{c}\text { EV particle concentration (e.g. exo's/mL } \\
\text { PBS) }\end{array}$ & IV - tail vein & 9 & 3 per week for 3 weeks & Yes & 2 & $1 \mathrm{e} 9$ or $1 \mathrm{e} 10$ particles \\
\hline 2017 & Kamerkar & Multiple Doses of EV & $1 \mathrm{e} 8$ particles & $\begin{array}{c}\begin{array}{c}\text { EV particle concentration (e.g. exo's/mL } \\
\text { PBS) }\end{array} \\
\text { (a) }\end{array}$ & Intraperitoneal & 1 & Dosed every other day & No & & \\
\hline 2017 & Du & Single Dose of EVs & $2.5 \mathrm{e} 12$ & $\begin{array}{c}\text { EV particle concentration (e.g. exo's/mL } \\
\text { PBS) }\end{array}$ & IV - Other (e.g. peripheral sites) & 1 & & No & & \\
\hline 2017 & Wang & Single Dose of EVs & $200 u g$ & EV protein concentration (e.g. ug) & Direct tissue injection & 1 & & No & & \\
\hline 2017 & Zhao & Single Dose of EVs & $2.5,5$ or 10 ug & EV protein concentration (e.g. ug) & Subcutaneous & 1 & & Yes & 3 & $2.5,5$ or 10 ug \\
\hline 2017 & Shao & Single Dose of EVs & 20 ug & EV protein concentration (e.g. ug) & Direct tissue injection & 1 & & No & 型 & 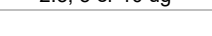 \\
\hline 2017 & Tao & Single Dose of EVs & Not Described & Not Described & Subcutaneous & 1 & & No & & \\
\hline 2017 & Huang & Single Dose of EVs & 50 or 100 ug & EV protein concentration (e.g. ug) & Subcutaneous & 1 & & Yes & 2 & 50 or 100 ug \\
\hline 2017 & Tamura & Single Dose of EVs & 10ug & EV protein concentration (e.g. ug) & IV - tail vein & 1 & & No & & \\
\hline 2017 & $\begin{array}{l}\text { Grigorian- } \\
\text { Shamagian }\end{array}$ & Multiple Doses of EV & 1000ug & EV protein concentration (e.g. ug) & Intraperitoneal & 2 & Day 0 and 2 weeks; & No & & \\
\hline 2017 & Ranghino & Single Dose of EVs & 4e8 particles & $\begin{array}{l}\text { \# of EVs made over time by cell culture } \\
\text { (MSCs) }\end{array}$ & IV - tail vein & 1 & & No & & \\
\hline 2017 & Cui & Single Dose of EVs & $400 u g$ & EV protein concentration (e.g. ug) & IV - tail vein & 1 & & No & & \\
\hline & & & & EV particle concentration (e.g. exo's/mL & & & & & & \\
\hline 2017 & $\begin{array}{l}\text { Henao Agudelo } \\
\text { Xin }\end{array}$ & Multiple Doses of EV & $8.38 \mathrm{e} 9$ & 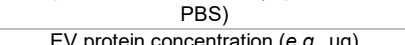 & $\begin{array}{c}\text { Intraperitoneal } \\
\text { IV - Oter (e } g \text { perinhera sites) }\end{array}$ & 4 & $0,24,48$ and $72 \mathrm{~h}$ & No & & \\
\hline 2017 & Xin & Single Dose of EVs & $\begin{array}{c}100 \text { ug } \\
5 \text { ug (matrigel) or } 1 \text { ug }\end{array}$ & EV protein concentration (e.g. ug) & IV - Other (e.g. peripheral sites) & 1 & & No & & \\
\hline 2017 & Lo Sicco & Both (Separate experiments) & $\begin{array}{l}\text { 5ug (matrigel) or 1ug } \\
\text { (direct, } 2 \text { doses) }\end{array}$ & EV protein concentration (e.g. ug) & Intramuscular (IM) & 2 & $2 \mathrm{~h}$ and day 4 & No & & \\
\hline 2017 & de Almeida & Multiple Doses of EV & 100ug & EV protein concentration (e.g. ug) & IV - Other (e.g. peripheral sites) & 2 & Days 1 and 3 & No & & \\
\hline 2018 & Luther & Single Dose of EVs & $0.5 \mathrm{ug} / \mathrm{g}$ & EV protein / weight of animal (e.g. ug/kg) & Direct tissue injection & 1 & & No & & \\
\hline 2018 & Williams & Multiple Doses of EV & 1e13 particles & $\begin{array}{c}\text { EV particle concentration (e.g. exo's } / \mathrm{mL} \\
\text { PBS) }\end{array}$ & IV - Other (e.g. peripheral sites) & 5 & $\begin{array}{l}\text { 9h post injury, and post- } \\
\text { injury days } 1,5,9,13\end{array}$ & No & & \\
\hline 2018 & McCulloh & Single Dose of EVs & $4 \mathrm{e} 8$ & $\begin{array}{c}\text { EV particle concentration (e.g. exo's } / \mathrm{mL} \\
\text { PBS) }\end{array}$ & Intraperitoneal & 1 & & Yes & 6 & 1.3e 5 to $4 \mathrm{e} 8$ particles \\
\hline 2018 & Zhang & Multiple Doses of EV & 1 or $10 \mathrm{ug}$ & EV protein concentration (e.g. ug) & Intraperitoneal & 12 & Every 3 days & Yes & 2 & 1ug and 10ug \\
\hline 2018 & Barile & Single Dose of EVs & 10e11 particles & $\begin{array}{c}\begin{array}{l}\text { EV particle concentration (e.g. exo's/mL } \\
\text { PBS) }\end{array} \\
\text { (a) }\end{array}$ & Direct tissue injection & 1 & & No & & \\
\hline 2018 & Otero-Ortega & Single Dose of EVs & $100 \mathrm{ug}$ & EV protein concentration (e.g. ug) & IV - tail vein & 1 & & No & & \\
\hline 2018 & Ahn & Single Dose of EVs & $20 u g$ & EV protein concentration (e.g. ug) & Intratracheal & 1 & & No & & \\
\hline 2018 & Jiang & Single Dose of EVs & $\begin{array}{l}\text { Variable }(6.4 \mathrm{e} 9 \\
\text { particles to } 2.4 \mathrm{e} 11 \\
\text { particles/kg) }\end{array}$ & $\begin{array}{l}\text { EV particle concentration (e.g. exo's } / \mathrm{mL} \\
\text { PBS), EV particles / weight of animal (e.g. } \\
\text { exo's } / \mathrm{kg} \text { ) }\end{array}$ & IV - tail vein & 1 & & Yes & 3 & $6 \mathrm{e} 10 / \mathrm{kg}$ to $2.4 \mathrm{e} 11 / \mathrm{kg}$ \\
\hline 2018 & Diomede & Single Dose of EVs & 100uL & Not Described & Implanted (e.g. with scaffolds) & 1 & & No & & \\
\hline 2018 & $\mathrm{He}$ & Single Dose of EVs & $\begin{array}{l}\text { 0.05ug, 0.1ug or } \\
0.15 \text { ug }\end{array}$ & EV protein concentration (e.g. ug) & Direct tissue injection & 1 & & Yes & 3 & $\begin{array}{l}\text { 0.05ug, 0.1ug or } \\
0.15 \text { ug }\end{array}$ \\
\hline 2018 & Blazquez & Single Dose of EVs & $4000 u g$ & EV protein concentration (e.g. ug) & Implanted (e.g. with scaffolds) & 1 & & No & & \\
\hline 2018 & Shen & Single Dose of EVs & 100ug & EV protein concentration (e.g. ug) & IV - tail vein & 1 & & No & & \\
\hline 2018 & Lang & Multiple Doses of EV & 10e10 particles & $\begin{array}{c}\text { EV particle concentration (e.g. exo's } / \mathrm{mL} \\
\text { PBS) }\end{array}$ & Intra-arterial, Intraperitoneal & $\begin{array}{l}\text { Up to } 56 \\
\text { doses }\end{array}$ & $\begin{array}{l}\text { Every other day up to } \\
110 \text { days, also Day } 14 \\
\text { and day } 21\end{array}$ & No & & \\
\hline 2018 & Wang & Single Dose of EVs & $400 u g$ & EV protein concentration (e.g. ug) & IV - tail vein & 1 & & No & & \\
\hline
\end{tabular}




\section{Supplemental File 3 - Dosage Data}

\begin{tabular}{|c|c|c|c|c|c|c|c|c|c|c|}
\hline 2018 & Cui & Multiple Doses of EV & 150ug & EV protein concentration (e.g. ug) & IV - Other (e.g. peripheral sites) & 9 & Bi-weekly for 4 months & No & & \\
\hline 2018 & Damania & Single Dose of EVs & $50 u g$ & EV protein concentration (e.g. ug) & IV - Other (e.g. peripheral sites) & 1 & & No & & \\
\hline 2018 & $\mathrm{Li}$ & Single Dose of EVs & 250 ug & EV protein concentration (e.g. ug) & Implanted (e.g. with scaffolds) & 1 & & No & & \\
\hline 2018 & Zhu & Single Dose of EVs & 10 or $100 \mathrm{ug}$ & EV protein concentration (e.g. ug) & Direct tissue injection & 1 & & Yes & 2 & 10ug or $100 \mathrm{ug}$ \\
\hline 2018 & Khatri & Single Dose of EVs & $80 \mathrm{ug} / \mathrm{kg}$ & EV protein / weight of animal (e.g. ug $/ \mathrm{kg})$ & Intratracheal & 1 & & No & & \\
\hline 2018 & Mead & Both (Same experiment) & 3e9 particles & $\begin{array}{l}\text { EV particle concentration (e.g. exo's/mL } \\
\text { PBS) }\end{array}$ & Direct tissue injection & $2,3,8$ & single, weekly, monthly & No & & \\
\hline 2018 & Wang & Multiple Doses of EV & 100ug & EV protein concentration (e.g. ug) & Intracerebroventricle & 8 & $\begin{array}{l}\text { every } 2 \text { days for } 2 \\
\text { weeks }\end{array}$ & No & & \\
\hline & & & & $\begin{array}{l}\text { EV particle concentration (e.g. exo's } / \mathrm{mL} \\
\mathrm{PBS} \text { ) }\end{array}$ & & & Once a week for 4 & & & \\
\hline $\begin{array}{l}2018 \\
2018\end{array}$ & $\begin{array}{c}\text { Otsuru } \\
\text { Wu }\end{array}$ & $\begin{array}{l}\text { Multiple Doses of EV } \\
\text { Single Dose of EVs }\end{array}$ & $\begin{array}{l}\text { 8.88e8 particles } \\
\text { 100ug }\end{array}$ & $\begin{array}{c}\text { PBS) } \\
\text { EV protein concentration (e.g. ug) }\end{array}$ & $\begin{array}{l}\text { IV - tail vein } \\
\text { IV - tail vein }\end{array}$ & $\begin{array}{l}4 \\
1\end{array}$ & $\begin{array}{l}\text { weeks } \\
\text {. }\end{array}$ & $\begin{array}{l}\text { No } \\
\text { No }\end{array}$ & & \\
\hline 2018 & Potter & Single Dose of EVs & 30 ug & EV protein concentration (e.g. ug) & Intra-arterial & 1 & & No & & \\
\hline 2018 & Ruppert & Single Dose of EVs & 1e9 particles & $\begin{array}{l}\text { EV particle concentration (e.g. exo's/mL } \\
\text { PBS) }\end{array}$ & IV - tail vein & 1 & & No & & \\
\hline 2018 & Han & Multiple Doses of EV & 50ug & EV protein concentration (e.g. ug) & Direct tissue injection & $2,4,6,8$ & $\begin{array}{l}\text { every week for } 2,4,6 \\
\text { or } 8 \text { weeks }\end{array}$ & No & & \\
\hline 2018 & Chen & Multiple Doses of EV & Not Described & Not Described & Intraperitoneal & 3 & $\begin{array}{l}\text { once per week for } 3 \\
\text { weeks }\end{array}$ & No & & \\
\hline 2018 & Mardpour & Single Dose of EVs & 350 ug & EV protein concentration (e.g. ug) & Direct tissue injection & 1 & & No & & \\
\hline 2018 & O'Brien & Multiple Doses of EV & $2.6 \mathrm{e} 7$ & $\begin{array}{l}\text { EV particle concentration (e.g. exo's } / \mathrm{mL} \\
\text { PBS) }\end{array}$ & IV - tail vein & 4 & Days 036 and 9 & No & & \\
\hline 2018 & Chang & Single Dose of EVs & 100ug & EV protein concentration (e.g. ug) & IV - Other (e.g. peripheral sites) & 1 & Days $0,3,0$ aliu $y$ & No & & \\
\hline 2018 & Tian & Single Dose of EVs & 10ug & EV protein concentration (e.g. ug) & Implanted (e.g. with scaffolds) & 1 & & No & & \\
\hline 2018 & Kou & Single Dose of EVs & 40 ug or 200 ug & EV protein concentration (e.g. ug) & Subcutaneous, Submucosal & 1 & & No & & \\
\hline 2018 & Chen & Single Dose of EVs & 200ug & EV protein concentration (e.g. ug) & Subcutaneous & 1 & & No & & \\
\hline 2018 & Jia & Single Dose of EVs & 200 ug & EV protein concentration (e.g. ug) & Direct tissue injection & 1 & & No & & \\
\hline 2018 & Cosenza & Multiple Doses of EV & $0.25 \mathrm{ug}$ & EV protein concentration (e.g. ug) & IV - Other (e.g. peripheral sites) & 2 & Days 18 and 24 & Yes & 3 & $\begin{array}{c}0.062,0.125 \text { and } 0.25 \\
\text { ug }\end{array}$ \\
\hline
\end{tabular}




\section{Supplemental File 4 - MSC-EV Modifications}

\begin{tabular}{|c|c|c|c|c|c|c|c|c|c|c|c|c|c|c|c|}
\hline Year & $\begin{array}{r}\begin{array}{r}\text { First } \\
\text { Author's } \\
\text { Last Name }\end{array} \\
\text { Last }\end{array}$ & Disease Model//njury & $\frac{\text { General Type of }}{\text { Modification }}$ & $\frac{\text { Specific Type of }}{\text { Modification }}$ & $\begin{array}{l}\text { Biological } \\
\text { Factor/Target }\end{array}$ & Specific Factor & $\begin{array}{l}\frac{\text { Reduced or }}{\text { Enhanced }} \\
\text { Expression }\end{array}$ & $\frac{\text { Mechanism of }}{\text { Action \#1 }}$ & $\frac{\text { Mechanism of }}{\text { Action \#2 }}$ & $-\frac{\text { Mechanism of }}{\text { Action \#3 }}$ & $\frac{\text { Mechanism of }}{\text { Action \#4 }}$ & $\begin{array}{l}\text { Reason for } \\
\text { modification }\end{array}$ & $\begin{array}{c}\frac{\text { Did modified }}{\text { (enhanced) EVs }} \\
\text { outperform } \\
\text { unmodified EVs? }\end{array}$ & $\begin{array}{c}\frac{\text { Did the }}{\text { modified }} \\
\text { (enhanced) EVs } \\
\frac{\text { improve organ }}{\text { function? }}\end{array}$ & $\frac{\frac{\text { Did the modified }}{\text { (enhanced) EVs }}}{\text { improve }}$ \\
\hline 2009a & Bruno & $\begin{array}{l}\text { Kidney, Acute Kidney } \\
\text { Injury }\end{array}$ & Modified (EVs directly) & $\begin{array}{c}\mathrm{EV} \\
\text { preconditioning }\end{array}$ & Enzyme & RNAse & N/A & Apoptosis & Proliferation & & & $\begin{array}{l}\text { Mechanism of } \\
\text { action }\end{array}$ & N/A & $\mathrm{N} / \mathrm{A}$ & $\mathrm{N} / \mathrm{A}$ \\
\hline $2009 \mathrm{~b}$ & Bruno & $\begin{array}{l}\text { Kidney, Acute Kidney } \\
\text { Injury }\end{array}$ & Modified (EVs directly) & $\begin{array}{c}\mathrm{EV} \\
\text { preconditioning }\end{array}$ & Enzyme & Trypsin & N/A & $\begin{array}{l}\text { EV incorporation } \\
\text { into target cells }\end{array}$ & & & & $\begin{array}{l}\text { Mechanism of } \\
\text { action }\end{array}$ & N/A & N/A & N/A \\
\hline $2009 c$ & Bruno & $\begin{array}{l}\text { Kidney, Acute Kidney } \\
\text { Injury }\end{array}$ & Modified (EVs directly) & $\begin{array}{l}\mathrm{EV} \\
\text { preconditioning }\end{array}$ & Chemical & $\begin{array}{c}\text { sHA (soluble } \\
\text { hyaluronic acid) }\end{array}$ & N/A & $\begin{array}{l}\text { EV incorporation } \\
\text { into target cells }\end{array}$ & & & & $\begin{array}{l}\text { Mechanism of } \\
\text { action }\end{array}$ & N/A & N/A & N/A \\
\hline 2011 & Chen & $\begin{array}{l}\text { Heart, Myocardial } \\
\text { infarction (ischemia- } \\
\text { reperfusion) }\end{array}$ & $\begin{array}{l}\text { Modified (MSCs before } \\
\text { EV isolation) }\end{array}$ & $\begin{array}{c}\text { MSC } \\
\text { transduction }\end{array}$ & Protein & MYC & Overexpression & Immortal cell line & & & & Enhnacement & No comparison & $\mathrm{N} / \mathrm{A}$ & N/A \\
\hline 2011 & Gatti & $\begin{array}{l}\text { Kidney, Ischemic / } \\
\text { Reperfusion, Acute } \\
\text { Kidney Injury, Chronic } \\
\text { Kidney Disease, } \\
\text { Nephrectomy }\end{array}$ & Modified (EVs directly) & $\begin{array}{c}E V \\
\text { preconditioning }\end{array}$ & Enzyme & RNAse & N/A & Apoptosis & Proliferation & & & $\begin{array}{l}\text { Mechanism of } \\
\text { action }\end{array}$ & N/A & N/A & N/A \\
\hline 2012 & Reis & $\begin{array}{l}\text { Kidney, Acute Kidney } \\
\text { Injury }\end{array}$ & Modified (EVs directly) & $\begin{array}{c}\text { EV } \\
\text { preconditioning }\end{array}$ & Enzyme & RNAse & $\mathrm{N} / \mathrm{A}$ & Necrosis & Proliferation & Apoptosis & & $\begin{array}{l}\text { Mechanism of } \\
\text { action }\end{array}$ & N/A & N/A & N/A \\
\hline 2012 & Zhang & $\begin{array}{l}\text { Ischemia (e.g. testing } \\
\text { angiogenesis) }\end{array}$ & $\begin{array}{l}\text { Modified (MSCs before } \\
\text { EV isolation) }\end{array}$ & $\begin{array}{c}\text { MSC } \\
\text { preconditioning }\end{array}$ & Hypoxia & $1 \% 02$ & $\mathrm{~N} / \mathrm{A}$ & EV secretion & N/A & N/A & & Enhancement & No comparison & N/A & N/A \\
\hline 2012 & Bruno & $\begin{array}{l}\text { Kidney, Acute Kidney } \\
\text { Injury, Nephrotoxicity }\end{array}$ & Modified (EVs directly) & $\begin{array}{c}\mathrm{EV} \\
\text { preconditioning }\end{array}$ & Enzyme & RNAse & N/A & Apoptosis & Proliferation & & & $\begin{array}{l}\text { Mechanism of } \\
\text { action }\end{array}$ & N/A & N/A & N/A \\
\hline 2013 & Kilpinen & $\begin{array}{l}\text { Kidney, Ischemic / } \\
\text { Reperfusion, Acute } \\
\text { Kidney Injury }\end{array}$ & $\begin{array}{l}\text { Modified (MSCs before } \\
\text { EV isolation) }\end{array}$ & $\begin{array}{c}\text { MSC } \\
\text { preconditioning }\end{array}$ & $\begin{array}{l}\text { Inflammatory } \\
\text { cytokine }\end{array}$ & IFN-y & N/A & Inflammation & & & & Enhancement & $\begin{array}{c}\text { Modified < } \\
\text { unmodified for most } \\
\text { In Vivo outcomes }\end{array}$ & Worse & N/A \\
\hline 2013 & Katakowski & Cancer & $\begin{array}{l}\text { Modified (MSCs before } \\
\text { EV isolation) }\end{array}$ & MSC transfection & miRNA & miR-146b & Overexpression & Tumorigenesis & & & & Enhancement & $\begin{array}{l}\text { All In Vivo } \\
\text { outcomes }\end{array}$ & Yes & N/A \\
\hline 2013 & Roccaro & Cancer & $\begin{array}{l}\text { Modified (MSCs before } \\
\text { EV isolation), Modified } \\
\text { (EVs directly) }\end{array}$ & $\begin{array}{l}\text { MSCs derived } \\
\text { from cancer } \\
\text { patients + Co- } \\
\text { treatment }\end{array}$ & Cancer + Cells & $\begin{array}{l}\text { Multiple myeloma } \\
\text { cells co-treated; } \\
\text { MSCs from MM } \\
\text { patients }\end{array}$ & N/A & Tumorigenesis & & & & $\begin{array}{l}\text { Mechanism of } \\
\text { action }\end{array}$ & N/A & N/A & N/A \\
\hline 2014a & Raisi & Nerve & $\begin{array}{l}\text { Modified (MSCs before } \\
\text { EV isolation), Modified } \\
\text { (EVs directly) }\end{array}$ & $\begin{array}{c}\text { MSC } \\
\text { preconditioning + } \\
\text { EV } \\
\text { Preconditioning }\end{array}$ & $\begin{array}{l}\text { Scaffold } \\
\text { (conduit) + } \\
\text { Endotoxin }\end{array}$ & $\begin{array}{l}\text { LPS (pro- } \\
\text { inflammatory) }\end{array}$ & N/A & N/A & & & & Enhancement & $\begin{array}{c}\text { Modified }< \\
\text { unmodified for most } \\
\text { In Vivo outcomes }\end{array}$ & Worse & N/A \\
\hline $2014 b$ & Raisi & Nerve & $\begin{array}{l}\text { Modified (MSCs before } \\
\text { EV isolation), Modified } \\
\text { (EVs directly) }\end{array}$ & $\begin{array}{c}\text { MSC } \\
\text { preconditioning + } \\
\text { EV } \\
\text { Preconditioning }\end{array}$ & $\begin{array}{l}\text { Scaffold } \\
\text { (conduit) + } \\
\text { Inflammatory } \\
\text { Cytokine }\end{array}$ & $\begin{array}{l}\text { Polyl:C (anti- } \\
\text { inflammatory) }\end{array}$ & N/A & Inflammation & Regeneration & & & Enhancement & $\begin{array}{l}\text { Some In Vivo } \\
\text { outcomes }\end{array}$ & No & N/A \\
\hline 2014a & Feng & $\begin{array}{c}\text { Heart, Myocardial } \\
\text { Infarction (permanent } \\
\text { ligation) }\end{array}$ & $\begin{array}{l}\text { Modified (MSCs before } \\
\text { EV isolation) }\end{array}$ & $\begin{array}{c}\text { MSC } \\
\text { preconditioning }\end{array}$ & Hypoxia & $\begin{array}{l}\text { Anoxia/reoxygenation } \\
\text { cycles }\end{array}$ & N/A & Cell survival & Fibrosis & & & Enhancement & $\begin{array}{l}\text { All In Vivo } \\
\text { outcomes }\end{array}$ & N/A & N/A \\
\hline $2014 b$ & Feng & $\begin{array}{l}\text { Heart, Myocardial } \\
\text { Infarction (permanent } \\
\text { ligation) }\end{array}$ & $\begin{array}{l}\text { Modified (MSCs before } \\
\text { EV isolation) }\end{array}$ & $\begin{array}{c}\text { MSC } \\
\text { preconditioning + } \\
\text { MSC transfection }\end{array}$ & $\underset{\text { miRNA }}{\text { Hypoxia + }}$ & $\begin{array}{l}\text { Anoxia/reoxygenation } \\
\text { cycles + miR-22 } \\
\text { inhibitor }\end{array}$ & Knockdown & Cell survival & Fibrosis & & & $\begin{array}{l}\text { Mechanism of } \\
\text { action }\end{array}$ & N/A & N/A & N/A \\
\hline $2014 a$ & Zhu & Lung, Acute Lung Injury & $\begin{array}{l}\text { Modified (MSCs before } \\
\text { EV isolation) }\end{array}$ & MSC transfection & protein & KGF siRNA & Knockdown & Inflammation & & & & $\begin{array}{l}\text { Mechanism of } \\
\text { action }\end{array}$ & N/A & N/A & N/A \\
\hline 2014b & Zhu & Lung, Acute Lung Injury & $\begin{array}{l}\text { Modified (MSCs before } \\
\text { EV isolation) }\end{array}$ & Co-treatment & Protein & $\begin{array}{l}\text { anti-KGF neutralizing } \\
\text { antibody }\end{array}$ & $\begin{array}{c}\text { Inhibitor / } \\
\text { Neutraliznig AB }\end{array}$ & Inflammation & & & & $\begin{array}{l}\text { Mechanism of } \\
\text { action }\end{array}$ & N/A & N/A & N/A \\
\hline 2014 & $\mathrm{Du}$ & Cancer & Modified (EVs directly) & $\begin{array}{c}\text { EV } \\
\text { preconditioning }\end{array}$ & Enzyme & RNAse & $\mathrm{N} / \mathrm{A}$ & Tumorigenesis & & & & $\begin{array}{l}\text { Mechanism of } \\
\text { action }\end{array}$ & N/A & N/A & N/A \\
\hline 2014 & Choi & $\begin{array}{l}\text { Kidney, Ischemic / } \\
\text { Reperfusion, Acute } \\
\text { Kidney Injury }\end{array}$ & Modified (EVs directly) & $\begin{array}{c}\text { EV } \\
\text { preconditioning }\end{array}$ & Enzyme & RNAse & N/A & Angiogenesis & apoptosis & Proliferation & & $\begin{array}{l}\text { Mechanism of } \\
\text { action }\end{array}$ & N/A & N/A & N/A \\
\hline 2014 & Bian & $\begin{array}{l}\text { Heart, Myocardial } \\
\text { Infarction (permanent } \\
\text { ligation) }\end{array}$ & $\begin{array}{l}\text { Modified (MSCs before } \\
\text { EV isolation) }\end{array}$ & $\begin{array}{c}\text { MSC } \\
\text { preconditioning }\end{array}$ & Hypoxia & $1 \% O 2$ & N/A & N/A & N/A & $\mathrm{N} / \mathrm{A}$ & & N/A & No comparison & N/A & N/A \\
\hline 2015a & Lou & Cancer & $\begin{array}{l}\text { Co-injected (e.g. EV + } \\
\text { MSCs into animals), } \\
\text { Modified (MSCs before } \\
\text { EV isolation) }\end{array}$ & $\begin{array}{c}\text { MSC transfection } \\
+ \text { co-treatment }\end{array}$ & $\begin{array}{c}\text { miRNA + } \\
\text { chemotherapeuti } \\
c\end{array}$ & $\begin{array}{l}\text { hsa-miR-122 + } \\
\text { sorafenib }\end{array}$ & Overexpression & Chemosensitivity & Tumorigenesis & & & Enhancement & $\begin{array}{l}\text { All In Vivo } \\
\text { outcomes }\end{array}$ & Yes & N/A \\
\hline
\end{tabular}


Supplemental File 4 - MSC-EV Modifications

\begin{tabular}{|c|c|c|c|c|c|c|c|c|c|c|c|c|c|c|}
\hline $2015 b$ & Lou & Cancer & $\begin{array}{l}\text { Co-injected (e.g. EV + } \\
\text { MSCs into animals), } \\
\text { Modified (MSCs before } \\
\text { EV isolation) }\end{array}$ & MSC transfection & miRNA & has-miR-122 & Overexpression & Tumorigenesis & & & Enhancement & No difference & No & N/A \\
\hline $2015 a$ & Monsel & Lung, Acute Lung Injury & $\begin{array}{l}\text { Modified (MSCs before } \\
\text { EV isolation) }\end{array}$ & Co-treatment & Protein & $\begin{array}{l}\text { KGF neutralizing } \\
\text { antibody }\end{array}$ & $\begin{array}{c}\text { Inhibitor / } \\
\text { Neutraliznig AB }\end{array}$ & $\begin{array}{l}\text { No specific } \\
\text { mechanism } \\
\text { targeted }\end{array}$ & & & $\begin{array}{l}\text { Mechanism of } \\
\text { action }\end{array}$ & N/A & $N / A$ & N/A \\
\hline $2015 b$ & Monsel & Lung, Acute Lung Injury & $\begin{array}{l}\text { Modified (MSCs before } \\
\text { EV isolation) }\end{array}$ & $\begin{array}{c}\text { EV } \\
\text { preconditioning }\end{array}$ & Protein & $\begin{array}{l}\text { CD44 neutralizing } \\
\text { antibody }\end{array}$ & $\begin{array}{c}\text { Inhibitor / } \\
\text { Neutraliznig AB }\end{array}$ & $\begin{array}{l}\text { EV incorporation } \\
\text { into target cells }\end{array}$ & & & $\begin{array}{l}\text { Mechanism of } \\
\text { action }\end{array}$ & N/A & N/A & N/A \\
\hline $2015 c$ & Monsel & Lung, Acute Lung Injury & $\begin{array}{l}\text { Modified (MSCs before } \\
\text { EV isolation) }\end{array}$ & $\begin{array}{l}\text { MSC } \\
\text { preconditioning }\end{array}$ & $\begin{array}{l}\text { Inflammatory } \\
\text { cytokine }\end{array}$ & $\begin{array}{c}\text { Poly(l(IC) (TLR3 } \\
\text { agonist) }\end{array}$ & N/A & Inflammation & Phagocytosis & & Enhancement & $\begin{array}{l}\text { Some In Vivo } \\
\text { outcomes }\end{array}$ & N/A & N/A \\
\hline $2015 a$ & Zhang & $\begin{array}{l}\text { Wound, Angiogenesis } \\
\text { (e.g. matrigel plug) }\end{array}$ & $\begin{array}{l}\text { Modified (MSCs before } \\
\text { EV isolation) }\end{array}$ & Co-treatment & Inhibitor & $\begin{array}{l}\text { ICG-001 (B-catenin } \\
\text { inhibitor) }\end{array}$ & $\begin{array}{c}\text { Inhibitor / } \\
\text { Neutraliznig AB }\end{array}$ & Angiogenesis & & & $\begin{array}{l}\text { Mechanism of } \\
\text { action }\end{array}$ & N/A & $\mathrm{N} / \mathrm{A}$ & N/A \\
\hline $2015 b$ & Zhang & $\begin{array}{l}\text { Wound, Angiogenesis } \\
\text { (e.g. matrigel plug) }\end{array}$ & $\begin{array}{l}\text { Modified (MSCs before } \\
\text { EV isolation) }\end{array}$ & $\begin{array}{c}\text { MSC } \\
\text { transduction }\end{array}$ & Protein & Wnt4 shRNA & Knockdown & Angiogenesis & & & $\begin{array}{l}\text { Mechanism of } \\
\text { action }\end{array}$ & N/A & $\mathrm{N} / \mathrm{A}$ & $\mathrm{N} / \mathrm{A}$ \\
\hline 2015a & Zhang & Wound & $\begin{array}{l}\text { Co-injected (e.g. EV + } \\
\text { MSCs into animals), } \\
\text { Modified (MSCs before } \\
\text { EV isolation) }\end{array}$ & Co-treatment & Inhibitor & $\begin{array}{l}\text { ICG001 ( } \beta \text {-catenin } \\
\text { inhibitor) }\end{array}$ & $\begin{array}{c}\text { Inhibitor / } \\
\text { Neutraliznig AB }\end{array}$ & Proliferation & Cell migration & & $\begin{array}{l}\text { Mechanism of } \\
\text { action }\end{array}$ & N/A & $N / A$ & N/A \\
\hline $2015 b$ & Zhang & Wound & $\begin{array}{l}\text { Co-injected (e.g. EV + } \\
\text { MSCs into animals), } \\
\text { Modified (MSCs before } \\
\text { EV isolation) }\end{array}$ & $\begin{array}{c}\text { MSC } \\
\text { transduction }\end{array}$ & Protein & Wnt4 shRNA & Knockdown & Proliferation & Cell migration & & $\begin{array}{l}\text { Mechanism of } \\
\text { action }\end{array}$ & N/A & $\mathrm{N} / \mathrm{A}$ & N/A \\
\hline $2015 \mathrm{c}$ & Zhang & Wound & $\begin{array}{l}\text { Co-injected (e.g. EV + } \\
\text { MSCs into animals), } \\
\text { Modified (MSCs before } \\
\text { EV isolation) }\end{array}$ & Co-treatment & Inhibitor & $\begin{array}{l}\text { LY294002 (Akt } \\
\text { inhibitor) }\end{array}$ & $\begin{array}{c}\text { Inhibitor / } \\
\text { Neutraliznig AB }\end{array}$ & Apoptosis & Proliferation & Cell migration & $\begin{array}{l}\text { Mechanism of } \\
\text { action }\end{array}$ & N/A & $\mathrm{N} / \mathrm{A}$ & N/A \\
\hline 2015 & Kang & $\begin{array}{l}\text { Heart, Myocardial } \\
\text { Infarction (permanent } \\
\text { ligation) }\end{array}$ & $\begin{array}{l}\text { Co-injected (e.g. EV + } \\
\text { MSCs into animals), } \\
\text { Modified (MSCs before } \\
\text { EV isolation) }\end{array}$ & $\begin{array}{c}\text { MSC } \\
\text { Transfection + } \\
\text { Co-treatment }\end{array}$ & Protein + Cells & CXCR4 + MSC Sheet & Overexpression & Angiogenesis & Apoptosis & & Enhancement & $\begin{array}{l}\text { All In Vivo } \\
\text { outcomes }\end{array}$ & Yes & N/A \\
\hline 2015 & $\mathrm{Li}$ & Lung, Acute Lung Injury & $\begin{array}{l}\text { Modified (MSCs before } \\
\text { EV isolation) }\end{array}$ & $\begin{array}{c}\text { MSC } \\
\text { preconditioning }\end{array}$ & Hypoxia & $\% 02$ not specified & $\mathrm{N} / \mathrm{A}$ & Inflammation & & & Enhancement & $\begin{array}{l}\text { Most In Vivo } \\
\text { outcomes }\end{array}$ & $\mathrm{N} / \mathrm{A}$ & N/A \\
\hline 2015 & Yang & Ischemic Stroke & $\begin{array}{l}\text { Modified (MSCs before } \\
\text { EV isolation) }\end{array}$ & $\begin{array}{l}\text { MSC } \\
\text { preconditioning }\end{array}$ & Herbs & $\begin{array}{l}\text { BYHWD (Buyang } \\
\text { Huanwu decoction) }\end{array}$ & $\mathrm{N} / \mathrm{A}$ & Angiogenesis & & & Enhancement & Unclear & N/A & N/A \\
\hline 2015 & $\mathrm{Ti}$ & Diabetes, Wound & $\begin{array}{l}\text { Modified (MSCs before } \\
\text { EV isolation) }\end{array}$ & $\begin{array}{c}\text { MSC } \\
\text { preconditioning }\end{array}$ & Endotoxin & LPS & N/A & Inflammation & & & Enhancement & Unclear & N/A & N/A \\
\hline 2015 & Wang & Sepsis & $\begin{array}{l}\text { Modified (MSCs before } \\
\text { EV isolation) }\end{array}$ & $\begin{array}{l}\text { MSCs derived } \\
\text { from KO animal } \\
\text { model }\end{array}$ & miRNA & $\operatorname{miR}-223$ & Knockout & Inflammation & & & $\begin{array}{l}\text { Mechanism of } \\
\text { action }\end{array}$ & N/A & $N / A$ & N/A \\
\hline 2015 & Wang & $\begin{array}{l}\text { Kidney, Chronic Kidney } \\
\text { Disease, Unilateral } \\
\text { Ureteral Obstruction } \\
\text { (UUO) }\end{array}$ & $\begin{array}{l}\text { Modified (MSCs before } \\
\text { EV isolation) }\end{array}$ & $\begin{array}{c}\text { MSC } \\
\text { preconditioning }\end{array}$ & Hormone & EPO & N/A & Fibrosis & Apoptosis & & Enhancement & $\begin{array}{l}\text { Some In Vivo } \\
\text { outcomes }\end{array}$ & No & N/A \\
\hline 2015 & Choi & $\begin{array}{l}\text { Kidney, Chronic Kidney } \\
\text { Disease, Unilateral } \\
\text { Ureteral Obstruction } \\
\text { (UUO) }\end{array}$ & Modified (EVs directly) & $\begin{array}{c}E V \\
\text { preconditioning }\end{array}$ & Enzyme & RNAse & N/A & Fibrosis & Apoptosis & Proliferation & $\begin{array}{l}\text { Mechanism of } \\
\text { action }\end{array}$ & N/A & $N / A$ & N/A \\
\hline 2015 & Ju & $\begin{array}{l}\text { Kidney, Acute Kidney } \\
\text { Injury }\end{array}$ & Modified (EVs directly) & $\begin{array}{c}\text { EV } \\
\text { preconditioning }\end{array}$ & Enzyme & RNAse & N/A & Fibrosis & Apoptosis & Proliferation & $\begin{array}{l}\text { Mechanism of } \\
\text { action }\end{array}$ & N/A & $\mathrm{N} / \mathrm{A}$ & N/A \\
\hline 2015 & Yu & $\begin{array}{l}\text { Heart, Myocardial } \\
\text { Infarction (permanent } \\
\text { ligation) }\end{array}$ & $\begin{array}{l}\text { Modified (MSCs before } \\
\text { EV isolation) }\end{array}$ & $\begin{array}{c}\text { MSC } \\
\text { transduction }\end{array}$ & Protein & GATA-4 & Overexpression & Apoptosis & Fibrosis & & Enhancement & $\begin{array}{l}\text { Most In Vivo } \\
\text { outcomes }\end{array}$ & Yes & N/A \\
\hline 2015 & Collino & $\begin{array}{l}\text { Kidney, Acute Kidney } \\
\text { Injury }\end{array}$ & $\begin{array}{l}\text { Modified (MSCs before } \\
\text { EV isolation) }\end{array}$ & $\begin{array}{c}\text { MSC } \\
\text { transduction }\end{array}$ & Protein & Drosha shRNA & Knockdown & miRNA depletion & Necrosis & & $\begin{array}{l}\text { Mechanism of } \\
\text { action }\end{array}$ & N/A & N/A & N/A \\
\hline 2016a & Wen & $\begin{array}{l}\text { Organ transplantation } \\
\text { (e.g. solid organs, skin } \\
\text { grafts, etc.), Diabetes }\end{array}$ & $\begin{array}{l}\text { Modified (MSCs before } \\
\text { EV isolation) }\end{array}$ & $\begin{array}{c}\text { MSC } \\
\text { preconditioning }\end{array}$ & $\begin{array}{l}\text { Co-culture of } \\
\text { cells }\end{array}$ & PBMCs & N/A & Inflammation & & & Enhancement & No Difference & $N / A$ & N/A \\
\hline $2016 \mathrm{~b}$ & Wen & $\begin{array}{l}\text { Organ transplantation } \\
\text { (e.g. solid organs, skin } \\
\text { grafts, etc.), Diabetes }\end{array}$ & $\begin{array}{l}\text { Modified (MSCs before } \\
\text { EV isolation) }\end{array}$ & $\begin{array}{l}\text { Co-treatment + } \\
\text { MSC } \\
\text { preconditioning }\end{array}$ & $\begin{array}{l}\text { cells + Co- } \\
\text { culture of cells }\end{array}$ & $\begin{array}{l}\text { Co-treatment: } \\
\text { transplantation of } \\
\text { MSCs transfected } \\
\text { with anti-miR-375 and } \\
\text { pshFas; MSC } \\
\text { preconditioning: } \\
\text { PBMCs }\end{array}$ & 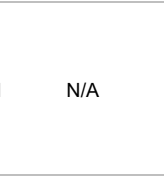 & Inflammation & Apoptosis & $\begin{array}{c}\text { Insulin } \\
\text { dependence }\end{array}$ & Enhancement & No comparison & $\mathrm{N} / \mathrm{A}$ & N/A \\
\hline $2016 a$ & Vrijsen & $\begin{array}{l}\text { Angiogenesis (e.g. } \\
\text { matrigel plug) }\end{array}$ & $\begin{array}{l}\text { Co-injected (e.g. EV + } \\
\text { MSCs into animals) }\end{array}$ & $\begin{array}{c}\mathrm{EV} \\
\text { preconditioning }\end{array}$ & Protein & $\begin{array}{c}\text { aEMMPRIN } \\
\text { neutralizing antibody }\end{array}$ & $\begin{array}{c}\text { Inhibitor / } \\
\text { Neutraliznig AB }\end{array}$ & Angiogenesis & & & $\begin{array}{l}\text { Mechanism of } \\
\text { action }\end{array}$ & N/A & N/A & N/A \\
\hline $2016 b$ & Vrijsen & $\begin{array}{l}\text { Angiogenesis (e.g. } \\
\text { matrigel plug) }\end{array}$ & $\begin{array}{l}\text { Co-injected (e.g. EV + } \\
\text { MSCs into animals) }\end{array}$ & $\begin{array}{c}\text { MSC } \\
\text { transduction }\end{array}$ & Protein & EMMPRIN shRNA & Knockdown & Angiogenesis & & & $\begin{array}{l}\text { Mechanism of } \\
\text { action }\end{array}$ & N/A & N/A & N/A \\
\hline
\end{tabular}




\section{Supplemental File 4 - MSC-EV Modifications}

\begin{tabular}{|c|c|c|c|c|c|c|c|c|c|c|c|c|c|c|c|}
\hline 2016 & Yu & Eye & $\begin{array}{l}\text { Co-injected (e.g. EV + } \\
\text { MSCs into animals) }\end{array}$ & Co-treatment & $\begin{array}{l}\text { Inflammatory } \\
\text { cytokine }\end{array}$ & MCP-1 & N/A & Inflammation & & & & $\begin{array}{l}\text { Mechanism of } \\
\text { action }\end{array}$ & N/A & N/A & $\mathrm{N} / \mathrm{A}$ \\
\hline 2016 & Shen & $\begin{array}{l}\text { Kidney, Ischemic / } \\
\text { Reperfusion }\end{array}$ & $\begin{array}{l}\text { Modified (MSCs before } \\
\text { EV isolation) }\end{array}$ & MSC transfection & Protein & CCR-2 siRNA & Knockdown & Inflammation & & & & $\begin{array}{l}\text { Mechanism of } \\
\text { action }\end{array}$ & N/A & $\mathrm{N} / \mathrm{A}$ & N/A \\
\hline 2016 & Zou & $\begin{array}{l}\text { Kidney, Ischemic / } \\
\text { Reperfusion }\end{array}$ & Modified (EVs directly) & $\begin{array}{c}\mathrm{EV} \\
\text { preconditioning }\end{array}$ & Enzyme & RNAse & $\mathrm{N} / \mathrm{A}$ & Apoptosis & Angiogenesis & Fibrosis & & $\begin{array}{l}\text { Mechanism of } \\
\text { action }\end{array}$ & N/A & $\mathrm{N} / \mathrm{A}$ & $\mathrm{N} / \mathrm{A}$ \\
\hline 2016 & Gu & $\begin{array}{l}\text { Kidney, Ischemic / } \\
\text { Reperfusion }\end{array}$ & $\begin{array}{l}\text { Modified (MSCs before } \\
\text { EV isolation) }\end{array}$ & MSC transfection & miRNA & $\begin{array}{l}\text { miR-30b, miR-30c, } \\
\text { and/or miR-30d } \\
\text { antagomirs }\end{array}$ & Knockdown & $\begin{array}{l}\text { Mitochondrial } \\
\text { function }\end{array}$ & Apoptosis & & & $\begin{array}{l}\text { Mechanism of } \\
\text { action }\end{array}$ & N/A & N/A & N/A \\
\hline 2016 & Lee & Ischemic Stroke & $\begin{array}{l}\text { Modified (MSCs before } \\
\text { EV isolation) }\end{array}$ & $\begin{array}{c}\text { MSC } \\
\text { preconditioning }\end{array}$ & Brain extract & $\begin{array}{l}\text { Normal rat brain } \\
\text { extract or stroke- } \\
\text { injured rat brain } \\
\text { extract }\end{array}$ & $N / A$ & Inflammation & Neurogenesis & & & Enhancement & $\begin{array}{l}\text { Some In Vivo } \\
\text { outcomes }\end{array}$ & No & N/A \\
\hline 2016 & Xie & Bone/Joint & $\begin{array}{l}\text { Co-injected (e.g. EV + } \\
\text { MSCs into animals), } \\
\text { Modified (EVs directly) }\end{array}$ & $\begin{array}{c}\text { EV } \\
\text { Preconditioning }\end{array}$ & $\begin{array}{l}\text { Scaffold + } \\
\text { Alginate }\end{array}$ & $\begin{array}{l}\text { Alginate solution and } \\
\text { polycaprolactone } \\
\text { scaffold }\end{array}$ & N/A & N/A & $N / A$ & N/A & & N/A & No comparison & N/A & N/A \\
\hline 2016 & Kalimuthu & Cancer & $\begin{array}{l}\text { Modified (MSCs before } \\
\text { EV isolation) }\end{array}$ & $\begin{array}{c}\text { MSC } \\
\text { transduction }\end{array}$ & Protein & Renilla luciferase & Overexpression & N/A & & & & Visualization & No comparison & N/A & N/A \\
\hline 2016 & Chen & Ischemic Stroke & $\begin{array}{l}\text { Co-injected (e.g. EV + } \\
\text { MSCs into animals) }\end{array}$ & Co-treatment & Cells & $\begin{array}{l}\text { Adipose-derived } \\
\text { MSCs }\end{array}$ & N/A & Angiogenesis & Inflammation & Fibrosis & $\begin{array}{l}\text { Mitochondrial } \\
\text { Function }\end{array}$ & Enhancement & $\begin{array}{l}\text { Most In Vivo } \\
\text { outcomes }\end{array}$ & No & $\mathrm{N} / \mathrm{A}$ \\
\hline 2016 & Liu & Aneurysm & $\begin{array}{l}\text { Co-injected (e.g. EV + } \\
\text { MSCs into animals) }\end{array}$ & Co-treatment & Inhibitor & $\begin{array}{l}\text { GW 627368X (EP4 } \\
\text { receptor antagonist) }\end{array}$ & $\begin{array}{c}\text { Inhibitor / } \\
\text { Neutraliznig AB }\end{array}$ & Inflammation & & & & $\begin{array}{l}\text { Mechanism of } \\
\text { action }\end{array}$ & $\mathrm{N} / \mathrm{A}$ & N/A & N/A \\
\hline 2016 & Zhang & Wound & $\begin{array}{l}\text { Modified (MSCs before } \\
\text { EV isolation) }\end{array}$ & $\begin{array}{c}\text { MSC } \\
\text { transduction }\end{array}$ & Protein & 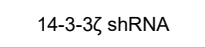 & Knockdown & $\begin{array}{l}\text { Stem cell } \\
\text { expansion }\end{array}$ & $\begin{array}{l}\text { Collagen } \\
\text { deposition }\end{array}$ & & & $\begin{array}{l}\text { Mechanism of } \\
\text { action }\end{array}$ & N/A & N/A & N/A \\
\hline 2016 & Li & Wound & $\begin{array}{l}\text { Modified (MSCs before } \\
\text { EV isolation) }\end{array}$ & MSC transfection & miRNA & miR-181c & Overexpression & Inflammation & & & & Enhancement & $\begin{array}{l}\text { Most In Vivo } \\
\text { outcomes }\end{array}$ & N/A & N/A \\
\hline 2016 & Fang & Wound & Modified (EVs directly) & EV transfection & miRNA & $\begin{array}{l}\text { miR-21, miR-23a, } \\
\text { miR-125b, and miR- } \\
145 \text { antagomirs }\end{array}$ & Knockdown & $\begin{array}{l}\text { Myofibroblast } \\
\text { formation }\end{array}$ & & & & $\begin{array}{l}\text { Mechanism of } \\
\text { action }\end{array}$ & N/A & N/A & N/A \\
\hline 2016 & Qi & Bone/Joint & Modified (EVs directly) & $\begin{array}{c}\text { EV } \\
\text { Preconditioning }\end{array}$ & Scaffold & $\beta$-TCP scaffold & N/A & N/A & N/A & N/A & & N/A & No comparison & N/A & N/A \\
\hline 2016 & Qin & Bone/Joint & Modified (EVs directly) & $\begin{array}{c}\text { EV } \\
\text { Preconditioning }\end{array}$ & Scaffold & HyStem-HP hydrogel & N/A & N/A & N/A & N/A & & N/A & No comparison & N/A & N/A \\
\hline 2016 & $\mathrm{Ti}$ & Diabetes, Wound & $\begin{array}{l}\text { Modified (MSCs before } \\
\text { EV isolation) }\end{array}$ & $\begin{array}{c}\text { MSC } \\
\text { preconditioning }\end{array}$ & Endotoxin & LPS & N/A & Inflammation & Regeneration & & & Enhancement & Unclear & N/A & $\mathrm{N} / \mathrm{A}$ \\
\hline 2017a & $\begin{array}{c}\text { Gonzalez- } \\
\text { King }\end{array}$ & $\begin{array}{l}\text { Angiogenesis (e.g. } \\
\text { matrigel plug) }\end{array}$ & $\begin{array}{l}\text { Modified (MSCs before } \\
\text { EV isolation) }\end{array}$ & $\begin{array}{c}\text { MSC } \\
\text { transduction }\end{array}$ & Protein & HIF-1a & Overexpression & Angiogenesis & & & & Enhancement & $\begin{array}{l}\text { All In Vivo } \\
\text { outcomes }\end{array}$ & $\mathrm{N} / \mathrm{A}$ & N/A \\
\hline $2017 \mathrm{~b}$ & $\begin{array}{c}\text { Gonzalez- } \\
\text { King }\end{array}$ & $\begin{array}{l}\text { Angiogenesis (e.g. } \\
\text { matrigel plug) }\end{array}$ & $\begin{array}{l}\text { Modified (MSCs before } \\
\text { EV isolation) }\end{array}$ & $\begin{array}{c}\text { MSC } \\
\text { transduction + } \\
E V \\
\text { preconditioning }\end{array}$ & Protein + Protein & $\begin{array}{l}\text { HIF-1 } \alpha+\text { Jagged1 } \\
\text { neutralizing antibody }\end{array}$ & $\begin{array}{l}\text { Overexpression } \\
+ \text { Inhibitor } \\
\text { Neutralizing } A B\end{array}$ & Angiogenesis & & & & $\begin{array}{l}\text { Mechanism of } \\
\text { action }\end{array}$ & N/A & $\mathrm{N} / \mathrm{A}$ & N/A \\
\hline $2017 \mathrm{c}$ & $\begin{array}{l}\text { Gonzalez- } \\
\text { King }\end{array}$ & $\begin{array}{l}\text { Angiogenesis (e.g. } \\
\text { matrigel plug) }\end{array}$ & $\begin{array}{l}\text { Modified (MSCs before } \\
\text { EV isolation) }\end{array}$ & $\begin{array}{c}\text { EV } \\
\text { preconditioning }\end{array}$ & Protein & $\begin{array}{l}\text { Jagged1 neutralizing } \\
\text { antibody }\end{array}$ & $\begin{array}{c}\text { Inhibitor / } \\
\text { Neutraliznig AB }\end{array}$ & Angiogenesis & & & & $\begin{array}{l}\text { Mechanism of } \\
\text { action }\end{array}$ & N/A & N/A & N/A \\
\hline 2017a & Song & Sepsis & $\begin{array}{l}\text { Modified (MSCs before } \\
\text { EV isolation) }\end{array}$ & $\begin{array}{c}\text { MSC } \\
\text { preconditioning }\end{array}$ & $\begin{array}{l}\text { Inflammatory } \\
\text { cytokine }\end{array}$ & IL-1 $\beta$ & N/A & Inflammation & & & & Enhancement & $\begin{array}{l}\text { All In Vivo } \\
\text { outcomes }\end{array}$ & N/A & Yes \\
\hline $2017 b$ & Song & Sepsis & $\begin{array}{l}\text { Modified (MSCs before } \\
\text { EV isolation) }\end{array}$ & MSC transfection & $\begin{array}{l}\text { Inflammatory } \\
\text { cytokine }{ }^{+} \\
\text {miRNA }\end{array}$ & miR-146a mimic & Overexpression & Inflammation & & & & Enhancement & $\begin{array}{l}\text { Most In Vivo } \\
\text { outcomes }\end{array}$ & N/A & Yes \\
\hline $2017 c$ & Song & Sepsis & $\begin{array}{l}\text { Modified (MSCs before } \\
\text { EV isolation) }\end{array}$ & $\begin{array}{c}\text { MSC } \\
\text { preconditioning + } \\
\text { MSC transfection }\end{array}$ & $\begin{array}{l}\text { Inflammatory } \\
\text { cytokine }{ }^{+} \\
\text {miRNA }\end{array}$ & $\begin{array}{l}\mathrm{IL}-1 \beta+\operatorname{miR}-146 \mathrm{a} \\
\text { inhibitor }\end{array}$ & Knockdown & Inflammation & & & & $\begin{array}{l}\text { Mechanism of } \\
\text { action }\end{array}$ & N/A & N/A & N/A \\
\hline 2017a & Kamerkar & Cancer & $\begin{array}{l}\text { Co-injected (e.g. EV + } \\
\text { MSCs into animals), } \\
\text { Modified (EVs directly) }\end{array}$ & MSC transfection & protein & $K_{R A S^{\wedge} G 12 D}$ shRNA & Overexpression & Tumorigenesis & & & & Enhancement & $\begin{array}{l}\text { Most In Vivo } \\
\text { outcomes }\end{array}$ & N/A & Yes \\
\hline $2017 \mathrm{~b}$ & Kamerkar & Cancer & $\begin{array}{l}\text { Co-injected (e.g. EV + } \\
\text { MSCs into animals), } \\
\text { Modified (EVs directly) }\end{array}$ & $\begin{array}{c}\text { MSC transfection } \\
+\mathrm{EV} \\
\text { preconditioning }\end{array}$ & $\begin{array}{l}\text { protein + } \\
\text { enzyme }\end{array}$ & $\begin{array}{c}\mathrm{KRAS}^{\wedge} \mathrm{G} 12 \mathrm{D} \text { shRNA } \\
\text { + Proteinase K + } \\
\text { RNAse A }\end{array}$ & $\begin{array}{l}\text { Overexpression } \\
\text { + Knockdown }\end{array}$ & Tumorigenesis & & & & $\begin{array}{l}\text { Mechanism of } \\
\text { action }\end{array}$ & N/A & N/A & N/A \\
\hline $2017 c$ & Kamerkar & Cancer & $\begin{array}{l}\text { Co-injected (e.g. EV + } \\
\text { MSCs into animals), } \\
\text { Modified (EVs directly) }\end{array}$ & $\begin{array}{c}\text { MSC transfection } \\
+\mathrm{EV} \\
\text { preconditioning }\end{array}$ & $\begin{array}{l}\text { protein + } \\
\text { enzyme }\end{array}$ & $\begin{array}{l}\text { KRAS^G12D shRNA } \\
+ \text { +RNAse A }\end{array}$ & $\begin{array}{l}\text { Overexpression } \\
+ \text { Knockdown }\end{array}$ & Tumorigenesis & & & & $\begin{array}{l}\text { Mechanism of } \\
\text { action }\end{array}$ & N/A & N/A & N/A \\
\hline 2017d & Kamerkar & Cancer & $\begin{array}{l}\text { Co-injected (e.g. EV + } \\
\text { MSCs into animals), } \\
\text { Modified (EVs directly) }\end{array}$ & $\begin{array}{c}\text { MSC transfection } \\
+\mathrm{EV} \\
\text { preconditioning }\end{array}$ & protein + protein & $\begin{array}{l}\text { KRAS^G12D shRNA } \\
+ \text { CD47 neutralizing } \\
\text { antibody }\end{array}$ & $\begin{array}{l}\text { Overexpression } \\
+ \text { inhibitor } / \\
\text { neutralizing } \mathrm{AB}\end{array}$ & Tumorigenesis & Phagocytosis & & & $\begin{array}{l}\text { Mechanism of } \\
\text { action }\end{array}$ & N/A & N/A & N/A \\
\hline
\end{tabular}


Supplemental File 4 - MSC-EV Modifications

\begin{tabular}{|c|c|c|c|c|c|c|c|c|c|c|c|c|c|c|c|}
\hline $2017 \mathrm{e}$ & Kamerkar & Cancer & $\begin{array}{l}\text { Co-injected (e.g. EV + } \\
\text { MSCs into animals), } \\
\text { Modified (EVs directly) }\end{array}$ & $\begin{array}{c}\text { MSC transfection } \\
+ \text { MSCs derived } \\
\text { from KO animal } \\
\text { model }\end{array}$ & protein + protein & $\begin{array}{c}\mathrm{KRAS}^{\wedge} \mathrm{G} 12 \mathrm{D} \text { shRNA } \\
+\mathrm{CD} 47\end{array}$ & Overexpression & Tumorigenesis & Phagocytosis & & & $\begin{array}{l}\text { Mechanism of } \\
\text { action }\end{array}$ & N/A & $\mathrm{N} / \mathrm{A}$ & N/A \\
\hline $2017 \mathrm{a}$ & Du & Liver & $\begin{array}{l}\text { Co-injected (e.g. EV + } \\
\text { MSCs into animals) }\end{array}$ & Co-treatment & Inhibitor & SKII (SK inhibitor) & $\begin{array}{c}\text { Inhibitor / } \\
\text { Neutraliznig AB }\end{array}$ & Proliferation & & & & $\begin{array}{l}\text { Mechanism of } \\
\text { action }\end{array}$ & N/A & $\mathrm{N} / \mathrm{A}$ & $\mathrm{N} / \mathrm{A}$ \\
\hline 2017b & Du & Liver & $\begin{array}{l}\text { Co-injected (e.g. EV + } \\
\text { MSCs into animals) }\end{array}$ & Co-treatment & Inhibitor & $\begin{array}{l}\text { VPC23019 (S1P1 } \\
\text { receptor antagonist) }\end{array}$ & $\begin{array}{c}\text { Inhibitor / } \\
\text { Neutraliznig AB }\end{array}$ & Proliferation & & & & $\begin{array}{l}\text { Mechanism of } \\
\text { action }\end{array}$ & N/A & $\mathrm{N} / \mathrm{A}$ & $\mathrm{N} / \mathrm{A}$ \\
\hline $2017 a$ & de Almeida & $\begin{array}{l}\text { Kidney, Acute Kidney } \\
\text { Injury, Nephrotoxicity }\end{array}$ & Modified (EVs directly) & $\begin{array}{c}\text { EV } \\
\text { preconditioning }\end{array}$ & Enzyme & $\begin{array}{c}\text { RNAse A + } \\
\text { Proteinase K }\end{array}$ & N/A & Apoptosis & Proliferation & & & $\begin{array}{l}\text { Mechanism of } \\
\text { action }\end{array}$ & N/A & $\mathrm{N} / \mathrm{A}$ & $\mathrm{N} / \mathrm{A}$ \\
\hline 2017b & de Almeida & $\begin{array}{l}\text { Kidney, Acute Kidney } \\
\text { Injury, Nephrotoxicity }\end{array}$ & Modified (EVs directly) & $\begin{array}{c}\text { EV } \\
\text { preconditioning }\end{array}$ & Enzyme & $\begin{array}{c}\text { DNAse I+ Proteinase } \\
\mathrm{K}\end{array}$ & N/A & Apoptosis & Proliferation & & & $\begin{array}{l}\text { Mechanism of } \\
\text { action }\end{array}$ & N/A & $\mathrm{N} / \mathrm{A}$ & $\mathrm{N} / \mathrm{A}$ \\
\hline $2017 \mathrm{c}$ & de Almeida & $\begin{array}{l}\text { Kidney, Acute Kidney } \\
\text { Injury, Nephrotoxicity }\end{array}$ & Modified (EVs directly) & $\begin{array}{c}E V \\
\text { preconditioning }\end{array}$ & Enzyme & $\begin{array}{c}\text { Proteinase } \mathrm{K}+ \\
\text { trypsin }+ \text { collagenase } \\
1 \mathrm{~A}\end{array}$ & N/A & Apoptosis & Proliferation & & & $\begin{array}{l}\text { Mechanism of } \\
\text { action }\end{array}$ & N/A & $\mathrm{N} / \mathrm{A}$ & N/A \\
\hline 2017 & Cheng & $\begin{array}{l}\text { Intervertebral disc } \\
\text { degeneration }\end{array}$ & $\begin{array}{l}\text { Modified (MSCs before } \\
\text { EV isolation) }\end{array}$ & MSC transfection & miRNA & agomiR-21 & Overexpression & Cell survival & Apoptosis & & & $\begin{array}{l}\text { Mechanism of } \\
\text { action }\end{array}$ & N/A & $\mathrm{N} / \mathrm{A}$ & $\mathrm{N} / \mathrm{A}$ \\
\hline 2017 & Zhu & $\begin{array}{l}\text { Heart, Myocardial } \\
\text { Infarction (permanent } \\
\text { ligation) }\end{array}$ & $\begin{array}{l}\text { Modified (MSCs before } \\
\text { EV isolation) }\end{array}$ & $\begin{array}{c}\text { MSC } \\
\text { preconditioning }\end{array}$ & Hypoxia & $0.5 \% \mathrm{O} 2$ & N/A & EV secretion & Angiogenesis & Apoptosis & Cell migration & Enhancement & $\begin{array}{l}\text { Most In Vivo } \\
\text { outcomes }\end{array}$ & Yes & Yes \\
\hline 2017 & Mead & Eye & $\begin{array}{l}\text { Modified (MSCs before } \\
\text { EV isolation) }\end{array}$ & MSC transfection & $\begin{array}{l}\text { Protein/miRNA } \\
\text { (Ago2) }\end{array}$ & Argonaute 2 siRNA & Knockdown & Neuroprotection & Regeneration & & & $\begin{array}{l}\text { Mechanism of } \\
\text { action }\end{array}$ & N/A & $\mathrm{N} / \mathrm{A}$ & $\mathrm{N} / \mathrm{A}$ \\
\hline 2017 & Yuan & $\begin{array}{l}\text { Kidney, Ischemic / } \\
\text { Reperfusion }\end{array}$ & $\begin{array}{l}\text { Modified (MSCs before } \\
\text { EV isolation) }\end{array}$ & KO iPSC line & Protein & SP1 & Knockout & Necroptosis & & & & $\begin{array}{l}\text { Mechanism of } \\
\text { action }\end{array}$ & N/A & $\mathrm{N} / \mathrm{A}$ & N/A \\
\hline 2017 & Chen & $\begin{array}{l}\text { Kidney, Ischemic / } \\
\text { Reperfusion }\end{array}$ & $\begin{array}{l}\text { Co-injected (e.g. EV + } \\
\text { MSCs into animals) }\end{array}$ & Co-treatment & Inhibitor & U0126 & $\begin{array}{c}\text { Inhibitor / } \\
\text { Neutraliznig AB }\end{array}$ & $\begin{array}{l}\text { Cell cycle } \\
\text { progression }\end{array}$ & Fibrosis & Proliferation & Apoptosis & $\begin{array}{l}\text { Mechanism of } \\
\text { action }\end{array}$ & N/A & $\mathrm{N} / \mathrm{A}$ & $\mathrm{N} / \mathrm{A}$ \\
\hline 2017 & Zhang & Traumatic Brain Injury & $\begin{array}{l}\text { Modified (MSCs before } \\
\text { EV isolation) }\end{array}$ & $\begin{array}{c}\text { MSC } \\
\text { preconditioning }\end{array}$ & Scaffold & Ultrafoam scaffold & N/A & $3 \mathrm{D}$ culture & Angiogenesis & Neurogenesis & Inflammation & Enhancement & $\begin{array}{l}\text { Some In Vivo } \\
\text { outcomes }\end{array}$ & No & $\mathrm{N} / \mathrm{A}$ \\
\hline 2017 & Shi & Diabetes, Wound & Modified (EVs directly) & $\begin{array}{c}\text { EV } \\
\text { Preconditioning }\end{array}$ & Scaffold & $\begin{array}{l}\text { Chitosan/silk } \\
\text { hydrogel sponge }\end{array}$ & N/A & N/A & N/A & N/A & & $\mathrm{N} / \mathrm{A}$ & N/A & $\mathrm{N} / \mathrm{A}$ & N/A \\
\hline 2017 & Gangadaran & $\begin{array}{l}\text { Ischemia (e.g. testing } \\
\text { angiogenesis) }\end{array}$ & Modified (EVs directly) & $\begin{array}{c}\mathrm{EV} \\
\text { Preconditioning }\end{array}$ & Scaffold & Matrigel & N/A & Angiogenesis & Retention & & & Enhancement & $\begin{array}{l}\text { Most In Vivo } \\
\text { outcomes }\end{array}$ & Yes & N/A \\
\hline 2017 & Sun & Liver & $\begin{array}{l}\text { Co-injected (e.g. EV + } \\
\text { MSCs into animals) }\end{array}$ & Co-treatment & Hormone & Melatonin & N/A & Oxidative stress & Inflammation & Apoptosis & $\begin{array}{l}\text { Mitochondrial } \\
\text { Function }\end{array}$ & Enhancement & $\begin{array}{l}\text { All In Vivo } \\
\text { outcomes }\end{array}$ & Yes & N/A \\
\hline 2017 & Qu & Liver & $\begin{array}{l}\text { Modified (MSCs before } \\
\text { EV isolation) }\end{array}$ & MSC transfection & miRNA & miR-181-5p & Overexpression & Fibrosis & Autophagy & Inflammation & & Enhancement & $\begin{array}{l}\text { Some In Vivo } \\
\text { outcomes }\end{array}$ & Yes & $\mathrm{N} / \mathrm{A}$ \\
\hline 2017 & Xie & Bone/Joint & Modified (EVs directly) & $\begin{array}{c}\text { EV } \\
\text { Preconditioning }\end{array}$ & Scaffold & $\begin{array}{l}\text { Decalcified bone } \\
\text { matrix }\end{array}$ & N/A & N/A & $\mathrm{N} / \mathrm{A}$ & N/A & & N/A & N/A & $\mathrm{N} / \mathrm{A}$ & $\mathrm{N} / \mathrm{A}$ \\
\hline 2017 & Wang & $\begin{array}{l}\text { Heart, Myocardial } \\
\text { Infarction (permanent } \\
\text { ligation) }\end{array}$ & $\begin{array}{l}\text { Modified (MSCs before } \\
\text { EV isolation) }\end{array}$ & MSC transfection & miRNA & miR-210 siRNA & Knockdown & Angiogenesis & Fibrosis & & & $\begin{array}{l}\text { Mechanism of } \\
\text { action }\end{array}$ & N/A & $\mathrm{N} / \mathrm{A}$ & $\mathrm{N} / \mathrm{A}$ \\
\hline 2017 & Ma & $\begin{array}{l}\text { Heart, Myocardial } \\
\text { Infarction (permanent } \\
\text { ligation) }\end{array}$ & $\begin{array}{l}\text { Modified (MSCs before } \\
\text { EV isolation) }\end{array}$ & $\begin{array}{c}\text { MSC } \\
\text { transduction }\end{array}$ & Protein & Akt & Overexpression & Angiogenesis & Cell migration & & & Enhancement & $\begin{array}{l}\text { Most In Vivo } \\
\text { outcomes }\end{array}$ & Yes & $\mathrm{N} / \mathrm{A}$ \\
\hline 2017 & $\mathrm{Li}$ & Bone/Joint & $\begin{array}{l}\text { Modified (MSCs before } \\
\text { EV isolation) }\end{array}$ & $\begin{array}{c}\text { MSC } \\
\text { transduction }\end{array}$ & $\begin{array}{l}\text { Protein } \\
\text { (mutation) }\end{array}$ & Mutant HIF-1 $\alpha$ & Mutation & Osteogenesis & Angiogenesis & & & Enhancement & $\begin{array}{l}\text { Most In Vivo } \\
\text { outcomes }\end{array}$ & $\mathrm{N} / \mathrm{A}$ & N/A \\
\hline 2017 & Eirin & $\begin{array}{l}\text { Kidney, Chronic Kidney } \\
\text { Disease }\end{array}$ & $\begin{array}{l}\text { Modified (MSCs before } \\
\text { EV isolation) }\end{array}$ & MSC transfection & Protein & IL-10 siRNA & Knockdown & Inflammation & & & & $\begin{array}{l}\text { Mechanism of } \\
\text { action }\end{array}$ & N/A & $\mathrm{N} / \mathrm{A}$ & $\mathrm{N} / \mathrm{A}$ \\
\hline 2017 & Tang & Lung, Acute Lung Injury & $\begin{array}{l}\text { Modified (MSCS before } \\
\text { EV isolation) }\end{array}$ & $\begin{array}{c}\text { MSC } \\
\text { transduction }\end{array}$ & Protein & Ang-1 shRNA & Knockdown & $\begin{array}{c}\text { Vascular } \\
\text { stabilization }\end{array}$ & Inflammation & & & $\begin{array}{l}\text { Mechanism of } \\
\text { action }\end{array}$ & N/A & $\mathrm{N} / \mathrm{A}$ & $\mathrm{N} / \mathrm{A}$ \\
\hline 2017 & Du & $\begin{array}{l}\text { Ischemia (e.g. testing } \\
\text { angiogenesis) }\end{array}$ & $\begin{array}{l}\text { Modified (MSCs before } \\
\text { EV isolation) }\end{array}$ & $\begin{array}{c}\text { MSC } \\
\text { preconditioning }\end{array}$ & Polymer & $\begin{array}{l}\text { Chitosan NO- } \\
\text { releasing polymer }\end{array}$ & N/A & Angiogenesis & & & & Enhancement & $\begin{array}{l}\text { All In Vivo } \\
\text { outcomes }\end{array}$ & Yes & N/A \\
\hline 2017 & Moisseiev & Eye & $\begin{array}{l}\text { Modified (MSCs before } \\
\text { EV isolation) }\end{array}$ & $\begin{array}{c}\text { MSC } \\
\text { preconditioning }\end{array}$ & Hypoxia & $1 \% \bigcirc 2$ & N/A & N/A & N/A & N/A & & N/A & No comparison & $\mathrm{N} / \mathrm{A}$ & N/A \\
\hline 2017 & Liu & $\begin{array}{l}\text { Heart, Myocardial } \\
\text { infarction (ischemia- } \\
\text { reperfusion) }\end{array}$ & $\begin{array}{l}\text { Modified (MSCs before } \\
\text { EV isolation) }\end{array}$ & $\begin{array}{c}\text { MSC } \\
\text { preconditioning }\end{array}$ & Hypoxia & $1 \% O 2$ & N/A & N/A & $\mathrm{N} / \mathrm{A}$ & $\mathrm{N} / \mathrm{A}$ & & N/A & No comparison & $\mathrm{N} / \mathrm{A}$ & N/A \\
\hline 2017 & xin & Ischemic Stroke & $\begin{array}{l}\text { Modified (MSCs before } \\
\text { EV isolation) }\end{array}$ & $\begin{array}{l}\text { MSC } \\
\text { transduction }\end{array}$ & miRNA & pre-miR-133b & Overexpression & $\begin{array}{l}\text { Neurite } \\
\text { remodeling }\end{array}$ & Retention & & & Enhancement & $\begin{array}{l}\text { All In Vivo } \\
\text { outcomes }\end{array}$ & Yes & N/A \\
\hline 2017 & Yan & Liver & $\begin{array}{l}\text { Modified (MSCs before } \\
\text { EV isolation) }\end{array}$ & MSC transfection & Protein & GPX1 siRNA & Knockdown & Oxidative stress & Apoptosis & & & $\begin{array}{l}\text { Mechanism of } \\
\text { action }\end{array}$ & N/A & $\mathrm{N} / \mathrm{A}$ & $\mathrm{N} / \mathrm{A}$ \\
\hline 2017 & Tao & Bone/Joint & $\begin{array}{l}\text { Modified (MSCs before } \\
\text { EV isolation) }\end{array}$ & $\begin{array}{c}\text { MSC } \\
\text { transduction }\end{array}$ & miRNA & $m i R-140-5 p$ & Overexpression & Proliferation & Cell migration & $\begin{array}{l}\text { Collagen } \\
\text { Deposition }\end{array}$ & & Enhancement & $\begin{array}{l}\text { All In Vivo } \\
\text { outcomes }\end{array}$ & $\mathrm{N} / \mathrm{A}$ & N/A \\
\hline 2017 & Tao & Diabetes, Wound & $\begin{array}{l}\text { Modified (MSCs before } \\
\text { EV isolation), Modified } \\
\text { (EVs directly) }\end{array}$ & $\begin{array}{c}\text { EV } \\
\text { Preconditioning + } \\
\text { MSC } \\
\text { transduction }\end{array}$ & $\begin{array}{c}\text { Scaffold + } \\
\text { miRNA }\end{array}$ & $\begin{array}{c}\text { Chitosan gel + miR- } \\
126-3 p\end{array}$ & Overexpression & Angiogenesis & Regeneration & & & Enhancement & No comparison & $\mathrm{N} / \mathrm{A}$ & N/A \\
\hline 2017 & Tamura & Liver & Modified (EVs directly) & $\begin{array}{c}E V \\
\text { preconditioning }\end{array}$ & Polysaccharide & Cationized pullulan & $\mathrm{N} / \mathrm{A}$ & $\begin{array}{l}\text { EV incorporation } \\
\text { into target cells }\end{array}$ & Inflammation & Necrosis & & Enhancement & $\begin{array}{l}\text { Most In Vivo } \\
\text { outcomes }\end{array}$ & Yes & $\mathrm{N} / \mathrm{A}$ \\
\hline
\end{tabular}


Supplemental File 4 - MSC-EV Modifications

\begin{tabular}{|c|c|c|c|c|c|c|c|c|c|c|c|c|c|c|c|}
\hline 2017 & Ranghino & $\begin{array}{l}\text { Kidney, Ischemic / } \\
\text { Reperfusion, Acute } \\
\text { Kidney Injury, } \\
\text { Nephrectomy }\end{array}$ & Modified (EVs directly) & $\begin{array}{c}\text { EV } \\
\text { preconditioning }\end{array}$ & Enzyme & RNAse & N/A & Necrosis & Proliferation & Apoptosis & & $\begin{array}{l}\text { Mechanism of } \\
\text { action }\end{array}$ & N/A & N/A & $N / A$ \\
\hline 2017 & Xin & Ischemic Stroke & $\begin{array}{l}\text { Modified (MSCs before } \\
\text { EV isolation) }\end{array}$ & MSC transfection & miRNA & miR-17-92 cluster & Overexpression & Neurogenesis & $\begin{array}{c}\text { Neurite } \\
\text { remodeling }\end{array}$ & & & Enhancement & $\begin{array}{l}\text { All In Vivo } \\
\text { outcomes }\end{array}$ & Yes & N/A \\
\hline 2017 & Lo Sicco & $\begin{array}{l}\text { Muscle, Angiogenesis } \\
\text { (e.g. matrigel plug) }\end{array}$ & $\begin{array}{l}\text { Modified (MSCs before } \\
\text { EV isolation) }\end{array}$ & $\begin{array}{c}\text { MSC } \\
\text { preconditioning }\end{array}$ & Hypoxia & $\% 02$ not specified & N/A & Inflammation & Angiogenesis & Myogenesis & & Enhancement & Unclear & N/A & N/A \\
\hline 2018 & Luther & $\begin{array}{l}\text { Heart, Myocardial } \\
\text { infarction (ischemia- } \\
\text { reperfusion) }\end{array}$ & $\begin{array}{l}\text { Modified (MSCs before } \\
\text { EV isolation) }\end{array}$ & $\begin{array}{l}\text { MSCs derived } \\
\text { from KO animal } \\
\text { model }\end{array}$ & miRNA & miR-21a & Knockout & Apoptosis & & & & $\begin{array}{l}\text { Mechanism of } \\
\text { action }\end{array}$ & N/A & N/A & N/A \\
\hline 2018 & Ahn & Lung, BPD & $\begin{array}{l}\text { Modified (MSCs before } \\
\text { EV isolation) }\end{array}$ & MSC transfection & Protein & VEGF siRNA & Knockdown & Angiogenesis & Apoptosis & Inflammation & & $\begin{array}{l}\text { Mechanism of } \\
\text { action }\end{array}$ & N/A & N/A & N/A \\
\hline 2018 & Blazquez & Incisional hernia & Modified (EVs directly) & $\begin{array}{c}\text { EV } \\
\text { Preconditioning }\end{array}$ & Scaffold & $\begin{array}{l}\text { Fibring glue + } \\
\text { surgical mesh }\end{array}$ & N/A & N/A & & & & N/A & N/A & N/A & N/A \\
\hline 2018 & Shen & $\begin{array}{l}\text { Hemorrhagic Stroke } \\
\text { (e.g. Intracranial } \\
\text { Hemorrhage) }\end{array}$ & $\begin{array}{l}\text { Modified (MSCs before } \\
\text { EV isolation) }\end{array}$ & MSC transfection & miRNA & miR-133b & Overexpression & Apoptosis & & & & Enhancement & $\begin{array}{l}\text { All In Vivo } \\
\text { outcomes }\end{array}$ & N/A & N/A \\
\hline 2018 & Lang & Cancer & $\begin{array}{l}\text { Modified (MSCs before } \\
\text { EV isolation) }\end{array}$ & $\begin{array}{c}\text { MSC } \\
\text { transduction }\end{array}$ & miRNA & miR-124a & Overexpression & Tumorigenesis & $\begin{array}{c}\text { Lipid } \\
\text { metabolism }\end{array}$ & & & Enhancement & $\begin{array}{l}\text { All In Vivo } \\
\text { outcomes }\end{array}$ & N/A & Yes \\
\hline 2018 & Cui & $\begin{array}{l}\text { Cognitive impairment } \\
\text { (e.g. Alzheimer's, } \\
\text { Parkinson's Disease, } \\
\text { etc.) }\end{array}$ & $\begin{array}{l}\text { Modified (MSCs before } \\
\text { EV isolation) }\end{array}$ & $\begin{array}{c}\text { MSC } \\
\text { preconditioning }\end{array}$ & Hypoxia & $0 \% O 2$ & N/A & N/A & apoptosis & inflammation & $\begin{array}{c}\text { plaque } \\
\text { deposition }\end{array}$ & Enhancement & $\begin{array}{l}\text { Most In Vivo } \\
\text { outcomes }\end{array}$ & Yes & N/A \\
\hline 2018 & $\mathrm{Li}$ & Bone/Joint & Modified (EVs directly) & $\begin{array}{c}\text { EV } \\
\text { Preconditioning }\end{array}$ & Scaffold & $\begin{array}{l}\text { Poly(lactic-co-glycolic } \\
\text { acid) (PLGA) or } \\
\text { polydopamine-coated } \\
\text { PLGA (pDA/PLGA) }\end{array}$ & N/A & N/A & & & & N/A & $\mathrm{N} / \mathrm{A}$ & N/A & $N / A$ \\
\hline 2018 & Mead & Eye & $\begin{array}{l}\text { Modified (MSCs before } \\
\text { EV isolation) }\end{array}$ & MSC transfection & $\begin{array}{l}\text { Protein/miRNA } \\
\text { (Ago2) }\end{array}$ & Argonaute 2 siRNA & Knockdown & miRNA depletion & & & & $\begin{array}{l}\text { Mechanism of } \\
\text { action }\end{array}$ & N/A & N/A & N/A \\
\hline 2018 & Ruppert & Spinal cord injury & $\begin{array}{l}\text { Modified (MSCs before } \\
\text { EV isolation) }\end{array}$ & $\begin{array}{c}\text { MSC } \\
\text { preconditioning }\end{array}$ & $\begin{array}{l}\text { Inflammatory } \\
\text { cytokine }\end{array}$ & TNF- $\alpha+$ IFN- $y$ & N/A & Inflammation & & & & Enhancement & $\begin{array}{l}\text { Some In Vivo } \\
\text { outcomes }\end{array}$ & Yes & N/A \\
\hline 2018 & Han & $\begin{array}{l}\text { Organ transplantation } \\
\text { (e.g. solid organs, skin } \\
\text { grafts, etc.) }\end{array}$ & $\begin{array}{l}\text { Modified (MSCs before } \\
\text { EV isolation) }\end{array}$ & $\begin{array}{c}\text { MSC } \\
\text { preconditioning }\end{array}$ & Hypoxia & $5 \% \bigcirc 2$ & N/A & Angiogenesis & Cell survival & Inflammation & & Enhancement & $\begin{array}{l}\text { Most In Vivo } \\
\text { outcomes }\end{array}$ & Yes & N/A \\
\hline 2018 & O'Brien & Cancer & $\begin{array}{l}\text { Modified (MSCs before } \\
\text { EV isolation) }\end{array}$ & $\begin{array}{c}\text { MSC } \\
\text { transduction }\end{array}$ & miRNA & miR-379 & Overexpression & Tumorigenesis & & & & Enhancement & $\begin{array}{l}\text { All In Vivo } \\
\text { outcomes }\end{array}$ & Yes & $\mathrm{N} / \mathrm{A}$ \\
\hline 2018 & Chang & Sepsis & $\begin{array}{l}\text { Modified (MSCs before } \\
\text { EV isolation) }\end{array}$ & $\begin{array}{c}\text { MSC } \\
\text { preconditioning }\end{array}$ & $\begin{array}{l}\text { Hypoxia/starvati } \\
\text { on }\end{array}$ & $\begin{array}{l}1 \% \text { O2 followed by } \\
\text { serum deprivation }\end{array}$ & N/A & Inflammation & $\begin{array}{l}\text { Oxidative } \\
\text { stress }\end{array}$ & & & Enhancement & $\begin{array}{c}\text { Modified < } \\
\text { unmodified for most } \\
\text { In Vivo outcomes }\end{array}$ & Worse & Worse \\
\hline 2018 & Tian & Bone/Joint & $\begin{array}{l}\text { Modified (EVs directly), } \\
\text { Modified (MSCs before } \\
\text { EV isolation) }\end{array}$ & $\begin{array}{c}\text { EV } \\
\text { Preconditioning + } \\
\text { MSC } \\
\text { Transfection }\end{array}$ & $\begin{array}{l}\text { Scaffold + } \\
\text { Protein } \\
\text { (Mutation) }\end{array}$ & Scaffold / HIF1a & Mutation & Apoptosis & Inflammation & Regeneration & & Enhancement & $\begin{array}{l}\text { All In Vivo } \\
\text { outcomes }\end{array}$ & Yes & N/A \\
\hline 2018 & Chen & Diabetes, Wound & $\begin{array}{l}\text { Modified (MSCs before } \\
\text { EV isolation) }\end{array}$ & $\begin{array}{c}\text { MSC } \\
\text { transduction }\end{array}$ & Protein & shDMBT1 & Knockdown & Angiogenesis & Proliferation & $\begin{array}{l}\text { Collagen } \\
\text { Deposition }\end{array}$ & & $\begin{array}{l}\text { Mechanism of } \\
\text { action }\end{array}$ & N/A & N/A & N/A \\
\hline 2018 & Jia & $\begin{array}{l}\text { Kidney, Acute Kidney } \\
\text { Injury, Nephrotoxicity }\end{array}$ & $\begin{array}{l}\text { Modified (MSCs before } \\
\text { EV isolation) }\end{array}$ & $\begin{array}{c}\text { MSC } \\
\text { transduction }\end{array}$ & Protein & $14-3-3 \zeta$ & Overexpression & Autophagy & Proliferation & Apoptosis & & Enhancement & $\begin{array}{l}\text { All In Vivo } \\
\text { outcomes }\end{array}$ & Yes & $N / A$ \\
\hline 2018a & Diomede & Bone/Joint & $\begin{array}{l}\text { Co-injected (e.g. EV + } \\
\text { MSCs into animals), } \\
\text { Modified (EVs directly) }\end{array}$ & $\begin{array}{c}\text { EV } \\
\text { preconditioning }\end{array}$ & Polymer & Polyethyeleneimine & N/A & $\begin{array}{l}\text { EV incorporation } \\
\text { into target cells }\end{array}$ & osteogenesis & angiogenesis & & Enhancement & Unclear & N/A & N/A \\
\hline $2018 b$ & Diomede & Bone/Joint & $\begin{array}{l}\text { Co-injected (e.g. EV + } \\
\text { MSCs into animals), } \\
\text { Modified (EVs directly) }\end{array}$ & Co-treatment & Cells & $\begin{array}{l}\text { Human gingival } \\
\text { MSCs }\end{array}$ & N/A & N/A & & & & Enhancement & Unclear & $N / A$ & $N / A$ \\
\hline 2018a & Chen & Liver & $\begin{array}{l}\text { Modified (MSCs before } \\
\text { EV isolation) }\end{array}$ & $\begin{array}{c}\mathrm{MSC} \\
\text { transduction }\end{array}$ & miRNA & pre-miR-223 & Overexpression & Inflammation & Apoptosis & & & Enhancement & $\begin{array}{l}\text { All In Vivo } \\
\text { outcomes }\end{array}$ & Yes & N/A \\
\hline $2018 b$ & Chen & Liver & $\begin{array}{l}\text { Modified (MSCs before } \\
\text { EV isolation) }\end{array}$ & MSC transfection & miRNA & miR-223 inhibitor & Knockdown & Inflammation & Apoptosis & & & $\begin{array}{c}\text { Mechanism of } \\
\text { action }\end{array}$ & N/A & N/A & $N / A$ \\
\hline 2018a & Kou & Diabetes, Wound & $\begin{array}{l}\text { Modified (MSCs before } \\
\text { EV isolation) }\end{array}$ & $\begin{array}{c}\text { KO animal model } \\
+ \text { MSCs derived } \\
\text { from KO animal } \\
\text { model }\end{array}$ & $\begin{array}{l}\text { Anti- } \\
\text { inflammatory } \\
\text { cytokine }\end{array}$ & $\begin{array}{l}\text { IL-1RA (IL-1 receptor } \\
\text { antagonist) }\end{array}$ & $\begin{array}{c}\text { Inhibitor / } \\
\text { Neutraliznig AB }\end{array}$ & Inflammation & & & & $\begin{array}{l}\text { Mechanism of } \\
\text { action }\end{array}$ & N/A & N/A & N/A \\
\hline $2018 b$ & Kou & Diabetes, Wound & $\begin{array}{l}\text { Modified (MSCs before } \\
\text { EV isolation) }\end{array}$ & $\begin{array}{c}\text { MSC } \\
\text { preconditioning }\end{array}$ & $\begin{array}{l}\text { Inflammatory } \\
\text { cytokine }\end{array}$ & TNF- $\alpha$ & N/A & Inflammation & Regeneration & & & Enhancement & $\begin{array}{l}\text { All In Vivo } \\
\text { outcomes }\end{array}$ & Yes & N/A \\
\hline $2018 c$ & Kou & Diabetes, Wound & $\begin{array}{l}\text { Modified (MSCs before } \\
\text { EV isolation) }\end{array}$ & $\begin{array}{l}\text { MSCs derived } \\
\text { from KO animal } \\
\text { model }\end{array}$ & $\begin{array}{l}\text { Anti- } \\
\text { inflammatory } \\
\text { cytokine }\end{array}$ & $\begin{array}{l}\text { IL-1RA (IL-1 receptor } \\
\text { antagonist) }\end{array}$ & $\begin{array}{c}\text { Inhibitor / } \\
\text { Neutraliznig AB }\end{array}$ & Inflammation & & & & $\begin{array}{l}\text { Mechanism of } \\
\text { action }\end{array}$ & N/A & N/A & $N / A$ \\
\hline
\end{tabular}




\section{Supplemental File 5-PRISMA Checklist}

\begin{tabular}{|c|c|c|c|}
\hline Section/topic & $\#$ & Checklist item & $\begin{array}{l}\text { Reported on } \\
\text { page \# }\end{array}$ \\
\hline \multicolumn{4}{|l|}{ TITLE } \\
\hline Title & 1 & Identify the report as a systematic review, meta-analysis, or both. & $\mathrm{N} / \mathrm{A}$ \\
\hline \multicolumn{4}{|l|}{ ABSTRACT } \\
\hline Structured summary & 2 & $\begin{array}{l}\text { Provide a structured summary including, as applicable: background; objectives; data sources; study eligibility } \\
\text { criteria, participants, and interventions; study appraisal and synthesis methods; results; limitations; conclusions } \\
\text { and implications of key findings; systematic review registration number. }\end{array}$ & Page 2 \\
\hline \multicolumn{4}{|l|}{ INTRODUCTION } \\
\hline Rationale & 3 & Describe the rationale for the review in the context of what is already known. & Page 3-5 \\
\hline Objectives & 4 & $\begin{array}{l}\text { Provide an explicit statement of questions being addressed with reference to participants, interventions, } \\
\text { comparisons, outcomes, and study design (PICOS). }\end{array}$ & Pages 5 \\
\hline \multicolumn{4}{|l|}{ METHODS } \\
\hline Protocol and registration & 5 & $\begin{array}{l}\text { Indicate if a review protocol exists, if and where it can be accessed (e.g. Web address), and, if available, provide } \\
\text { registration information including registration number. }\end{array}$ & Page 22-23 \\
\hline Eligibility criteria & 6 & $\begin{array}{l}\text { Specify study characteristics (e.g. PICOS, length of follow-up) and report characteristics (e.g. years considered, } \\
\text { language, publication status) used as criteria for eligibility, giving rationale. }\end{array}$ & Page 23-24 \\
\hline Information sources & 7 & $\begin{array}{l}\text { Describe all information sources (e.g. databases with dates of coverage, contact with study authors to identify } \\
\text { additional studies) in the search and date last searched. }\end{array}$ & Page 24 \\
\hline Search & 8 & $\begin{array}{l}\text { Present full electronic search strategy for at least one database, including any limits used, such that it could be } \\
\text { repeated. }\end{array}$ & $\begin{array}{l}\text { Page 24, } \\
\text { Suppl. File } 7\end{array}$ \\
\hline Study selection & 9 & $\begin{array}{l}\text { State the process for selecting studies (i.e., screening, eligibility, included in systematic review, and, if applicable, } \\
\text { included in the meta-analysis). }\end{array}$ & Pages 24 \\
\hline Data collection process & 10 & $\begin{array}{l}\text { Describe method of data extraction from reports (e.g. piloted forms, independently, in duplicate) and any } \\
\text { processes for obtaining and confirming data from investigators. }\end{array}$ & Pages 25-27 \\
\hline Data items & 11 & $\begin{array}{l}\text { List and define all variables for which data were sought (e.g. PICOS, funding sources) and any assumptions and } \\
\text { simplifications made. }\end{array}$ & Pages 25-27 \\
\hline $\begin{array}{l}\text { Risk of bias in individual } \\
\text { studies }\end{array}$ & 12 & $\begin{array}{l}\text { Describe methods used for assessing risk of bias of individual studies (including specification of whether this was } \\
\text { done at the study or outcome level), and how this information is to be used in any data synthesis. }\end{array}$ & $\mathrm{N} / \mathrm{A}$ \\
\hline Summary measures & 13 & State the principal summary measures (e.g. risk ratio, difference in means). & Page 26-27 \\
\hline Synthesis of results & 14 & $\begin{array}{l}\text { Describe the methods of handling data and combining results of studies, if done, including measures of } \\
\text { consistency }\left(e . g .\left.\right|^{2}\right) \text { for each meta-analysis. }\end{array}$ & Page 26-27 \\
\hline
\end{tabular}




\begin{tabular}{|c|c|c|c|}
\hline Section/topic & $\#$ & Checklist item & $\begin{array}{l}\text { Reported } \\
\text { on page \# }\end{array}$ \\
\hline Risk of bias across studies & 15 & $\begin{array}{l}\text { Specify any assessment of risk of bias that may affect the cumulative evidence (e.g. publication bias, selective } \\
\text { reporting within studies). }\end{array}$ & $\mathrm{N} / \mathrm{A}$ \\
\hline Additional analyses & 16 & $\begin{array}{l}\text { Describe methods of additional analyses (e.g. sensitivity or subgroup analyses, meta-regression), if done, } \\
\text { indicating which were pre-specified. }\end{array}$ & Page 26-27 \\
\hline \multicolumn{4}{|l|}{ RESULTS } \\
\hline Study selection & 17 & $\begin{array}{l}\text { Give numbers of studies screened, assessed for eligibility, and included in the review, with reasons for exclusions } \\
\text { at each stage, ideally with a flow diagram. }\end{array}$ & Page 6 \\
\hline Study characteristics & 18 & $\begin{array}{l}\text { For each study, present characteristics for which data were extracted (e.g. study size, PICOS, follow-up period) } \\
\text { and provide the citations. }\end{array}$ & $\begin{array}{l}\text { Page 6, } \\
\text { Suppl. Files } \\
1-5\end{array}$ \\
\hline Risk of bias within studies & 19 & Present data on risk of bias of each study and, if available, any outcome level assessment (see item 12). & $\mathrm{N} / \mathrm{A}$ \\
\hline Results of individual studies & 20 & $\begin{array}{l}\text { For all outcomes considered (benefits or harms), present, for each study: (a) simple summary data for each } \\
\text { intervention group (b) effect estimates and confidence intervals, ideally with a forest plot. }\end{array}$ & $\begin{array}{l}\text { Pages 6-20, } \\
\text { Suppl. Files } \\
2-5\end{array}$ \\
\hline Synthesis of results & 21 & Present results of each meta-analysis done, including confidence intervals and measures of consistency. & Pages 6-20 \\
\hline Risk of bias across studies & 22 & Present results of any assessment of risk of bias across studies (see Item 15). & N/A \\
\hline Additional analysis & 23 & Give results of additional analyses, if done (e.g. sensitivity or subgroup analyses, meta-regression [see Item 16]). & Pages 6-20 \\
\hline \multicolumn{4}{|l|}{ DISCUSSION } \\
\hline Summary of evidence & 24 & $\begin{array}{l}\text { Summarize the main findings including the strength of evidence for each main outcome; consider their relevance } \\
\text { to key groups (e.g. healthcare providers, users, and policy makers). }\end{array}$ & Page 6-20 \\
\hline Limitations & 25 & $\begin{array}{l}\text { Discuss limitations at study and outcome level (e.g. risk of bias), and at review-level (e.g. incomplete retrieval of } \\
\text { identified research, reporting bias). }\end{array}$ & Page 20 \\
\hline Conclusions & 26 & Provide a general interpretation of the results in the context of other evidence, and implications for future research. & Pages 20-22 \\
\hline \multicolumn{4}{|l|}{ FUNDING } \\
\hline Funding & 27 & $\begin{array}{l}\text { Describe sources of funding for the systematic review and other support (e.g. supply of data); role of funders for } \\
\text { the systematic review. }\end{array}$ & Page 28 \\
\hline
\end{tabular}

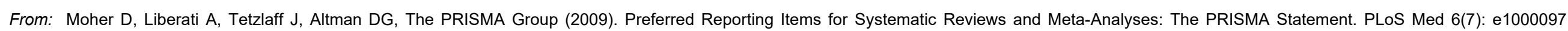
doi:10.1371/journal.pmed1000097

For more information, visit: www.prisma-statement.org. 


\section{Supplemental File 6 - Search Strategy}

Database: Ovid MEDLINE(R) ALL Search Strategy:

1 Mesenchymal Stromal Cells/

2 Mesenchymal Stem Cell Transplantation/

3 Multipotent Stem Cells/

4 (MSC or MSCs or ADMSC or ADMSCs or BM-MSC or BM-MSCs or BMD-MSC or BMDMSCs or BMDMSC or BMDMSCs).tw,kw.

5 (mesenchymal adj5 (cell* or stem or stromal or progenitor* or multipotent or bone marrow or adipose or placenta*)).tw.

6 (mesenchymal and (cell* or stem or stromal or progenitor or multipotent or bone marrow or adipose or placenta*)).kw.

7 ((multipotent or multi-potent) adj (stroma* cell ${ }^{*}$ or stem cell $\left.\left.{ }^{\star}\right)\right) . t w$.

8 ((multipotent or multi-potent) and $\left(\right.$ stroma $^{*}$ cell $^{*}$ or stem cell $\left.\left.{ }^{*}\right)\right) . k w$.

9 (colony-forming adj2 fibroblast* ${ }^{*}$.tw.

10 marrow stroma* cell*.tw.

11 Mesoderm/cy

12 or/1-11

13 Exosomes/ or Extracellular Vesicles/

14 exosom*.tw,kw.

15 Cell-Derived Microparticles/

16 (microvesicle* or micro vesicle ${ }^{*}$ ).tw,kw.

17 ((cell or cells or extracellular) adj2 vesicle*).tw.

18 microparticle*.tw,kw.

19 ((cell or cells or extracellular) and vesicle* $). k w$.

20 or/13-19

$21 \quad 12$ and 20

22 exp "animal experimentation"/ or exp "models, animal"/ or exp "invertebrates"/ or "Animals"/ or exp "animal population groups"/ or "chordata"/ or exp "chordata, nonvertebrate"/ or "vertebrates"/ or exp "amphibians"/ or exp "birds"/ or exp "fishes"/ or exp "reptiles"/ or "mammals"/ or "primates"/ or exp "artiodactyla"/ or exp "carnivora"/ or exp "cetacea"/ or exp "chiroptera"/ or exp "elephants"/ or exp "hyraxes"/ or exp "insectivora"/ or exp "lagomorpha"/ or exp "marsupialia"/ or exp "monotremata"/ or exp "perissodactyla"/ or exp "rodentia"/ or exp "scandentia"/ or exp "sirenia"/ or exp "xenarthra"/ or "haplorhini"/ or exp "strepsirhini"/ or exp "platyrrhini"/ or exp "tarsii"/ or "catarrhini"/ or exp "cercopithecidae"/ or exp "hylobatidae"/ or "hominidae"/ or exp "gorilla gorilla"/ or exp "pan paniscus"/ or exp "pan troglodytes"/ or exp "pongo pygmaeus"/ (6252795) 23 (animals or animal or mice or mus or mouse or murine or woodmouse or rats or rat or murinae or muridae or cottonrat or cottonrats or hamster or hamsters or cricetinae or rodentia or rodent or rodents or pigs or pig or swine or swines or piglets or piglet or boar or boars or "sus scrofa" or ferrets or ferret or polecat or polecats or "mustela putorius" or "guinea pigs" or "guinea pig" or cavia or callithrix or marmoset or marmosets or cebuella or hapale or octodon or chinchilla or chinchillas or gerbillinae or gerbil or gerbils or jird or jirds or merione or meriones or rabbits or rabbit or hares or hare or diptera or flies or fly or dipteral or drosphila or drosophilidae or cats or cat or carus or felis or nematoda or nematode or nematoda or nematode or nematodes or sipunculida or dogs or dog or canine or canines or canis or sheep or sheeps or mouflon or mouflons or ovis or goats or goat or capra or capras or rupicapra or chamois or haplorhini or monkey or monkeys or anthropoidea or anthropoids or saguinus or tamarin or tamarins or leontopithecus or hominidae or ape or apes or pan or paniscus or "pan paniscus" or bonobo or bonobos or troglodytes or "pan troglodytes" or gibbon or gibbons or siamang or siamangs or 
nomascus or symphalangus or chimpanzee or chimpanzees or prosimians or "bush baby" or prosimian or bush babies or galagos or galago or pongidae or gorilla or gorillas or pongo or pygmaeus or "pongo pygmaeus" or orangutans or pygmaeus or lemur or lemurs or lemuridae or horse or horses or pongo or equus or cow or calf or bull or chicken or chickens or gallus or quail or bird or birds or quails or poultry or poultries or fowl or fowls or reptile or reptilia or reptiles or snakes or snake or lizard or lizards or alligator or alligators or crocodile or crocodiles or turtle or turtles or amphibian or amphibians or amphibia or frog or frogs or bombina or salientia or toad or toads or "epidalea calamita" or salamander or salamanders or eel or eels or fish or fishes or pisces or catfish or catfishes or siluriformes or arius or heteropneustes or sheatfish or perch or perches or percidae or perca or trout or trouts or char or chars or salvelinus or "fathead minnow" or minnow or cyprinidae or carps or carp or zebrafish or zebrafishes or goldfish or goldfishes or guppy or guppies or chub or chubs or tinca or barbels or barbus or pimephales or promelas or "poecilia reticulata" or mullet or mullets or seahorse or seahorses or mugil curema or atlantic cod or shark or sharks or catshark or anguilla or salmonid or salmonids or whitefish or whitefishes or salmon or salmons or sole or solea or "sea lamprey" or lamprey or lampreys or pumpkinseed or sunfish or sunfishes or tilapia or tilapias or turbot or turbots or flatfish or flatfishes or sciuridae or squirrel or squirrels or chipmunk or chipmunks or suslik or susliks or vole or voles or lemming or lemmings or muskrat or muskrats or lemmus or otter or otters or marten or martens or martes or weasel or badger or badgers or ermine or mink or minks or sable or sables or gulo or gulos or wolverine or wolverines or minks or mustela or llama or llamas or alpaca or alpacas or camelid or camelids or guanaco or guanacos or chiroptera or chiropteras or bat or bats or fox or foxes or iguana or iguanas or xenopus laevis or parakeet or parakeets or parrot or parrots or donkey or donkeys or mule or mules or zebra or zebras or shrew or shrews or bison or bisons or buffalo or buffaloes or deer or deers or bear or bears or panda or pandas or "wild hog" or "wild boar" or fitchew or fitch or beaver or beavers or jerboa or jerboas or capybara or capybaras).tw.

24 Drug Evaluation, Preclinical/

25 (preclinic* or pre clinic*).tw,kw.

2622 or 23 or 24 or 25

$27 \quad 21$ and 26

Database: Embase Classic+Embase Search Strategy:

1 exp mesenchymal stem cell/

2 exp mesenchymal stem cell transplantation/

3 exp mesenchymal stroma cell/

4 (MSC or MSCs or ADMSC or ADMSCs or BM-MSC or BM-MSCs or BMD-MSC or BMDMSCs or BMDMSC or BMDMSCs or BMSC or BMSCs or HBMSC or HBMSCs or ABMSC or ABMSCs or MAPC or MAPCs).tw.

$5 \quad\left(\left(\left(\right.\right.\right.$ multipotent or multi-potent) adj3 (stem or stroma $\$ 1$ or progenitor* $\left.{ }^{*}\right)$ and (cell\$1 or cellinduced)).tw.

6 multipotent stem cell/

7 (mesenchymal adj5 (cell* or stem or stroma* or progenitor* or multipotent or bone marrow or adipose or placenta*)).tw.

8 (colony-forming adj2 fibroblast $\left.{ }^{*}\right)$.tw.

9 (marrow stroma* adj2 cell*).tw. 


\begin{abstract}
10 or $/ 1-9$
11 exosome/

12 exosom*.tw.

13 (microvesicle* or micro vesicle*).tw.

14 microparticle*.tw.

15 ((cell or cells or extracellular) adj2 vesicle*).tw.

16 exp membrane microparticle/

17 or/11-16

$18 \quad 10$ and 17

19 exp animal experiment/ or exp animal model/ or exp experimental animal/ or exp transgenic animal/ or exp male animal/ or exp female animal/ or exp juvenile animal/ or animal/ or chordata/ or vertebrate/

20 tetrapod/ or exp fish/ or amniote/ or exp amphibia/ or mammal/ or exp reptile/ or exp sauropsid/ or therian/ or exp monotremate/ or placental mammals/ or exp marsupial/ or Euarchontoglires/ or exp Afrotheria/ or exp Boreoeutheria/ or exp Laurasiatheria/ or exp Xenarthra/ or primate/ or exp Dermoptera/ or exp Glires/ or exp Scandentia/ or Haplorhini/ or exp prosimian/ or simian/ or exp tarsiiform/ or Catarrhini/ or exp Platyrrhini/ or ape/ or exp Cercopithecidae/ or hominid/ or exp hylobatidae/ or exp chimpanzee/ or exp gorilla/ or exp orang utan/
\end{abstract}

21 (preclinic* or pre clinic*).tw.

22 (animal or animals or pisces or fish or fishes or catfish or catfishes or sheatfish or silurus or arius or heteropneustes or clarias or gariepinus or fathead minnow or fathead minnows or pimephales or promelas or cichlidae or trout or trouts or char or chars or salvelinus or salmo or oncorhynchus or guppy or guppies or millionfish or poecilia or goldfish or goldfishes or carassius or auratus or mullet or mullets or mugil or curema or shark or sharks or cod or cods or gadus or morhua or carp or carps or cyprinus or carpio or killifish or eel or eels or anguilla or zander or sander or lucioperca or stizostedion or turbot or turbots or psetta or flatfish or flatfishes or plaice or pleuronectes or platessa or tilapia or tilapias).tw.

23 (oreochromis or sarotherodon or common sole or dover sole or solea or zebrafish or zebrafishes or danio or rerio or seabass or dicentrarchus or labrax or morone or lamprey or lampreys or petromyzon or pumpkinseed or pumpkinseeds or lepomis or gibbosus or herring or clupea or harengus or amphibia or amphibian or amphibians or anura or salientia or frog or frogs or rana or toad or toads or bufo or xenopus or laevis or bombina or epidalea or calamita or salamander or salamanders or newt or newts or triturus or reptilia or reptile or reptiles or bearded dragon or pogona or vitticeps or iguana or iguanas or lizard).tw.

24 (lizards or anguis fragilis or turtle or turtles or snakes or snake or aves or bird or birds or quail or quails or coturnix or bobwhite or colinus or virginianus or poultry or poultries or fowl or fowls or chicken or chickens or gallus or zebra finch or taeniopygia or guttata or canary or canaries or serinus or canaria or parakeet or parakeets or grasskeet or parrot or parrots or psittacine or psittacines or shelduck or tadorna or goose or geese or branta or leucopsis or woodlark or lullula or flycatcher or ficedula or hypoleuca or dove or doves or geopelia or cuneata or duck or ducks or greylag or graylag or anser or harrier or circus pygargus or red knot or great knot or calidris or canutus or godwit or limosa or lapponica or meleagris or gallopavo or jackdaw or corvus or monedula or ruff or philomachus or pugnax or lapwing or peewit or plover or vanellus or swan or cygnus or columbianus or bewickii or gull or chroicocephalus or ridibundus).tw.

25 (albifrons or great tit or parus or aythya or fuligula or streptopelia or risoria or spoonbill or platalea or leucorodia or blackbird or turdus or merula or blue tit or cyanistes or pigeon or pigeons or columba or pintail or anas or starling or sturnus or owl or athene noctua or pochard or ferina or cockatiel or nymphicus or hollandicus or skylark or alauda or tern or sterna or teal or crecca or oystercatcher or haematopus or ostralegus or shrew or shrews or sorex or araneus or crocidura or russula or european mole or talpa or chiroptera or bat or bats or eptesicus or serotinus or 
myotis or dasycneme or daubentonii or pipistrelle or pipistrellus or cat or cats or felis or catus or feline or dog or dogs or canis or canine or canines or otter or otters or lutra or badger or badgers or meles or fitchew or fitch or foumart or foulmart or ferrets or ferret or polecat or polecats or mustela or putorius or weasel or weasels or fox or foxes or vulpes or common seal or phoca or vitulina or grey seal or halichoerus or horse or horses or equus or equine or equidae or donkey or donkeys or mule or mules or pig or pigs or swine or swines or hog or hogs or boar or boars or porcine or piglet or piglets or sus or scrofa or llama or llamas or lama or glama or deer or deers or cervus or elaphus or cow or cows or bos taurus or bos indicus or bovine or bull or bulls).tw.

26 (cattle or bison or bisons or sheep or sheeps or ovis aries or ovine or lamb or lambs or mouflon or mouflons or goat or goats or capra or caprine or chamois or rupicapra or leporidae or lagomorpha or lagomorph or rabbit or rabbits or oryctolagus or cuniculus or laprine or hares or lepus or rodentia or rodent or rodents or murinae or mouse or mice or mus or musculus or murine or woodmouse or apodemus or rat or rats or rattus or norvegicus or guinea pig or guinea pigs or cavia or porcellus or hamster or hamsters or mesocricetus or cricetulus or cricetus or gerbil or gerbils or jird or jirds or meriones or unguiculatus or jerboa or jerboas or jaculus or chinchilla or chinchillas or beaver or beavers or castor fiber or castor canadensis or sciuridae or squirrel or squirrels or sciurus or chipmunk or chipmunks or marmot or marmots or marmota or suslik or susliks or spermophilus or cynomys or cottonrat or cottonrats or sigmodon or vole or voles or microtus or myodes or glareolus or primate).tw.

27 (primates or prosimian or prosimians or lemur or lemurs or lemuridae or loris or bush baby or bush babies or bushbaby or bushbabies or galago or galagos or anthropoidea or anthropoids or simian or simians or monkey or monkeys or marmoset or marmosets or callithrix or cebuella or tamarin or tamarins or saguinus or leontopithecus or squirrel monkey or squirrel monkeys or saimiri or night monkey or night monkeys or owl monkey or owl monkeys or douroucoulis or aotus or spider monkey or spider monkeys or ateles or baboon or baboons or papio or rhesus monkey or macaque or macaca or mulatta or cynomolgus or fascicularis or green monkey or green monkeys or chlorocebus or vervet or vervets or pygerythrus or hominoidea or ape or apes or hylobatidae or gibbon or gibbons or siamang or siamangs or nomascus or symphalangus or hominidae or orangutan or orangutans or pongo or chimpanzee or chimpanzees or pan troglodytes or bonobo or bonobos or pan paniscus or gorilla or gorillas or troglodytes).tw.

28 or/19-27

$29 \quad 18$ and 28

30 conference abstract.pt.

3129 not 30 


\section{Supplemental File 7 - Reference List for 206 Included Studies}

1. Ahn, S. Y.; Park, W. S.; Kim, Y. E.; Sung, D. K.; Sung, S. I.; Ahn, J. Y.; Chang, Y. S., Vascular Endothelial Growth Factor Mediates the Therapeutic Efficacy of Mesenchymal Stem Cell-Derived Extracellular Vesicles against Neonatal Hyperoxic Lung Injury. Exp. Mol. Med. 2018, 50, 1-12.

2. Aliotta, J. M.; Pereira, M.; Wen, S.; Dooner, M. S.; Tatto, M. D.; Papa, E.; Cheng, Y.; Goldberg, L.; Ventetuolo, C. E.; Liang, O.; Klinger, J. R.; Quesenberry, P. J., Bone Marrow Endothelial Progenitor Cells Are the Cellular Mediators of Pulmonary Hypertension in the Murine Monocrotaline Injury Model. Stem Cells Transl. Med. 2017, 6, 1595-1606.

3. $\quad$ Aliotta, J. M.; Pereira, M.; Wen, S.; Dooner, M. S.; Tatto, M. D.; Papa, E.; Goldberg, L. R.; Baird, G. L.; Ventetuolo, C. E.; Quesenberry, P. J.; Klinger, J. R., Exosomes Induce and Reverse Monocrotaline-Induced Pulmonary Hypertension in Mice. Cardiovasc. Res. 2016, 110, 319-330.

4. Almeida, D. C. d.; Bassi, E. J.; Azevedo, H.; Anderson, L.; Origassa, C. S. T.; Cenedeze, M. A.; Andrade-Oliveira, V. d.; Felizardo, R. J. F.; Silva, R. C. d.; Hiyane, M. I.; Semedo, P.; Reis, M. A.; Moreira-Filho, C. A.; Verjovski-Almeida, S.; Pacheco-Silva, A.; Camara, N. O. S., A Regulatory miRNA-mRNA Network Is Associated with Tissue Repair Induced by Mesenchymal Stromal Cells in Acute Kidney Injury. Front. Immunol. 2017, 7.

5. $\quad$ Arslan, F.; Lai, R. C.; Smeets, M. B.; Akeroyd, L.; Choo, A.; Aguor, E. N.; Timmers, L.; Rijen, H. V. v.; Doevendans, P. A.; Pasterkamp, G.; Lim, S. K.; Kleijn, D. P. d., Mesenchymal Stem Cell-Derived Exosomes Increase Atp Levels, Decrease Oxidative Stress and Activate Pi3k/Akt Pathway to Enhance Myocardial Viability and Prevent Adverse Remodeling after Myocardial Ischemia/Reperfusion Injury. Stem Cell Res. 2013, 10, 301-312.

6. Bai, L.; Shao, H.; Wang, H.; Zhang, Z.; Su, C.; Dong, L.; Yu, B.; Chen, X.; Li, X.; Zhang, $X .$, Effects of Mesenchymal Stem Cell-Derived Exosomes on Experimental Autoimmune Uveitis. Sci. Rep. 2017, 7, 1-11.

7. Barile, L.; Cervio, E.; Lionetti, V.; Milano, G.; Ciullo, A.; Biemmi, V.; Bolis, S.; Altomare, C.; Matteucci, M.; Disilvestre, D.; Fertig, T. E.; Torre, T.; Demertzis, S.; Mauri, P.; Moccetti, T.; Vassalli, G., Cardioprotection by Cardiac Progenitor Cell-Secreted Exosomes:Role of Pregnancy-Associated Plasma Protein-A. Cardiovasc. Res. 2018, 114, 992-1005.

8. Bian, S.; Zhang, L.; Duan, L.; Wang, X.; Min, Y.; Yu, H., Extracellular Vesicles Derived from Human Bone Marrow Mesenchymal Stem Cells Promote Angiogenesis in a Rat Myocardial Infarction Model. J. Mol. Med. 2014, 92, 387-397.

9. Blazquez, R.; Sanchez-Margallo, F. M.; Alvarez, V.; Uson, A.; Marinaro, F.; Casado, J. G., Fibrin Glue Mesh Fixation Combined with Mesenchymal Stem Cells or Exosomes Modulates the Inflammatory Reaction in a Murine Model of Incisional Hernia. Acta Biomater. 2018, 71, 318-329.

10. Brien, K. P. O.; Khan, S.; Gilligan, K. E.; Zafar, H.; Lalor, P.; Glynn, C.; Flatharta, C. O.; Ingoldsby, H.; Dockery, P.; Bhulbh, A. D.; Schweber, J. R.; John, K. S.; Leahy, M.; Murphy, J. M.; Gallagher, W. M.; Brien, T. O.; Kerin, M. J.; Dwyer, R. M., Employing Mesenchymal Stem Cells to Support Tumor-Targeted Delivery of Extracellular Vesicle (EV)Encapsulated microRNA-379. Oncogene 2018, 37, 2137-2149.

11. Bruno, S.; Collino, F.; Deregibus, M. C.; Grange, C.; Tetta, C.; Camussi, G., Microvesicles Derived from Human Bone Marrow Mesenchymal Stem Cells Inhibit Tumor Growth. Stem Cells Dev. 2013, 22, 758-771.

12. Bruno, S.; Grange, C.; Collino, F.; Deregibus, M. C.; Cantaluppi, V.; Biancone, L.; Tetta, C.; Camussi, G., Microvesicles Derived from Mesenchymal Stem Cells Enhance Survival in a Lethal Model of Acute Kidney Injury. PLoS One 2012, 7, e33115. 
13. Bruno, S.; Grange, C.; Deregibus, M. C.; Calogero, R. A.; Saviozzi, S.; Collino, F.; Morando, L.; Busca, A.; Falda, M.; Bussolati, B.; Tetta, C.; Camussi, G., Mesenchymal Stem Cell-Derived Microvesicles Protect against Acute Tubular Injury. J. Am. Soc. Nephrol. 2009, 20, 1053-1067.

14. Bruno, S.; Tapparo, M.; Collino, F.; Chiabotto, G.; Deregibus, M. C.; Lindoso, R. S.; Neri, F.; Kholia, S.; Giunti, S.; Wen, S.; Quesenberry, P.; Camussi, G., Renal Regenerative Potential of Different Extracellular Vesicle Populations Derived from Bone Marrow Mesenchymal Stromal Cells. Tissue Eng., Part A 2017, 23, 1262-1273.

15. Casado, J. G.; Blazquez, R.; Vela, F. J.; Alvarez, V.; Tarazona, R.; Sanchez-Margallo, F. M., Mesenchymal Stem Cell-Derived Exosomes: Immunomodulatory Evaluation in an Antigen-Induced Synovitis Porcine Model. Front. Vet. Sci. 2017, 4, 39.

16. Castro, L. L. d.; Xisto, D. G.; Kitoko, J. Z.; Cruz, F. F.; Olsen, P. C.; Redondo, P. A. G.; Ferreira, T. P. T.; Weiss, D. J.; Martins, M. A.; Morales, M. M.; Rocco, P. R. M., Human Adipose Tissue Mesenchymal Stromal Cells and Their Extracellular Vesicles Act Differentially on Lung Mechanics and Inflammation in Experimental Allergic Asthma. Stem Cell. Res. Ther. 2017, 8, 1-12.

17. Chang, C. L.; Sung, P. H.; Chen, K. H.; Shao, P. L.; Yang, C. C.; Cheng, B. C.; Lin, K. C.; Chen, C. H.; Chai, H. T.; Chang, H. W.; Yip, H. K.; Chen, H. H., Adipose-Derived Mesenchymal Stem Cell-Derived Exosomes Alleviate Overwhelming Systemic Inflammatory Reaction and Organ Damage and Improve Outcome in Rat Sepsis Syndrome. Am. J. Transl. Res. 2018, 10, 1053-1070.

18. Chen, C. Y.; Rao, S. S.; Ren, L.; Hu, X. K.; Tan, Y. J.; Hu, Y.; Luo, J.; Liu, Y. W.; Yin, H.; Huang, J.; Cao, J.; Wang, Z. X.; Liu, Z. Z.; Liu, H. M.; Tang, S. Y.; Xu, R.; Xie, H., Exosomal Dmbt1 from Human Urine-Derived Stem Cells Facilitates Diabetic Wound Repair by Promoting Angiogenesis. Theranostics 2018, 8, 1607-1623.

19. Chen, J. Y.; An, R.; Liu, Z. J.; Wang, J. J.; Chen, S. Z.; Hong, M. M.; Liu, J. H.; Xiao, M. Y.; Chen, Y. F., Therapeutic Effects of Mesenchymal Stem Cell-Derived Microvesicles on Pulmonary Arterial Hypertension in Rats. Acta Pharmacol. Sin. 2014, 35, 1121-1128.

20. Chen, K. H.; Chen, C. H.; Wallace, C. G.; Yuen, C. M.; Kao, G. S.; Chen, Y. L.; Shao, P. L.; Chen, Y. L.; Chai, H. T.; Lin, K. C.; Liu, C. F.; Chang, H. W.; Lee, M. S.; Yip, H. K., Intravenous Administration of Xenogenic Adipose-Derived Mesenchymal Stem Cells (ADMSC) and ADMSC-Derived Exosomes Markedly Reduced Brain Infarct Volume and Preserved Neurological Function in Rat after Acute Ischemic Stroke. Oncotarget 2016, 7, 74537-74556.

21. Chen, L.; Lu, F. B.; Chen, D. Z.; Wu, J. L.; Hu, E. D.; Xu, L. M.; Zheng, M. H.; Li, H.; Huang, Y.; Jin, X. Y.; Gong, Y. W.; Lin, Z.; Wang, X. D.; Chen, Y. P., BMSCs-Derived miR-223Containing Exosomes Contribute to Liver Protection in Experimental Autoimmune Hepatitis. Mol. Immunol. 2018, 93, 38-46.

22. Chen, L.; Xiang, B.; Wang, X.; Xiang, C., Exosomes Derived from Human Menstrual Blood-Derived Stem Cells Alleviate Fulminant Hepatic Failure. Stem Cell. Res. Ther. 2017, 8, 1-15.

23. Chen, T. S.; Arslan, F.; Yin, Y.; Tan, S. S.; Lai, R. C.; Choo, A. B.; Padmanabhan, J.; Lee, C. N.; Kleijn, D. P. d.; Lim, S. K., Enabling a Robust Scalable Manufacturing Process for Therapeutic Exosomes through Oncogenic Immortalization of Human ESC-Derived MSCs. J. Transl. Med. 2011, 9, 1-10.

24. Chen, W.; Yan, Y.; Song, C.; Ding, Y.; Du, T., Microvesicles Derived from Human Wharton's Jelly Mesenchymal Stem Cells Ameliorate Ischemia-Reperfusion-Induced Renal Fibrosis by Releasing from G2/M Cell Cycle Arrest. Biochem. J. 2017, 474, 42074218.

25. Cheng, X.; Zhang, G.; Zhang, L.; Hu, Y.; Zhang, K.; Sun, X.; Zhao, C.; Li, H.; Li, Y. M.; Zhao, J., Mesenchymal Stem Cells Deliver Exogenous miR-21 via Exosomes to Inhibit 
Nucleus Pulposus Cell Apoptosis and Reduce Intervertebral Disc Degeneration. J. Cell. Mol. Med. 2018, 22, 261-276.

26. Choi, H. Y.; Lee, H. G.; Kim, B. S.; Ahn, S. H.; Jung, A.; Lee, M.; Lee, J. E.; Kim, H. J.; Ha, S. K.; Park, H. C., Mesenchymal Stem Cell-Derived Microparticles Ameliorate Peritubular Capillary Rarefaction via Inhibition of Endothelial-Mesenchymal Transition and Decrease Tubulointerstitial Fibrosis in Unilateral Ureteral Obstruction. Stem Cell. Res. Ther. 2015, 6, 18.

27. Choi, H. Y.; Moon, S. J.; Ratliff, B. B.; Ahn, S. H.; Jung, A.; Lee, M.; Lee, S.; Lim, B. J.; Kim, B. S.; Plotkin, M. D., Microparticles from Kidney-Derived Mesenchymal Stem Cells Act as Carriers of Proangiogenic Signals and Contribute to Recovery from Acute Kidney Injury. PLoS One 2014, 9, e87853.

28. Choi, M.; Ban, T.; Rhim, T., Therapeutic Use of Stem Cell Transplantation for Cell Replacement or Cytoprotective Effect of Microvesicle Released from Mesenchymal Stem Cell. Mol. Cells 2014, 37, 133-139.

29. Collino, F.; Bruno, S.; Incarnato, D.; Dettori, D.; Neri, F.; Provero, P.; Pomatto, M.; Oliviero, S.; Tetta, C.; Quesenberry, P. J.; Camussi, G., AKI Recovery Induced by Mesenchymal Stromal Cell-Derived Extracellular Vesicles Carrying microRNAs. J. Am. Soc. Nephrol. 2015, 26, 2349-2360.

30. Cosenza, S.; Ruiz, M.; Toupet, K.; Jorgensen, C.; Noel, D., Mesenchymal Stem Cells Derived Exosomes and Microparticles Protect Cartilage and Bone from Degradation in Osteoarthritis. Sci. Rep. 2017, 7, 1-12.

31. Cosenza, S.; Toupet, K.; Maumus, M.; Luz-Crawford, P.; Blanc-Brude, O.; Jorgensen, C.; Noel, D., Mesenchymal Stem Cells-Derived Exosomes Are More Immunosuppressive Than Microparticles in Inflammatory Arthritis. Theranostics 2018, 8, 1399-1410.

32. Cruz, F. F.; Borg, Z. D.; Goodwin, M.; Sokocevic, D.; Wagner, D. E.; Coffey, A.; Antunes, M.; Robinson, K. L.; Mitsialis, S. A.; Kourembanas, S.; Thane, K.; Hoffman, A. M.; McKenna, D. H.; Rocco, P. R.; Weiss, D. J., Systemic Administration of Human Bone Marrow-Derived Mesenchymal Stromal Cell Extracellular Vesicles Ameliorates Aspergillus Hyphal Extract-Induced Allergic Airway Inflammation in Immunocompetent Mice. Stem Cells Transl. Med. 2015, 4, 1302-1316.

33. Cui, G. H.; Wu, J.; Mou, F. F.; Xie, W. H.; Wang, F. B.; Wang, Q. L.; Fang, J.; Xu, Y. W.; Dong, Y. R.; Liu, J. R.; Guo, H. D., Exosomes Derived from Hypoxia-Preconditioned Mesenchymal Stromal Cells Ameliorate Cognitive Decline by Rescuing Synaptic Dysfunction and Regulating Inflammatory Responses in APP/PS1 Mice. FASEB J. 2018, 32, 654-668.

34. Cui, X.; He, Z.; Liang, Z.; Chen, Z.; Wang, H.; Zhang, J., Exosomes from Adipose-Derived Mesenchymal Stem Cells Protect the Myocardium against Ischemia/Reperfusion Injury through Wnt/B-Catenin Signaling Pathway. J. Cardiovasc. Pharmacol. 2017, 70, 225-231.

35. Damania, A.; Jaiman, D.; Teotia, A. K.; Kumar, A., Mesenchymal Stromal Cell-Derived Exosome-Rich Fractionated Secretome Confers a Hepatoprotective Effect in Liver Injury. Stem Cell. Res. Ther. 2018, 9, 1-12.

36. Deng, M.; Xiao, H.; Zhang, H.; Peng, H.; Yuan, H.; Xu, Y.; Zhang, G.; Hu, Z., Mesenchymal Stem Cell-Derived Extracellular Vesicles Ameliorates Hippocampal Synaptic Impairment after Transient Global Ischemia. Front. Cell. Neurosci. 2017, 11, 205.

37. Diomede, F.; Gugliandolo, A.; Cardelli, P.; Merciaro, I.; Ettorre, V.; Traini, T.; Bedini, R.; Scionti, D.; Bramanti, A.; Nanci, A.; Caputi, S.; Fontana, A.; Mazzon, E.; Trubiani, O., Three-Dimensional Printed PLA Scaffold and Human Gingival Stem Cell-Derived Extracellular Vesicles: A New Tool for Bone Defect Repair. Stem Cell. Res. Ther. 2018, 9, 104.

38. Doeppner, T. R.; Herz, J.; Gorgens, A.; Schlechter, J.; Ludwig, A. K.; Radtke, S.; Miroschedji, K. d.; Horn, P. A.; Giebel, B.; Hermann, D. M., Extracellular Vesicles Improve 
Post-Stroke Neuroregeneration and Prevent Postischemic Immunosuppression. Stem Cells Transl. Med. 2015, 4, 1131-1143.

39. Drommelschmidt, K.; Serdar, M.; Bendix, I.; Herz, J.; Bertling, F.; Prager, S.; Keller, M.; Ludwig, A. K.; Duhan, V.; Radtke, S.; Miroschedji, K. d.; Horn, P. A.; Looij, Y. v. d.; Giebel, B.; Felderhoff-Muser, U., Mesenchymal Stem Cell-Derived Extracellular Vesicles Ameliorate Inflammation-Induced Preterm Brain Injury. Brain. Behav. Immun. 2017, 60, 220-232.

40. Du, T.; Ju, G.; Wu, S.; Cheng, Z.; Cheng, J.; Zou, X.; Zhang, G.; Miao, S.; Liu, G.; Zhu, Y., Microvesicles Derived from Human Wharton's Jelly Mesenchymal Stem Cells Promote Human Renal Cancer Cell Growth and Aggressiveness through Induction of Hepatocyte Growth Factor. PLoS One 2014, 9, e96836.

41. Du, W.; Zhang, K.; Zhang, S.; Wang, R.; Nie, Y.; Tao, H.; Han, Z.; Liang, L.; Wang, D.; Liu, J.; Liu, N.; Han, Z.; Kong, D.; Zhao, Q.; Li, Z., Enhanced Proangiogenic Potential of Mesenchymal Stem Cell-Derived Exosomes Stimulated by a Nitric Oxide Releasing Polymer. Biomaterials 2017, 133, 70-81.

42. Du, Y.; Li, D.; Han, C.; Wu, H.; Xu, L.; Zhang, M.; Zhang, J.; Chen, X., Exosomes from Human-Induced Pluripotent Stem Cell-Derived Mesenchymal Stromal Cells (hiPSCMSCs) Protect Liver against Hepatic Ischemia/ Reperfusion Injury via Activating Sphingosine Kinase and Sphingosine-1-Phosphate Signaling Pathway. Cell. Physiol. Biochem. 2017, 43, 611-625.

43. Eirin, A.; Zhu, X. Y.; Puranik, A. S.; Tang, H.; McGurren, K. A.; Wijnen, A. J. v.; Lerman, A.; Lerman, L. O., Mesenchymal Stem Cell-Derived Extracellular Vesicles Attenuate Kidney Inflammation. Kidney Int. 2017, 92, 114-124.

44. El-Tookhy, O. S.; Shamaa, A. A.; Shehab, G. G.; Abdallah, A. N.; Azzam, O. M., Histological Evaluation of Experimentally Induced Critical Size Defect Skin Wounds Using Exosomal Solution of Mesenchymal Stem Cells Derived Microvesicles. Int. J. Stem Cells 2017, 10, 144-153.

45. Fang, S.; Xu, C.; Zhang, Y.; Xue, C.; Yang, C.; Bi, H.; Qian, X.; Wu, M.; Ji, K.; Zhao, Y.; Wang, Y.; Liu, H.; Xing, X., Umbilical Cord-Derived Mesenchymal Stem Cell-Derived Exosomal Micrornas Suppress Myofibroblast Differentiation by Inhibiting the Transforming Growth Factor-Beta/Smad2 Pathway during Wound Healing. Stem Cells Transl. Med. 2016, 5, 1425-1439.

46. Feng, Y.; Huang, W.; Wani, M.; Yu, X.; Ashraf, M., Ischemic Preconditioning Potentiates the Protective Effect of Stem Cells through Secretion of Exosomes by Targeting Mecp2 via miR-22. PLoS One 2014, 9, e88685.

47. Feng, Y.; Lu, S. H.; Wang, X.; Cui, J. J.; Li, X.; Du, W. J.; Wang, Y.; Li, J. J.; Song, B. Q.; Chen, F.; Ma, F. X.; Chi, Y.; Yang, S. G.; Han, Z. C., Biological Characteristics of Exosomes Secreted by Human Bone Marrow Mesenchymal Stem Cells. Zhongguo Shiyan Xueyexue Zazhi 2014, 22, 595-599.

48. Fujii, S.; Miura, Y.; Fujishiro, A.; Shindo, T.; Shimazu, Y.; Hirai, H.; Tahara, H.; TakaoriKondo, A.; Ichinohe, T.; Maekawa, T., Graft-versus-Host Disease Amelioration by Human Bone Marrow Mesenchymal Stromal/Stem Cell-Derived Extracellular Vesicles Is Associated with Peripheral Preservation of Naive T Cell Populations. Stem Cells 2018, 36, 434-445.

49. Furuta, T.; Miyaki, S.; Ishitobi, H.; Ogura, T.; Kato, Y.; Kamei, N.; Miyado, K.; Higashi, Y.; Ochi, M., Mesenchymal Stem Cell-Derived Exosomes Promote Fracture Healing in a Mouse Model. Stem Cells Transl. Med. 2016, 5, 1620-1630.

50. Gangadaran, P.; Rajendran, R. L.; Lee, H. W.; Kalimuthu, S.; Hong, C. M.; Jeong, S. Y.; Lee, S. W.; Lee, J.; Ahn, B. C., Extracellular Vesicles from Mesenchymal Stem Cells Activates VEGF Receptors and Accelerates Recovery of Hindlimb Ischemia. J. Controlled Release 2017, 264, 112-126. 
51. Gatti, S.; Bruno, S.; Deregibus, M. C.; Sordi, A.; Cantaluppi, V.; Tetta, C.; Camussi, G., Microvesicles Derived from Human Adult Mesenchymal Stem Cells Protect against Ischaemia-Reperfusion-Induced Acute and Chronic Kidney Injury. Nephrol., Dial., Transplant. 2011, 26, 1474-1483.

52. Geiger, A.; Walker, A.; Nissen, E., Human Fibrocyte-Derived Exosomes Accelerate Wound Healing in Genetically Diabetic Mice. Biochem. Biophys. Res. Commun. 2015, 467, 303-309.

53. Gong, M.; Yu, B.; Wang, J.; Wang, Y.; Liu, M.; Paul, C.; Millard, R. W.; Xiao, D. S.; Ashraf, M.; Xu, M., Mesenchymal Stem Cells Release Exosomes That Transfer miRNAs to Endothelial Cells and Promote Angiogenesis. Oncotarget 2017, 8, 45200-45212.

54. Gonzalez-King, H.; Garcia, N. A.; Ontoria-Oviedo, I.; Ciria, M.; Montero, J. A.; Sepulveda, P., Hypoxia Inducible Factor-1alpha Potentiates Jagged 1-Mediated Angiogenesis by Mesenchymal Stem Cell-Derived Exosomes. Stem Cells 2017, 35, 1747-1759.

55. Grigorian-Shamagian, L.; Fereydooni, S.; Liu, W.; Echavez, A.; Marban, E., Harnessing the Heart's Resistance to Malignant Tumors: Cardiacderived Extracellular Vesicles Decrease Fibrosarcoma Growth and Leukemia-Related Mortality in Rodents. Oncotarget 2017, 8, 99624-99636.

56. Gu, D.; Zou, X.; Ju, G.; Zhang, G.; Bao, E.; Zhu, Y., Mesenchymal Stromal Cells Derived Extracellular Vesicles Ameliorate Acute Renal Ischemia Reperfusion Injury by Inhibition of Mitochondrial Fission through miR-30. Stem Cells Int. 2016, 2016.

57. Gu, Z.; Zhao, X.; Yang, N.; Wang, F.; Deng, A.; Zhao, S.; Luo, L.; Wei, H.; Guan, L.; Gao, Z.; Li, Y.; Wang, L.; Liu, D.; Gao, C., Extracellular Vesicles Released from Human Umbilical Cord-Derived Mesenchymal Stromal Cells Prevent Life-Threatening Acute Graft-versus-Host Disease in a Mouse Model of Allogeneic Hematopoietic Stem Cell Transplantation. Stem Cells Dev. 2016, 25, 1874-1883.

58. Guo, S. C.; Tao, S. C.; Yin, W. J.; Qi, X.; Sheng, J. G.; Zhang, C. Q., Exosomes from Human Synovial-Derived Mesenchymal Stem Cells Prevent Glucocorticoid-Induced Osteonecrosis of the Femoral Head in the Rat. Int. J. Biol. Sci. 2016, 12, 1262-1272.

59. Haga, H.; Yan, I. K.; Borrelli, D. A.; Matsuda, A.; Parasramka, M.; Shukla, N.; Lee, D. D.; Patel, T., Extracellular Vesicles from Bone Marrow-Derived Mesenchymal Stem Cells Protect against Murine Hepatic Ischemia/Reperfusion Injury. Liver Transpl. 2017, 23, 791803.

60. Haga, H.; Yan, I. K.; Takahashi, K.; Matsuda, A.; Patel, T., Extracellular Vesicles from Bone Marrow-Derived Mesenchymal Stem Cells Improve Survival from Lethal Hepatic Failure in Mice. Stem Cells Transl. Med. 2017, 6, 1262-1272.

61. Han, Y. D.; Bai, Y.; Yan, X. L.; Ren, J.; Zeng, Q.; Li, X. D.; Pei, X. T.; Han, Y., CoTransplantation of Exosomes Derived from Hypoxia-Preconditioned Adipose Mesenchymal Stem Cells Promotes Neovascularization and Graft Survival in Fat Grafting. Biochem. Biophys. Res. Commun. 2018, 497, 305-312.

62. He, G. H.; Zhang, W.; Ma, Y. X.; Yang, J.; Chen, L.; Song, J.; Chen, S., Mesenchymal Stem Cells-Derived Exosomes Ameliorate Blue Light Stimulation in Retinal Pigment Epithelium Cells and Retinal Laser Injury by VEGF-Dependent Mechanism. Int 2018, 11, 559-566.

63. He, J.; Wang, Y.; Sun, S.; Yu, M.; Wang, C.; Pei, X.; Zhu, B.; Wu, J.; Zhao, W., Bone Marrow Stem Cells-Derived Microvesicles Protect against Renal Injury in the Mouse Remnant Kidney Model. Nephrology 2012, 17, 493-500.

64. Henao Agudelo, J. S.; Braga, T. T.; Amano, M. T.; Cenedeze, M. A.; Cavinato, R. A.; Peixoto-Santos, A. R.; Muscará, M. N.; Teixeira, S. A.; Cruz, M. C.; Castoldi, A., Mesenchymal Stromal Cell-Derived Microvesicles Regulate an Internal Pro-Inflammatory Program in Activated Macrophages. Front. Immunol. 2017, 8, 881. 
65. Hu, B.; Chen, S.; Zou, M.; He, Z.; Shao, S.; Liu, B., Effect of Extracellular Vesicles on Neural Functional Recovery and Immunologic Suppression after Rat Cerebral Apoplexy. Cell. Physiol. Biochem. 2016, 40, 155-162.

66. Hu, G. W.; Li, Q.; Niu, X.; Hu, B.; Liu, J.; Zhou, S. M.; Guo, S. C.; Lang, H. L.; Zhang, C. Q.; Wang, Y.; Deng, Z. F., Exosomes Secreted by Human-Induced Pluripotent Stem CellDerived Mesenchymal Stem Cells Attenuate Limb Ischemia by Promoting Angiogenesis in Mice. Stem Cell. Res. Ther. 2015, 6, 10.

67. Hu, L.; Wang, J.; Zhou, X.; Xiong, Z.; Zhao, J.; Yu, R.; Huang, F.; Zhang, H.; Chen, L., Exosomes Derived from Human Adipose Mensenchymal Stem Cells Accelerates Cutaneous Wound Healing via Optimizing the Characteristics of Fibroblasts. Sci. Rep. 2016, 6, 32993.

68. Huang, H.; Feng, S.; Zhang, W.; Li, W.; Xu, P.; Wang, X.; Ai, A., Bone Marrow Mesenchymal Stem Cell-Derived Extracellular Vesicles Improve the Survival of Transplanted Fat Grafts. Mol. Med. Report. 2017, 16, 3069-3078.

69. Huang, J. H.; Yin, X. M.; Xu, Y.; Xu, C. C.; Lin, X.; Ye, F. B.; Cao, Y.; Lin, F. Y., Systemic Administration of Exosomes Released from Mesenchymal Stromal Cells Attenuates Apoptosis, Inflammation, and Promotes Angiogenesis after Spinal Cord Injury in Rats. J. Neurotrauma 2017, 34, 3388-3396.

70. Jia, H.; Liu, W.; Zhang, B.; Wang, J.; Wu, P.; Tandra, N.; Liang, Z.; Ji, C.; Yin, L.; Hu, X.; Yan, Y.; Mao, F.; Zhang, X.; Yu, J.; Xu, W.; Qian, H., HucMSC Exosomes-Delivered 143-3zeta Enhanced Autophagy via Modulation of ATG16L in Preventing Cisplatin-Induced Acute Kidney Injury. Am. J. Transl. Res. 2018, 10, 101-113.

71. Jiang, W.; Tan, Y.; Cai, M.; Zhao, T.; Mao, F.; Zhang, X.; Xu, W.; Yan, Z.; Qian, H.; Yan, Y., Human Umbilical Cord MSC-Derived Exosomes Suppress the Development of CCl4Induced Liver Injury through Antioxidant Effect. Stem Cells Int. 2018, 2018.

72. Ju, G. Q.; Cheng, J.; Zhong, L.; Wu, S.; Zou, X. Y.; Zhang, G. Y.; Gu, D.; Miao, S.; Zhu, Y. J.; Sun, J.; Du, T., Microvesicles Derived from Human Umbilical Cord Mesenchymal Stem Cells Facilitate Tubular Epithelial Cell Dedifferentiation and Growth via Hepatocyte Growth Factor Induction. PLoS One 2015, 10, e0121534.

73. Kalimuthu, S.; Gangadaran, P.; Li, X. J.; Oh, J. M.; Lee, H. W.; Jeong, S. Y.; Lee, S. W.; Lee, J.; Ahn, B. C., In Vivo Therapeutic Potential of Mesenchymal Stem Cell-Derived Extracellular Vesicles with Optical Imaging Reporter in Tumor Mice Model. Sci. Rep. 2016, 6, 1-11.

74. Kamerkar, S.; LeBleu, V. S.; Sugimoto, H.; Yang, S.; Ruivo, C. F.; Melo, S. A.; Lee, J. J.; Kalluri, R., Exosomes Facilitate Therapeutic Targeting of Oncogenic KRAS in Pancreatic Cancer. Nature 2017, 546, 498-503.

75. Kang, K.; Ma, R.; Cai, W.; Huang, W.; Paul, C.; Liang, J.; Wang, Y.; Zhao, T.; Kim, H. W.; Xu, M.; Millard, R. W.; Wen, Z.; Wang, Y., Exosomes Secreted from CXCR4 Overexpressing Mesenchymal Stem Cells Promote Cardioprotection via Akt Signaling Pathway Following Myocardial Infarction. Stem Cells Int. 2015, 2015.

76. Katakowski, M.; Buller, B.; Zheng, X.; Lu, Y.; Rogers, T.; Osobamiro, O.; Shu, W.; Jiang, F.; Chopp, M., Exosomes from Marrow Stromal Cells Expressing miR-146b Inhibit Glioma Growth. Cancer Lett. 2013, 335, 201-204.

77. Khatri, M.; Richardson, L. A.; Meulia, T., Mesenchymal Stem Cell-Derived Extracellular Vesicles Attenuate Influenza Virus-Induced Acute Lung Injury in a Pig Model. Stem Cell. Res. Ther. 2018, 9, 1-13.

78. Kilpinen, L.; Impola, U.; Sankkila, L.; Ritamo, I.; Aatonen, M.; Kilpinen, S.; Tuimala, J.; Valmu, L.; Levijoki, J.; Finckenberg, P.; Siljander, P.; Kankuri, E.; Mervaala, E.; Laitinen, S., Extracellular Membrane Vesicles from Umbilical Cord Blood-Derived MSC Protect against Ischemic Acute Kidney Injury, a Feature That Is Lost after Inflammatory Conditioning. J. Extracell. Vesicles 2013, 2, 21927. 
79. Kim, D. K.; Nishida, H.; An, S. Y.; Shetty, A. K.; Bartosh, T. J.; Prockop, D. J., Chromatographically Isolated CD63+CD81+ Extracellular Vesicles from Mesenchymal Stromal Cells Rescue Cognitive Impairments after TBI. Proc. Natl. Acad. Sci. U. S. A. 2016, 113, 170-175.

80. Ko, S. F.; Yip, H. K.; Zhen, Y. Y.; Lee, C. C.; Huang, C. C.; Ng, S. H.; Lin, J. W., AdiposeDerived Mesenchymal Stem Cell Exosomes Suppress Hepatocellular Carcinoma Growth in a Rat Model: Apparent Diffusion Coefficient, Natural Killer T-Cell Responses, and Histopathological Features. Stem Cells Int. 2015, 2015.

81. Koch, M.; Lemke, A.; Lange, C., Extracellular Vesicles from MSC Modulate the Immune Response to Renal Allografts in a MHC Disparate Rat Model. Stem Cells Int. 2015, 2015.

82. Komaki, M.; Numata, Y.; Morioka, C.; Honda, I.; Tooi, M.; Yokoyama, N.; Ayame, H.; Iwasaki, K.; Taki, A.; Oshima, N.; Morita, I., Exosomes of Human Placenta-Derived Mesenchymal Stem Cells Stimulate Angiogenesis. Stem Cell. Res. Ther. 2017, 8, 1-12.

83. Koppen, A. v.; Joles, J. A.; Balkom, B. W. v.; Lim, S. K.; Kleijn, D. d.; Giles, R. H.; Verhaar, M. C., Human Embryonic Mesenchymal Stem Cell-Derived Conditioned Medium Rescues Kidney Function in Rats with Established Chronic Kidney Disease. PLoS One 2012, 7, e38746.

84. Kou, X.; Xu, X.; Chen, C.; Sanmillan, M. L.; Cai, T.; Zhou, Y.; Giraudo, C.; Le, A.; Shi, S., The Fas/Fap-1/Cav-1 Complex Regulates IL-1RA Secretion in Mesenchymal Stem Cells to Accelerate Wound Healing. Sci. Transl. Med. 2018, 10.

85. Lai, R. C.; Arslan, F.; Tan, S. S.; Tan, B.; Choo, A.; Lee, M. M.; Chen, T. S.; Teh, B. J.; Eng, J. K.; Sidik, H.; Tanavde, V.; Hwang, W. S.; Lee, C. N.; Oakley, R. M. E.; Pasterkamp, G.; Kleijn, D. P. d.; Tan, K. H.; Lim, S. K., Derivation and Characterization of Human Fetal MSCs: An Alternative Cell Source for Large-Scale Production of Cardioprotective Microparticles. J. Mol. Cell. Cardiol. 2010, 48, 1215-1224.

86. Lai, R. C.; Tan, S. S.; Teh, B. J.; Sze, S. K.; Arslan, F.; Kleijn, D. P. d.; Choo, A.; Lim, S. K., Proteolytic Potential of the MSC Exosome Proteome: Implications for an ExosomeMediated Delivery of Therapeutic Proteasome. Int. J. Proteomics 2012, 2012.

87. Lang, F. M.; Hossain, A.; Gumin, J.; Momin, E. N.; Shimizu, Y.; Ledbetter, D.; Shahar, T.; Yamashita, S.; Kerrigan, B. P.; Fueyo, J.; Sawaya, R.; Lang, F. F., Mesenchymal Stem Cells as Natural Biofactories for Exosomes Carrying miR-124a in the Treatment of Gliomas. Neuro-Oncology 2018, 20, 380-390.

88. Lange, C.; Reimer, R.; Zustin, J.; Brunswig-Spickenheier, B., Mesenchymal Stromal Cells Protect from Consequences of HSCT-Transplantation Preparatory Irradiation: Insights into Possible Mechanisms. Cell. Ther. Transplant. 2016, 5, 50-58.

89. Lee, C.; Mitsialis, S. A.; Aslam, M.; Vitali, S. H.; Vergadi, E.; Konstantinou, G.; Sdrimas, K.; Fernandez-Gonzalez, A.; Kourembanas, S., Exosomes Mediate the Cytoprotective Action of Mesenchymal Stromal Cells on Hypoxia-Induced Pulmonary Hypertension. Circulation 2012, 126, 2601-2611.

90. Lee, J. K.; Park, S. R.; Jung, B. K.; Jeon, Y. K.; Lee, Y. S.; Kim, M. K.; Kim, Y. G.; Jang, J. Y.; Kim, C. W., Exosomes Derived from Mesenchymal Stem Cells Suppress Angiogenesis by Down-Regulating VEGF Expression in Breast Cancer Cells. PLoS One 2013, 8, e84256.

91. Lee, J. Y.; Kim, E.; Choi, S. M.; Kim, D. W.; Kim, K. P.; Lee, I.; Kim, H. S., Microvesicles from Brain-Extract-Treated Mesenchymal Stem Cells Improve Neurological Functions in a Rat Model of Ischemic Stroke. Sci. Rep. 2016, 6, 33038.

92. Li, H.; Liu, D.; Li, C.; Zhou, S.; Tian, D.; Xiao, D.; Zhang, H.; Gao, F.; Huang, J., Exosomes Secreted from Mutant-HIF-1alpha-Modified Bone-Marrow-Derived Mesenchymal Stem Cells Attenuate Early Steroid-Induced Avascular Necrosis of Femoral Head in Rabbit. Cell Biol. Int. 2017, 41, 1379-1390. 
93. Li, L.; Jin, S.; Zhang, Y., Ischemic Preconditioning Potentiates the Protective Effect of Mesenchymal Stem Cells on Endotoxin-Induced Acute Lung Injury in Mice through Secretion of Exosome. Int. J. Clin. Exp. Med. 2015, 8, 3825-3832.

94. Li, T.; Yan, Y.; Wang, B.; Qian, H.; Zhang, X.; Shen, L.; Wang, M.; Zhou, Y.; Zhu, W.; Li, W.; Xu, W., Exosomes Derived from Human Umbilical Cord Mesenchymal Stem Cells Alleviate Liver Fibrosis. Stem Cells Dev. 2013, 22, 845-854.

95. Li, W.; Liu, Y.; Zhang, P.; Tang, Y.; Zhou, M.; Jiang, W.; Zhang, X.; Wu, G.; Zhou, Y., Tissue-Engineered Bone Immobilized with Human Adipose Stem Cells-Derived Exosomes Promotes Bone Regeneration. ACS Appl. Mater. Interfaces 2018, 10, 52405254.

96. Li, X.; Liu, L.; Yang, J.; Yu, Y.; Chai, J.; Wang, L.; Ma, L.; Yin, H., Exosome Derived from Human Umbilical Cord Mesenchymal Stem Cell Mediates miR-181c Attenuating BurnInduced Excessive Inflammation. EBioMedicine 2016, 8, 72-82.

97. Li, Y.; Yang, Y. Y.; Ren, J. L.; Xu, F.; Chen, F. M.; Li, A., Exosomes Secreted by Stem Cells from Human Exfoliated Deciduous Teeth Contribute to Functional Recovery after Traumatic Brain Injury by Shifting Microglia M1/M2 Polarization in Rats. Stem Cell. Res. Ther. 2017, 8, 198.

98. Lin, K. C.; Yip, H. K.; Shao, P. L.; Wu, S. C.; Chen, K. H.; Chen, Y. T.; Yang, C. C.; Sun, C. K.; Kao, G. S.; Chen, S. Y.; Chai, H. T.; Chang, C. L.; Chen, C. H.; Lee, M. S., Combination of Adipose-Derived Mesenchymal Stem Cells (ADMSC) and ADMSCDerived Exosomes for Protecting Kidney from Acute Ischemia-Reperfusion Injury. Int. J. Cardiol. 2016, 216, 173-185.

99. Liu, J.; Kuwabara, A.; Kamio, Y.; Hu, S.; Park, J.; Hashimoto, T.; Lee, J. W., Human Mesenchymal Stem Cell-Derived Microvesicles Prevent the Rupture of Intracranial Aneurysm in Part by Suppression of Mast Cell Activation via a PGE2-Dependent Mechanism. Stem Cells 2016, 34, 2943-2955.

100. Liu, L.; Jin, X.; Hu, C. F.; Li, R.; Zhou, Z.; Shen, C. X., Exosomes Derived from Mesenchymal Stem Cells Rescue Myocardial Ischaemia/Reperfusion Injury by Inducing Cardiomyocyte Autophagy via Ampk and Akt Pathways. Cell. Physiol. Biochem. 2017, 43, 52-68.

101. Liu, R.; Shen, H.; Ma, J.; Sun, L.; Wei, M., Extracellular Vesicles Derived from Adipose Mesenchymal Stem Cells Regulate the Phenotype of Smooth Muscle Cells to Limit Intimal Hyperplasia. Cardiovasc. Drugs Ther. 2016, 30, 111-118.

102. Liu, X.; Li, Q.; Niu, X.; Hu, B.; Chen, S.; Song, W.; Ding, J.; Zhang, C.; Wang, Y., Exosomes Secreted from Human-Induced Pluripotent Stem Cell-Derived Mesenchymal Stem Cells Prevent Osteonecrosis of the Femoral Head by Promoting Angiogenesis. Int. J. Biol. Sci. 2017, 13, 232-244.

103. Long, Q.; Upadhya, D.; Hattiangady, B.; Kim, D. K.; An, S. Y.; Shuai, B.; Prockop, D. J.; Shetty, A. K., Intranasal MSC-Derived A1-Exosomes Ease Inflammation, and Prevent Abnormal Neurogenesis and Memory Dysfunction after Status Epilepticus. Proc. Natl. Acad. Sci. U. S. A. 2017, 114, E3536-E3545.

104. Lou, G.; Song, X.; Yang, F.; Wu, S.; Wang, J.; Chen, Z.; Liu, Y., Exosomes Derived from miR-122-Modified Adipose Tissue-Derived MSCs Increase Chemosensitivity of Hepatocellular Carcinoma. J. Hematol. Oncol. 2015, 8, 1-11.

105. Luther, K. M.; Haar, L.; McGuinness, M.; Wang, Y.; Lynch, T.; Phan, A.; Song, Y.; Shen, Z.; Gardner, G.; Kuffel, G.; Ren, X.; Zilliox, M. J.; Jones, W. K., Exosomal miR-21a-5p Mediates Cardioprotection by Mesenchymal Stem Cells. J. Mol. Cell. Cardiol. 2018, 23, 125-137.

106. Ma, J.; Zhao, Y.; Sun, L.; Sun, X.; Zhao, X.; Sun, X.; Qian, H.; Xu, W.; Zhu, W., Exosomes Derived from Akt-Modified Human Umbilical Cord Mesenchymal Stem Cells Improve 
Cardiac Regeneration and Promote Angiogenesis via Activating Platelet-Derived Growth Factor D. Stem Cells Transl. Med. 2017, 6, 51-59.

107. Mao, F.; Wu, Y.; Tang, X.; Kang, J.; Zhang, B.; Yan, Y.; Qian, H.; Zhang, X.; Xu, W., Exosomes Derived from Human Umbilical Cord Mesenchymal Stem Cells Relieve Inflammatory Bowel Disease in Mice. BioMed Res. Int. 2017, 2017.

108. Mardpour, S.; Hassani, S. N.; Mardpour, S.; Sayahpour, F.; Vosough, M.; Ai, J.; Aghdami, N.; Hamidieh, A. A.; Baharvand, H., Extracellular Vesicles Derived from Human Embryonic Stem Cell-MSCs Ameliorate Cirrhosis in Thioacetamide-Induced Chronic Liver Injury. J. Cell. Physiol. 2017, 233, 9330-9344.

109. McCulloh, C. J.; Olson, J. K.; Wang, Y.; Zhou, Y.; Tengberg, N. H.; Deshpande, S.; Besner, G. E., Treatment of Experimental Necrotizing Enterocolitis with Stem Cell-Derived Exosomes. J. Pediatr. Surg. 2018, 53, 1215-1220.

110. Mead, B.; Amaral, J.; Tomarev, S., Mesenchymal Stem Cell-Derived Small Extracellular Vesicles Promote Neuroprotection in Rodent Models of Glaucoma. Invest. Ophthalmol. Vis. Sci. 2018, 59, 702-714.

111. Mead, B.; Tomarev, S., Bone Marrow-Derived Mesenchymal Stem Cells-Derived Exosomes Promote Survival of Retinal Ganglion Cells through miRNA-Dependent Mechanisms. Stem Cells Transl. Med. 2017, 6, 1273-1285.

112. Moisseiev, E.; Anderson, J. D.; Oltjen, S.; Goswami, M.; Zawadzki, R. J.; Nolta, J. A.; Park, S. S., Protective Effect of Intravitreal Administration of Exosomes Derived from Mesenchymal Stem Cells on Retinal Ischemia. Curr. Eye Res. 2017, 42, 1358-1367.

113. Monsel, A.; Zhu, Y. G.; Gennai, S.; Hao, Q.; Hu, S.; Rouby, J. J.; Rosenzwajg, M.; Matthay, M. A.; Lee, J. W., Therapeutic Effects of Human Mesenchymal Stem Cell-Derived Microvesicles in Severe Pneumonia in Mice. Am. J. Respir. Crit. Care Med. 2015, 192, 324-336.

114. Nagaishi, K.; Mizue, Y.; Chikenji, T.; Otani, M.; Nakano, M.; Konari, N.; Fujimiya, M., Mesenchymal Stem Cell Therapy Ameliorates Diabetic Nephropathy via the Paracrine Effect of Renal Trophic Factors Including Exosomes. Sci. Rep. 2016, 6, 1-16.

115. Nakamura, Y.; Miyaki, S.; Ishitobi, H.; Matsuyama, S.; Nakasa, T.; Kamei, N.; Akimoto, T.; Higashi, Y.; Ochi, M., Mesenchymal-Stem-Cell-Derived Exosomes Accelerate Skeletal Muscle Regeneration. FEBS Lett. 2015, 589, 1257-1265.

116. Nakano, M.; Nagaishi, K.; Konari, N.; Saito, Y.; Chikenji, T.; Mizue, Y.; Fujimiya, M., Bone Marrow-Derived Mesenchymal Stem Cells Improve Diabetes-Induced Cognitive Impairment by Exosome Transfer into Damaged Neurons and Astrocytes. Sci. Rep. 2016, 6, 24805.

117. Nong, K.; Wang, W.; Niu, X.; Hu, B.; Ma, C.; Bai, Y.; Wu, B.; Wang, Y.; Ai, K., Hepatoprotective Effect of Exosomes from Human-Induced Pluripotent Stem Cell-Derived Mesenchymal Stromal Cells against Hepatic Ischemia-Reperfusion Injury in Rats. Cytotherapy 2016, 18, 1548-1559.

118. Ophelders, D. R.; Wolfs, T. G.; Jellema, R. K.; Zwanenburg, A.; Andriessen, P.; Delhaas, T.; Ludwig, A. K.; Radtke, S.; Peters, V.; Janssen, L.; Giebel, B.; Kramer, B. W., Mesenchymal Stromal Cell-Derived Extracellular Vesicles Protect the Fetal Brain after Hypoxia-Ischemia. Stem Cells Transl. Med. 2016, 5, 754-763.

119. Otero-Ortega, L.; Frutos, M. C. G. d.; Laso-Garcia, F.; Rodriguez-Frutos, B.; MedinaGutierrez, E.; Lopez, J. A.; Vazquez, J.; Diez-Tejedor, E.; Gutierrez-Fernandez, M., Exosomes Promote Restoration after an Experimental Animal Model of Intracerebral Hemorrhage. J. Cereb. Blood Flow Metab. 2018, 38, 767-779.

120. Otero-Ortega, L.; Laso-Garcia, F.; Frutos, M. D. G.-d.; Rodriguez-Frutos, B.; PascualGuerra, J.; Fuentes, B.; Diez-Tejedor, E.; Gutierrez-Fernandez, M., White Matter Repair after Extracellular Vesicles Administration in an Experimental Animal Model of Subcortical Stroke. Sci. Rep. 2017, 7, 1-11. 
121. Otsuru, S.; Desbourdes, L.; Guess, A. J.; Hofmann, T. J.; Relation, T.; Kaito, T.; Dominici, M.; Iwamoto, M.; Horwitz, E. M., Extracellular Vesicles Released from Mesenchymal Stromal Cells Stimulate Bone Growth in Osteogenesis Imperfecta. Cytotherapy 2018, 20, 62-73.

122. Potter, D. R.; Miyazawa, B. Y.; Gibb, S. L.; Deng, X.; Togaratti, P. P.; Croze, R. H.; Srivastava, A. K.; Trivedi, A.; Matthay, M.; Holcomb, J. B.; Schreiber, M. A.; Pati, S., Mesenchymal Stem Cell-Derived Extracellular Vesicles Attenuate Pulmonary Vascular Permeability and Lung Injury Induced by Hemorrhagic Shock and Trauma. J Trauma Acute Care Surg 2018, 84, 245-256.

123. Qi, X.; Zhang, J.; Yuan, H.; Xu, Z.; Li, Q.; Niu, X.; Hu, B.; Wang, Y.; Li, X., Exosomes Secreted by Human-Induced Pluripotent Stem Cell-Derived Mesenchymal Stem Cells Repair Critical-Sized Bone Defects through Enhanced Angiogenesis and Osteogenesis in Osteoporotic Rats. Int. J. Biol. Sci. 2016, 12, 836-849.

124. Qin, Y.; Wang, L.; Gao, Z.; Chen, G.; Zhang, C., Bone Marrow Stromal/Stem Cell-Derived Extracellular Vesicles Regulate Osteoblast Activity and Differentiation In Vitro and Promote Bone Regeneration In Vivo. Sci. Rep. 2016, 6, 1-11.

125. Qu, Y.; Zhang, Q.; Cai, X.; Li, F.; Ma, Z.; Xu, M.; Lu, L., Exosomes Derived from miR-1815p-Modified Adipose-Derived Mesenchymal Stem Cells Prevent Liver Fibrosis via Autophagy Activation. J. Cell. Mol. Med. 2017, 21, 2491-2502.

126. Rager, T. M.; Olson, J. K.; Zhou, Y.; Wang, Y.; Besner, G. E., Exosomes Secreted from Bone Marrow-Derived Mesenchymal Stem Cells Protect the Intestines from Experimental Necrotizing Enterocolitis. J. Pediatr. Surg. 2016, 51, 942-947.

127. Rahman, M. J.; Regn, D.; Bashratyan, R.; Dai, Y. D., Exosomes Released by Islet-Derived Mesenchymal Stem Cells Trigger Autoimmune Responses in Nod Mice. Diabetes 2014, 63, 1008-1020.

128. Raisi, A.; Azizi, S.; Delirezh, N.; Heshmatian, B.; Farshid, A. A.; Amini, K., The Mesenchymal Stem Cell-Derived Microvesicles Enhance Sciatic Nerve Regeneration in Rat: A Novel Approach in Peripheral Nerve Cell Therapy. J Trauma Acute Care Surg 2014, 76, 991-997.

129. Rajan, T. S.; Giacoppo, S.; Diomede, F.; Bramanti, P.; Trubiani, O.; Mazzon, E., Human Periodontal Ligament Stem Cells Secretome from Multiple Sclerosis Patients Suppresses Nalp3 Inflammasome Activation in Experimental Autoimmune Encephalomyelitis. Int. J. Immunopathol. Pharmacol. 2017, 30, 238-252.

130. Rajendran, R. L.; Gangadaran, P.; Bak, S. S.; Oh, J. M.; Kalimuthu, S.; Lee, H. W.; Baek, S. H.; Zhu, L.; Sung, Y. K.; Jeong, S. Y.; Lee, S. W.; Lee, J.; Ahn, B. C., Extracellular Vesicles Derived from MSCs Activates Dermal Papilla Cell In Vitro and Promotes Hair Follicle Conversion from Telogen to Anagen in Mice. Sci. Rep. 2017, 7, 1-12.

131. Ranghino, A.; Bruno, S.; Bussolati, B.; Moggio, A.; Dimuccio, V.; Tapparo, M.; Biancone, L.; Gontero, P.; Frea, B.; Camussi, G., The Effects of Glomerular and Tubular Renal Progenitors and Derived Extracellular Vesicles on Recovery from Acute Kidney Injury. Stem Cell. Res. Ther. 2017, 8, 1-15.

132. Reis, L. A.; Borges, F. T.; Simoes, M. J.; Borges, A. A.; Sinigaglia-Coimbra, R.; Schor, N., Bone Marrow-Derived Mesenchymal Stem Cells Repaired but Did Not Prevent Gentamicin-Induced Acute Kidney Injury through Paracrine Effects in Rats. PLoS One 2012, 7, e44092.

133. Roccaro, A. M.; Sacco, A.; Maiso, P.; Azab, A. K.; Tai, Y. T.; Reagan, M.; Azab, F.; Flores, L. M.; Campigotto, F.; Weller, E.; Anderson, K. C.; Scadden, D. T.; Ghobrial, I. M., BM Mesenchymal Stromal Cell-Derived Exosomes Facilitate Multiple Myeloma Progression. J. Clin. Invest. 2013, 123, 1542-1555.

134. Ruppert, K. A.; Nguyen, T. T.; Prabhakara, K. S.; Furman, N. E. T.; Srivastava, A. K.; Harting, M. T.; Cox, C. S.; Olson, S. D., Human Mesenchymal Stromal Cell-Derived 
Extracellular Vesicles Modify Microglial Response and Improve Clinical Outcomes in Experimental Spinal Cord Injury. Sci. Rep. 2018, 8, 1-12.

135. Schoefinius, J. S.; Brunswig-Spickenheier, B.; Speiseder, T.; Krebs, S.; Just, U.; Lange, C., Mesenchymal Stromal Cell-Derived Extracellular Vesicles Provide Long-Term Survival after Total Body Irradiation without Additional Hematopoietic Stem Cell Support. Stem Cells 2017, 35, 2379-2389.

136. Shao, L.; Zhang, Y.; Lan, B.; Wang, J.; Zhang, Z.; Zhang, L.; Xiao, P.; Meng, Q.; Geng, Y. J.; Yu, X. Y.; Li, Y., MiRNA-Sequence Indicates That Mesenchymal Stem Cells and Exosomes Have Similar Mechanism to Enhance Cardiac Repair. BioMed Res. Int. 2017, 2017.

137. Shen, B.; Liu, J.; Zhang, F.; Wang, Y.; Qin, Y.; Zhou, Z.; Qiu, J.; Fan, Y., CCR2 Positive Exosome Released by Mesenchymal Stem Cells Suppresses Macrophage Functions and Alleviates Ischemia/Reperfusion-Induced Renal Injury. Stem Cells Int. 2016, 2016.

138. Shen, H.; Yao, X.; Li, H.; Li, X.; Zhang, T.; Sun, Q.; Ji, C.; Chen, G., Role of Exosomes Derived from miR-133b Modified MSCs in an Experimental Rat Model of Intracerebral Hemorrhage. J. Mol. Neurosci. 2018, 64, 421-430.

139. Shi, Q.; Qian, Z.; Liu, D.; Sun, J.; Wang, X.; Liu, H.; Xu, J.; Guo, X., GMSC-Derived Exosomes Combined with a Chitosan/Silk Hydrogel Sponge Accelerates Wound Healing in a Diabetic Rat Skin Defect Model. Front. Physiol. 2017, 8, 904.

140. Shi, S.; Zhang, Q.; Xia, Y.; You, B.; Shan, Y.; Bao, L.; Li, L.; You, Y.; Gu, Z., Mesenchymal Stem Cell-Derived Exosomes Facilitate Nasopharyngeal Carcinoma Progression. Am. J. Cancer Res. 2016, 6, 459-472.

141. Shigemoto-Kuroda, T.; Oh, J. Y.; Kim, D. K.; Jeong, H. J.; Park, S. Y.; Lee, H. J.; Park, J. W.; Kim, T. W.; An, S. Y.; Prockop, D. J.; Lee, R. H., MSC-Derived Extracellular Vesicles Attenuate Immune Responses in Two Autoimmune Murine Models: Type 1 Diabetes and Uveoretinitis. Stem Cell Rep. 2017, 8, 1214-1225.

142. Sicco, C. L.; Reverberi, D.; Balbi, C.; Ulivi, V.; Principi, E.; Pascucci, L.; Becherini, P.; Bosco, M. C.; Varesio, L.; Franzin, C.; Pozzobon, M.; Cancedda, R.; Tasso, R., Mesenchymal Stem Cell-Derived Extracellular Vesicles as Mediators of Anti-Inflammatory Effects: Endorsement of Macrophage Polarization. Stem Cells Transl. Med. 2017, 6, 10181028.

143. Song, Y.; Dou, H.; Li, X.; Zhao, X.; Li, Y.; Liu, D.; Ji, J.; Liu, F.; Ding, L.; Ni, Y.; Hou, Y., Exosomal miR-146a Contributes to the Enhanced Therapeutic Efficacy of Interleukin1 beta-Primed Mesenchymal Stem Cells against Sepsis. Stem Cells 2017, 35, 1208-1221.

144. Stone, M. L.; Zhao, Y.; Smith, J. R.; Weiss, M. L.; Kron, I. L.; Laubach, V. E.; Sharma, A. K., Mesenchymal Stromal Cell-Derived Extracellular Vesicles Attenuate Lung IschemiaReperfusion Injury and Enhance Reconditioning of Donor Lungs after Circulatory Death. Respir. Res. 2017, 18, 1-12.

145. Sun, C. K.; Chen, C. H.; Chang, C. L.; Chiang, H. J.; Sung, P. H.; Chen, K. H.; Chen, Y. L.; Chen, S. Y.; Kao, G. S.; Chang, H. W.; Lee, M. S.; Yip, H. K., Melatonin Treatment Enhances Therapeutic Effects of Exosomes against Acute Liver Ischemia-Reperfusion Injury. Am. J. Transl. Res. 2017, 9, 1543-1560.

146. Sun, L.; Xu, R.; Sun, X.; Duan, Y.; Han, Y.; Zhao, Y.; Qian, H.; Zhu, W.; Xu, W., Safety Evaluation of Exosomes Derived from Human Umbilical Cord Mesenchymal Stromal Cell. Cytotherapy 2016, 18, 413-422.

147. Tamura, R.; Uemoto, S.; Tabata, Y., Immunosuppressive Effect of Mesenchymal Stem Cell-Derived Exosomes on a Concanavalin a-Induced Liver Injury Model. Inflammation Regener. 2016, 36, 26.

148. Tamura, R.; Uemoto, S.; Tabata, Y., Augmented Liver Targeting of Exosomes by Surface Modification with Cationized Pullulan. Acta Biomater. 2017, 57, 274-284. 
149. Tan, C. Y.; Lai, R. C.; Wong, W.; Dan, Y. Y.; Lim, S. K.; Ho, H. K., Mesenchymal Stem Cell-Derived Exosomes Promote Hepatic Regeneration in Drug-Induced Liver Injury Models. Stem Cell. Res. Ther. 2014, 5, 76.

150. Tang, X. D.; Shi, L.; Monsel, A.; Li, X. Y.; Zhu, H. L.; Zhu, Y. G.; Qu, J. M., Mesenchymal Stem Cell Microvesicles Attenuate Acute Lung Injury in Mice Partly Mediated by Ang-1 mRNA. Stem Cells 2017, 35, 1849-1859.

151. Tao, S. C.; Guo, S. C.; Li, M.; Ke, Q. F.; Guo, Y. P.; Zhang, C. Q., Chitosan Wound Dressings Incorporating Exosomes Derived from MicroRNA-126-Overexpressing Synovium Mesenchymal Stem Cells Provide Sustained Release of Exosomes and Heal Full-Thickness Skin Defects in a Diabetic Rat Model. Stem Cells Transl. Med. 2017, 6, 736-747.

152. Tao, S. C.; Yuan, T.; Zhang, Y. L.; Yin, W. J.; Guo, S. C.; Zhang, C. Q., Exosomes Derived from miR-140-5p-Overexpressing Human Synovial Mesenchymal Stem Cells Enhance Cartilage Tissue Regeneration and Prevent Osteoarthritis of the Knee in a Rat Model. Theranostics 2017, 7, 180-195.

153. Teng, X.; Chen, L.; Chen, W.; Yang, J.; Yang, Z.; Shen, Z., Mesenchymal Stem CellDerived Exosomes Improve the Microenvironment of Infarcted Myocardium Contributing to Angiogenesis and Anti-Inflammation. Cell. Physiol. Biochem. 2015, 37, 2415-2424.

154. Ti, D.; Hao, H.; Tong, C.; Liu, J.; Dong, L.; Zheng, J.; Zhao, Y.; Liu, H.; Fu, X.; Han, W., LPS-Preconditioned Mesenchymal Stromal Cells Modify Macrophage Polarization for Resolution of Chronic Inflammation via Exosome-Shuttled Let-7b. J. Transl. Med. 2015, 13, 308.

155. Ti, D. D.; Li, J. F.; Hao, H. J.; Tong, C.; Liu, J. J.; Dong, L.; Zang, L.; Mu, Y. M.; Fu, X. B.; Han, W. D., Lipopolysaccharides Priming Mesenchymal Stem Cells Accelerate Diabetic Wound Healing via Exosomes. Jiefangjun Yixue Zazhi 2016, 41, 528-533.

156. Tian, D.; Li, H.; Xiao, D.; Zhou, S.; Su, Y.; Liu, D.; Qi, H., Promotion Effect of Cartilage Regenerated Scaffolds Combined with Exosomes Derived from Mutant Type of HIF1alpha Modified BMSCs in Repairing Advanced Cartilage Defects. Jilin Daxue Xuebao, Yixueban 2018, 44, 216-222.

157. Vrijsen, K. R.; Maring, J. A.; Chamuleau, S. A.; Verhage, V.; Mol, E. A.; Deddens, J. C.; Metz, C. H.; Lodder, K.; Eeuwijk, E. C. v.; Dommelen, S. M. v.; Doevendans, P. A.; Smits, A. M.; Goumans, M. J.; Sluijter, J. P., Exosomes from Cardiomyocyte Progenitor Cells and Mesenchymal Stem Cells Stimulate Angiogenesis via Emmprin. Adv. Healthcare Mater. 2016, 5, 2555-2565.

158. Wang, B.; Jia, H.; Zhang, B.; Wang, J.; Ji, C.; Zhu, X.; Yan, Y.; Yin, L.; Yu, J.; Qian, H.; $\mathrm{Xu}, \quad$ W., Pre-Incubation with Hucmsc-Exosomes Prevents Cisplatin-Induced Nephrotoxicity by Activating Autophagy. Stem Cell. Res. Ther. 2017, 8, 1-14.

159. Wang, L.; Hu, L.; Zhou, X.; Xiong, Z.; Zhang, C.; Shehada, H. M. A.; Hu, B.; Song, J.; Chen, L., Exosomes Secreted by Human Adipose Mesenchymal Stem Cells Promote Scarless Cutaneous Repair by Regulating Extracellular Matrix Remodelling. Sci. Rep. 2017, 7, 1-12.

160. Wang, N.; Chen, C.; Yang, D.; Liao, Q.; Luo, H.; Wang, X.; Zhou, F.; Yang, X.; Yang, J.; Zeng, C.; Wang, W. E., Mesenchymal Stem Cells-Derived Extracellular Vesicles, via miR210, Improve Infarcted Cardiac Function by Promotion of Angiogenesis. Biochim. Biophys. Acta 2017, 1863, 2085-2092.

161. Wang, S. S.; Jia, J.; Wang, Z., Mesenchymal Stem Cell-Derived Extracellular Vesicles Suppresses Inos Expression and Ameliorates Neural Impairment in Alzheimer's Disease Mice. J. Alzheimer's Dis. 2018, 61, 1005-1013.

162. Wang, X.; Gu, H.; Qin, D.; Yang, L.; Huang, W.; Essandoh, K.; Wang, Y.; Caldwell, C. C.; Peng, T.; Zingarelli, B.; Fan, G. C., Exosomal miR-223 Contributes to Mesenchymal Stem Cell-Elicited Cardioprotection in Polymicrobial Sepsis. Sci. Rep. 2015, 5, 13721. 
163. Wang, X. L.; Zhao, Y. Y.; Sun, L.; Shi, Y.; Li, Z. Q.; Zhao, X. D.; Xu, C. G.; Ji, H. G.; Wang, M.; Xu, W. R.; Zhu, W., Exosomes Derived from Human Umbilical Cord Mesenchymal Stem Cells Improve Myocardial Repair via Upregulation of Smad7. Int. J. Mol. Med. 2018, 41, 3063-3072.

164. Wang, Y.; Lu, X.; He, J.; Zhao, W., Influence of Erythropoietin on Microvesicles Derived from Mesenchymal Stem Cells Protecting Renal Function of Chronic Kidney Disease. Stem Cell. Res. Ther. 2015, 6, 1-14.

165. Wang, Y.; Yu, D.; Liu, Z.; Zhou, F.; Dai, J.; Wu, B.; Zhou, J.; Heng, B. C.; Zou, X. H.; Ouyang, H.; Liu, H., Exosomes from Embryonic Mesenchymal Stem Cells Alleviate Osteoarthritis through Balancing Synthesis and Degradation of Cartilage Extracellular Matrix. Stem Cell. Res. Ther. 2017, 8, 1-13.

166. Webb, R. L.; Kaiser, E. E.; Scoville, S. L.; Thompson, T. A.; Fatima, S.; Pandya, C.; Sriram, K.; Swetenburg, R. L.; Vaibhav, K.; Arbab, A. S.; Baban, B.; Dhandapani, K. M.; Hess, D. C.; Hoda, M. N.; Stice, S. L., Human Neural Stem Cell Extracellular Vesicles Improve Tissue and Functional Recovery in the Murine Thromboembolic Stroke Model. Transl. Stroke Res. 2017, 28, 530-539.

167. Wen, D.; Peng, Y.; Liu, D.; Weizmann, Y.; Mahato, R. I., Mesenchymal Stem Cell and Derived Exosome as Small RNA Carrier and Immunomodulator to Improve Islet Transplantation. J. Controlled Release 2016, 238, 166-175.

168. Wen, S.; Dooner, M.; Cheng, Y.; Papa, E.; Tatto, M. D.; Pereira, M.; Deng, Y.; Goldberg, L.; Aliotta, J.; Chatterjee, D.; Stewart, C.; Carpanetto, A.; Collino, F.; Bruno, S.; Camussi, G.; Quesenberry, P., Mesenchymal Stromal Cell-Derived Extracellular Vesicles Rescue Radiation Damage to Murine Marrow Hematopoietic Cells. Leukemia 2016, 30, 22212231.

169. Williams, A. M.; Dennahy, I. S.; Bhatti, U. F.; Halaweish, I.; Xiong, Y.; Chang, P.; Nikolian, V. C.; Chtraklin, K.; Brown, J.; Zhang, Y.; Zhang, Z. G.; Chopp, M.; Buller, B.; Alam, H. B., Mesenchymal Stem Cell-Derived Exosomes Provide Neuroprotection and Improve LongTerm Neurologic Outcomes in a Swine Model of Traumatic Brain Injury and Hemorrhagic Shock. J. Neurotrauma 2018, 36, 54-60.

170. Willis, G. R.; Fernandez-Gonzalez, A.; Anastas, J.; Vitali, S. H.; Liu, X.; Ericsson, M.; Kwong, A.; Mitsialis, S. A.; Kourembanas, S., Mesenchymal Stromal Cell Exosomes Ameliorate Experimental Bronchopulmonary Dysplasia and Restore Lung Function through Macrophage Immunomodulation. Am. J. Respir. Crit. Care Med. 2018, 197, 104116.

171. Wu, S.; Ju, G. Q.; Du, T.; Zhu, Y. J.; Liu, G. H., Microvesicles Derived from Human Umbilical Cord Wharton's Jelly Mesenchymal Stem Cells Attenuate Bladder Tumor Cell Growth In Vitro and In Vivo. PLoS One 2013, 8, e61366.

172. Wu, X.; Yan, T.; Wang, Z.; Wu, X.; Cao, G.; Zhang, C.; Tian, X.; Wang, J., Micro-Vesicles Derived from Human Wharton's Jelly Mesenchymal Stromal Cells Mitigate Renal Ischemia-Reperfusion Injury in Rats after Cardiac Death Renal Transplantation. J. Cell. Biochem. 2018, 119, 1879-1888.

173. Xie, H.; Wang, Z.; Zhang, L.; Lei, Q.; Zhao, A.; Wang, H.; Li, Q.; Cao, Y.; Zhang, W. J.; Chen, Z., Extracellular Vesicle-Functionalized Decalcified Bone Matrix Scaffolds with Enhanced Pro-Angiogenic and Pro-Bone Regeneration Activities. Sci. Rep. 2017, 7, 45622.

174. Xie, H.; Wang, Z.; Zhang, L.; Lei, Q.; Zhao, A.; Wang, H.; Li, Q.; Chen, Z.; Zhang, W., Development of an Angiogenesis-Promoting Microvesicle-Alginate-Polycaprolactone Composite Graft for Bone Tissue Engineering Applications. Peerj 2016, 4, e2040.

175. Xin, H.; Katakowski, M.; Wang, F.; Qian, J. Y.; Liu, X. S.; Ali, M. M.; Buller, B.; Zhang, Z. G.; Chopp, M., MicroRNA Cluster miR-17-92 Cluster in Exosomes Enhance Neuroplasticity and Functional Recovery after Stroke in Rats. Stroke 2017, 48, 747-753. 
176. Xin, H.; Li, Y.; Cui, Y.; Yang, J. J.; Zhang, Z. G.; Chopp, M., Systemic Administration of Exosomes Released from Mesenchymal Stromal Cells Promote Functional Recovery and Neurovascular Plasticity after Stroke in Rats. J. Cereb. Blood Flow Metab. 2013, 33, 1711 1715.

177. Xin, H.; Wang, F.; Li, Y.; Lu, Q. E.; Cheung, W. L.; Zhang, Y.; Zhang, Z. G.; Chopp, M., Secondary Release of Exosomes from Astrocytes Contributes to the Increase in Neural Plasticity and Improvement of Functional Recovery after Stroke in Rats Treated with Exosomes Harvested from MicroRNA 133b-Overexpressing Multipotent Mesenchymal Stromal Cells. Cell Transplant. 2017, 26, 243-257.

178. Yan, Y.; Jiang, W.; Tan, Y.; Zou, S.; Zhang, H.; Mao, F.; Gong, A.; Qian, H.; Xu, W., HucMSC Exosome-Derived GPX1 Is Required for the Recovery of Hepatic Oxidant Injury. Mol. Ther. 2017, 25, 465-479.

179. Yang, J.; Gao, F.; Zhang, Y.; Liu, Y.; Zhang, D., Buyang Huanwu Decoction (BYHWD) Enhances Angiogenic Effect of Mesenchymal Stem Cell by Upregulating VEGF Expression after Focal Cerebral Ischemia. J. Mol. Neurosci. 2015, 56, 898-906.

180. Yang, J.; Liu, X. X.; Fan, H.; Tang, Q.; Shou, Z. X.; Zuo, D. M.; Zou, Z.; Xu, M.; Chen, Q. Y.; Peng, Y.; Deng, S. J.; Liu, Y. J., Extracellular Vesicles Derived from Bone Marrow Mesenchymal Stem Cells Protect against Experimental Colitis via Attenuating Colon Inflammation, Oxidative Stress and Apoptosis. PLoS One 2015, 10, e0140551.

181. Yin, G.; Hu, G.; Wan, R.; Yu, G.; Cang, X.; Xiong, J.; Ni, J.; Hu, Y.; Xing, M.; Fan, Y.; Xiao, W.; Qiu, L.; Tang, M.; Zhao, Y.; Wang, S.; Wang, X., Role of Microvesicles from Bone Marrow Mesenchymal Stem Cells in Acute Pancreatitis. Pancreas 2016, 45, 1282-1293.

182. Yu, B.; Kim, H. W.; Gong, M.; Wang, J.; Millard, R. W.; Wang, Y.; Ashraf, M.; Xu, M., Exosomes Secreted from GATA-4 Overexpressing Mesenchymal Stem Cells Serve as a Reservoir of Anti-Apoptotic microRNAs for Cardioprotection. Int. J. Cardiol. 2015, 182, 349-360.

183. Yu, B.; Shao, H.; Su, C.; Jiang, Y.; Chen, X.; Bai, L.; Zhang, Y.; Li, Q.; Zhang, X.; Li, X., Exosomes Derived from MSCs Ameliorate Retinal Laser Injury Partially by Inhibition of MCP-1. Sci. Rep. 2016, 6, 34562.

184. Yuan, X.; Li, D.; Chen, X.; Han, C.; Xu, L.; Huang, T.; Dong, Z.; Zhang, M., Extracellular Vesicles from Human-Induced Pluripotent Stem Cell-Derived Mesenchymal Stromal Cells (hiPSC-MSCs) Protect against Renal Ischemia/Reperfusion Injury via Delivering Specificity Protein (SP1) and Transcriptional Activating of Sphingosine Kinase 1 and Inhibiting Necroptosis. Cell Death Dis. 2017, 8, 1-18.

185. Zhang, B.; Shi, Y.; Gong, A.; Pan, Z.; Shi, H.; Yang, H.; Fu, H.; Yan, Y.; Zhang, X.; Wang, M.; Zhu, W.; Qian, H.; Xu, W., HucMSC Exosome-Delivered 14-3-3zeta Orchestrates SelfControl of the Wnt Response via Modulation of Yap during Cutaneous Regeneration. Stem Cells 2016, 34, 2485-2500.

186. Zhang, B.; Wang, M.; Gong, A.; Zhang, X.; Wu, X.; Zhu, Y.; Shi, H.; Wu, L.; Zhu, W.; Qian, $\mathrm{H}$.; Xu, W., HucMSC-Exosome Mediated-Wnt4 Signaling Is Required for Cutaneous Wound Healing. Stem Cells 2015, 33, 2158-2168.

187. Zhang, B.; Wu, X.; Zhang, X.; Sun, Y.; Yan, Y.; Shi, H.; Zhu, Y.; Wu, L.; Pan, Z.; Zhu, W.; Qian, H.; Xu, W., Human Umbilical Cord Mesenchymal Stem Cell Exosomes Enhance Angiogenesis through the Wnt4/Beta-Catenin Pathway. Stem Cells Transl. Med. 2015, 4, 513-522.

188. Zhang, B.; Yeo, R. W. Y.; Lai, R. C.; Sim, E. W. K.; Chin, K. C.; Lim, S. K., Mesenchymal Stromal Cell Exosome-Enhanced Regulatory T-Cell Production through an AntigenPresenting Cell-Mediated Pathway. Cytotherapy 2018, 20, 687-696.

189. Zhang, B.; Yin, Y.; Lai, R. C.; Tan, S. S.; Choo, A. B.; Lim, S. K., Mesenchymal Stem Cells Secrete Immunologically Active Exosomes. Stem Cells Dev. 2014, 23, 1233-1244. 
190. Zhang, G.; Zou, X.; Huang, Y.; Wang, F.; Miao, S.; Liu, G.; Chen, M.; Zhu, Y., Mesenchymal Stromal Cell-Derived Extracellular Vesicles Protect against Acute Kidney Injury through Anti-Oxidation by Enhancing Nrf2/ARE Activation in Rats. Kidney Blood Presssure Res. 2016, 41, 119-128.

191. Zhang, G.; Zou, X.; Miao, S.; Chen, J.; Du, T.; Zhong, L.; Ju, G.; Liu, G.; Zhu, Y., The AntiOxidative Role of Micro-Vesicles Derived from Human Wharton-Jelly Mesenchymal Stromal Cells through NOX2/Gp91(Phox) Suppression in Alleviating Renal IschemiaReperfusion Injury in Rats. PLoS One 2014, 9, e92129.

192. Zhang, H. C.; Liu, X. B.; Huang, S.; Bi, X. Y.; Wang, H. X.; Xie, L. X.; Wang, Y. Q.; Cao, X. F.; Lv, J.; Xiao, F. J.; Yang, Y.; Guo, Z. K., Microvesicles Derived from Human Umbilical Cord Mesenchymal Stem Cells Stimulated by Hypoxia Promote Angiogenesis Both In Vitro and In Vivo. Stem Cells Dev. 2012, 21, 3289-3297.

193. Zhang, J.; Guan, J.; Niu, X.; Hu, G.; Guo, S.; Li, Q.; Xie, Z.; Zhang, C.; Wang, Y., Exosomes Released from Human Induced Pluripotent Stem Cells-Derived MSCs Facilitate Cutaneous Wound Healing by Promoting Collagen Synthesis and Angiogenesis. J. Transl. Med. 2015, 13, 49.

194. Zhang, S.; Chu, W. C.; Lai, R. C.; Lim, S. K.; Hui, J. H.; Toh, W. S., Exosomes Derived from Human Embryonic Mesenchymal Stem Cells Promote Osteochondral Regeneration. Osteoarthritis Cartilage 2016, 24, 2135-2140.

195. Zhang, Y.; Chopp, M.; Meng, Y.; Katakowski, M.; Xin, H.; Mahmood, A.; Xiong, Y., Effect of Exosomes Derived from Multipluripotent Mesenchymal Stromal Cells on Functional Recovery and Neurovascular Plasticity in Rats after Traumatic Brain Injury. J. Neurosurg. 2015, 122, 856-867.

196. Zhang, Y.; Chopp, M.; Zhang, Z. G.; Katakowski, M.; Xin, H.; Qu, C.; Ali, M.; Mahmood, A.; Xiong, Y., Systemic Administration of Cell-Free Exosomes Generated by Human Bone Marrow Derived Mesenchymal Stem Cells Cultured under 2D and 3D Conditions Improves Functional Recovery in Rats after Traumatic Brain Injury. Neurochem. Int. 2017, 111, 6981.

197. Zhao, B.; Zhang, Y.; Han, S.; Zhang, W.; Zhou, Q.; Guan, H.; Liu, J.; Shi, J.; Su, L.; Hu, D., Exosomes Derived from Human Amniotic Epithelial Cells Accelerate Wound Healing and Inhibit Scar Formation. J. Mol. Histol. 2017, 48, 121-132.

198. Zhao, Y.; Sun, X.; Cao, W.; Ma, J.; Sun, L.; Qian, H.; Zhu, W.; Xu, W., Exosomes Derived from Human Umbilical Cord Mesenchymal Stem Cells Relieve Acute Myocardial Ischemic Injury. Stem Cells Int. 2015, 2015.

199. Zhou, Y.; Xu, H.; Xu, W.; Wang, B.; Wu, H.; Tao, Y.; Zhang, B.; Wang, M.; Mao, F.; Yan, Y.; Gao, S.; Gu, H.; Zhu, W.; Qian, H., Exosomes Released by Human Umbilical Cord Mesenchymal Stem Cells Protect against Cisplatin-Induced Renal Oxidative Stress and Apoptosis In Vivo and In Vitro. Stem Cell. Res. Ther. 2013, 4, 1-13.

200. Zhu, J.; Lu, K.; Zhang, N.; Zhao, Y.; Ma, Q.; Shen, J.; Lin, Y.; Xiang, P.; Tang, Y.; Hu, X.; Chen, J.; Zhu, W.; Webster, K. A.; Wang, J.; Yu, H., Myocardial Reparative Functions of Exosomes from Mesenchymal Stem Cells Are Enhanced by Hypoxia Treatment of the Cells via Transferring microRNA-210 in an Nsmase2-Dependent Way. Artif. Cells, Nanomed., Biotechnol. 2017, 46, 1659-1670.

201. Zhu, L. L.; Huang, X.; Yu, W.; Chen, H.; Chen, Y.; Dai, Y. T., Transplantation of Adipose Tissue-Derived Stem Cell-Derived Exosomes Ameliorates Erectile Function in Diabetic Rats. Andrologia 2018, 50, e12871.

202. Zhu, Y.; Wang, Y.; Zhao, B.; Niu, X.; Hu, B.; Li, Q.; Zhang, J.; Ding, J.; Chen, Y.; Wang, Y., Comparison of Exosomes Secreted by Induced Pluripotent Stem Cell-Derived Mesenchymal Stem Cells and Synovial Membrane-Derived Mesenchymal Stem Cells for the Treatment of Osteoarthritis. Stem Cell. Res. Ther. 2017, 8, 1-11. 
203. Zhu, Y. G.; Feng, X. M.; Abbott, J.; Fang, X. H.; Hao, Q.; Monsel, A.; Qu, J. M.; Matthay, M. A., Human Mesenchymal Stem Cell Microvesicles for Treatment of Escherichia Coli Endotoxin-Induced Acute Lung Injury in Mice. Stem Cells 2014, 32, 116-125.

204. Zou, X.; Gu, D.; Xing, X.; Cheng, Z.; Gong, D.; Zhang, G.; Zhu, Y., Human Mesenchymal Stromal Cell-Derived Extracellular Vesicles Alleviate Renal Ischemic Reperfusion Injury and Enhance Angiogenesis in Rats. Am. J. Transl. Res. 2016, 8, 4289-4299.

205. Zou, X.; Gu, D.; Zhang, G.; Zhong, L.; Cheng, Z.; Liu, G.; Zhu, Y., NK Cell Regulatory Property Is Involved in the Protective Role of MSC-Derived Extracellular Vesicles in Renal Ischemic Reperfusion Injury. Hum. Gene Ther. 2016, 27, 926-935.

206. Zou, X.; Zhang, G.; Cheng, Z.; Yin, D.; Du, T.; Ju, G.; Miao, S.; Liu, G.; Lu, M.; Zhu, Y., Microvesicles Derived from Human Wharton's Jelly Mesenchymal Stromal Cells Ameliorate Renal Ischemia-Reperfusion Injury in Rats by Suppressing CX3CL1. Stem Cell. Res. Ther. 2014, 5, 40. 